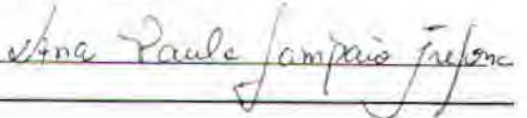

\title{
Especificação de um modelo formal para aplicações em sistemas hipermídia abertos
}

\author{
Aline Maria Malachini Miotto
}

Orientadora: Profa. Dra. Renata Pontin de Mattos Fortes

Dissertação apresentada ao Instituto de Ciências Matemáticas e de Computação - ICMC-USP, como parte dos requisitos para obtenção do título de Mestre em Ciências de Computação e Matemática Computacional.

USP - São Carlos

Outubro/2001 
A Camissão Julgadora:

Profa. Dra. Renata Pontin de Mattos Fortes

Profa. Dra. Maria das Graças Volpe Nunes

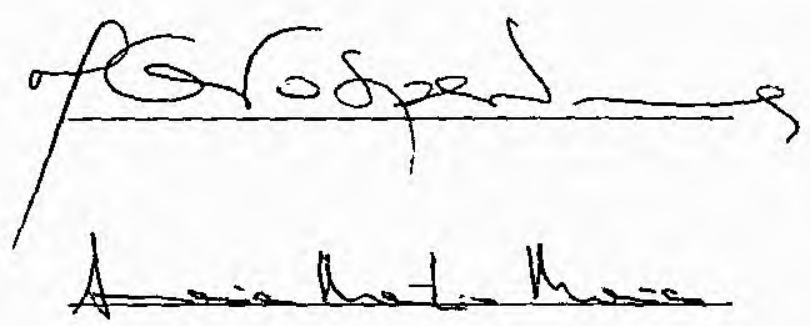




\section{Agradecimentos}

A DEUS, pelo dom da vida.

Aos meus pais queridos, Laert e Maria de Lourdes, e minhas irmãs, Anamaria e Denise, por tanto amor, dedicação, incentivo, por nunca medirem esforços para me ajudar e acreditarem em mim.

Ao Marcelo, pelo amor, paciência, incentivo e por compreender as minhas ausências.

À minha orientadora Profa. Dra. Renata Pontin de Mattos Fortes, contribuinte em grande parte de meu amadurecimento profissional e até mesmo pessoal, pela confiança depositada, pelos valiosos conselhos, pela grande paciência e pela amizade.

Aos professores Maria das Graças Volpe Nunes, José Carlos Maldonado e Maria da Graça Campos Pimentel por sempre estarem dispostos a me ajudar e contribuírem para o meu aprendizado.

Aos meus amigos Tati, Ellen, Débora, Elis, Andrea, Lú, Mayb, Ades e Auri pela amizade e por todos os momentos inesquecíveis que passamos juntos. Em especial ao Ades pela sua ajuda na revisão deste trabalho e por suas preciosas dicas.

Ao pessoal do Labes: Sandra, Elisa, Rejane, Gelza, André, Rodrigo, Reginaldo, Vangrei, Maria Istela, Simone, Thaise, Rosana, Jaqueline, Mateus e Willie.

Às meninas da seção de Pós-Graduação: Laura, Marília e Beth, e a todos os funcionários do ICMC, em especial à Maria (da biblioteca), por toda simpatia e atenção dispensados.

A todos que, de alguma forma, estiveram ao meu lado durante o desenvolvimento deste trabalho.

À FAPESP pelo apoio financeiro. 
1 Introdução 1

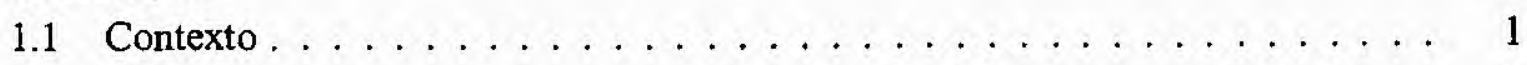

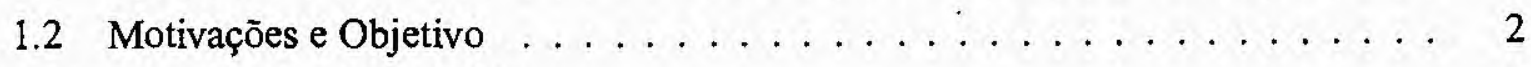

1.3 Organização do Trabalho ...................... 4

2 Sistemas Hipermídia Abertos 5

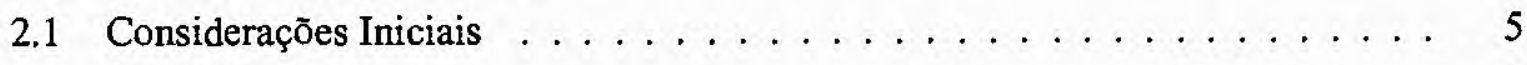

2.2 Características ........................... 6

2.3 Dois Exemplos: Microcosm e Devise Hypermedia . . . . . . . . . . . . 9

2.3.1 Microcosm ........................ 9

2.3.1.1 Características ..................... 9

2.3.1.2 Funcionalidades ................. 12

2.3 .2 Devise Hypermedia . . . . . . . . . . . . . . . . . 13

2.3.2.1 Características .................. 13

2.3.2.2 Funcionalidades .................. 15

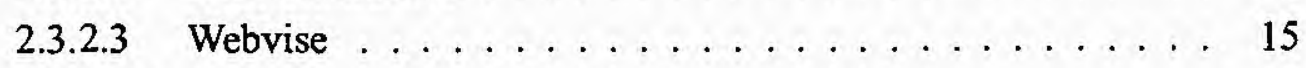

2.4 Aplicações em Sistemas Hipermídia Abertos . . . . . . . . . . . . . 17

2.4 .1 Requisitos ........................ 17

2.4.1.1 Separação entre estrutura e conteúdo da informação . . . . 17

2.4.1.2 Documentos em diferentes formatos .......... 17

2.4.1.3 Bases de ligações externas .............. . 17

2.4.1.4 Ligações "de" e "para" informações read-only . . . . . . 18

2.4.1.5 Ligaçōes em termos da semântica da informação . . . . . . 18

2.4.1.6 Documentos relacionados de diversas formas . . . . . . . 18

2.4.1.7 Questões de distribuição . . . . . . . . . . . . . . . . 19 


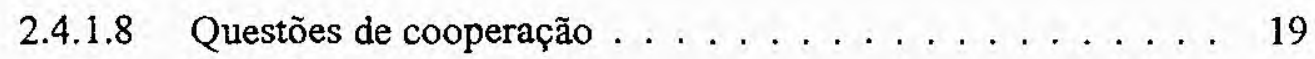

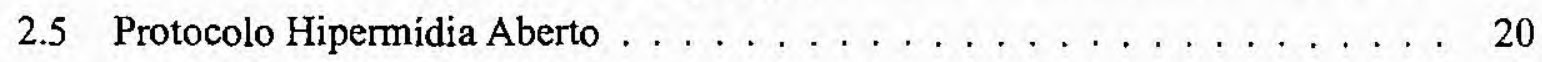

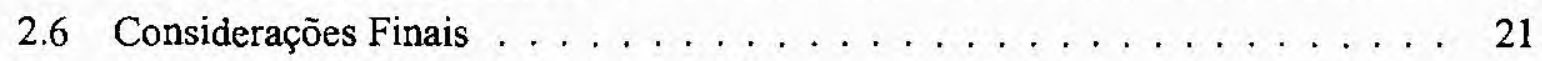

3 Statecharts, HMBS e XHMBS

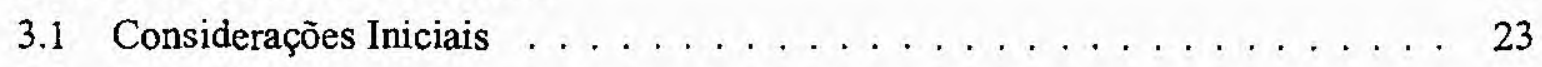

3.2 Statecharts . . . . . . . . . . . . . . . . . 23

3.3 Modelo HMBS . . . . . . . . . . . . . . . . . . 27

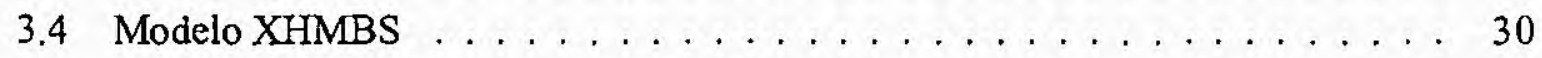

3.4 .1 História Temporal . . . . . . . . . . . . . 32

3.4 .2 Transições Temporais . . . . . . . . . . . . . . 32

3.4 .3 Mecanismos de Sincronização . . . . . . . . . . . . . 34

3.4.4 Modelo Hipermídia baseado em Hypercharts . . . . . . . . . 34

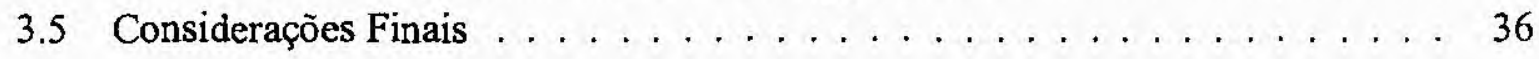

4 XHMBS e as Aplicaçōes em Sistemas Hipermídia Abertos 37

4.1 Considerações Iniciais . . . . . . . . . . . . . . . . . . 37

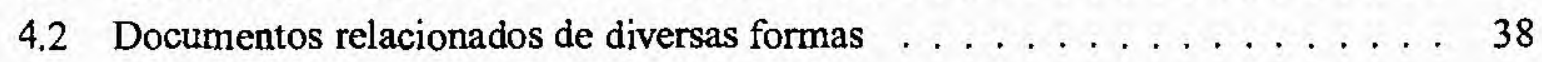

4.2.1 Ligações Específicas . . . . . . . . . . . . . . . 38

4.2 .2 Ligaçōes Bidirecionais . . . . . . . . . . . . . . . 40

4.2 .3 Ligações Globais . . . . . . . . . . . . . . . . . . . 42

4.2 .4 Ligações Locais $\ldots \ldots \ldots \ldots \ldots \ldots \ldots \ldots \ldots \ldots . \ldots \ldots 44$

4.2.5 Ligações Computadas ou Dinâmicas . . . . . . . . . . . . . 46

4.3 Ligações em termos da semântica da informação . . . . . . . . . . . 47

4.4 Bases de ligações externas públicas e privadas . . . . . . . . . . . 48

4.5 Separação entre estrutura e conteúdo da informação . . . . . . . . . 49

4.6 Ligações "de" e "para" informações read-only . . . . . . . . . . . . . 50

4.7 Documentos em diferentes formatos . . . . . . . . . . . . . 51

4.8 Comunicação, cooperação e distribuição $\ldots \ldots \ldots \ldots \ldots \ldots \ldots \ldots . \ldots \ldots$

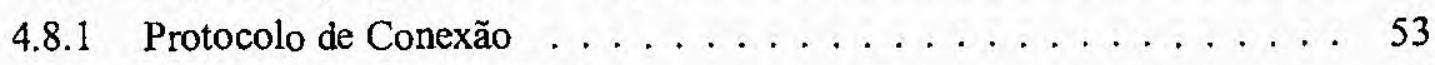

4.8 .2 Protocolo de Ligação Básico . . . . . . . . . . . . . . . . 54

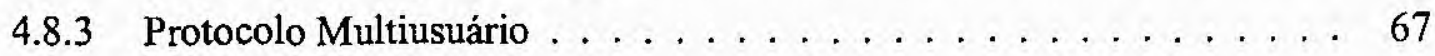

4.9 Considerações Finais $\ldots \ldots \ldots \ldots \ldots \ldots \ldots \ldots \ldots \ldots \ldots \ldots$

5 Especificação do modelo OXHMBS 73

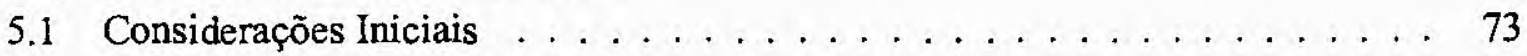

5.2 Aplicação hipermídia especificada em OXHMBS . . . . . . . . . 74

5.3 Semântica de Navegação do modelo OXHMBS . . . . . . . . . 77 
5.4 Exemplo de Especificação OXHMBS $\ldots \ldots \ldots \ldots \ldots \ldots \ldots$

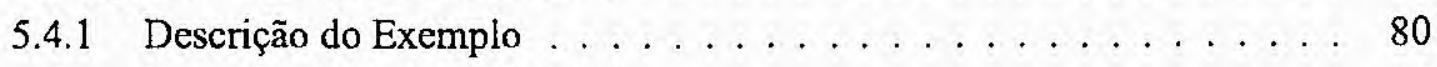

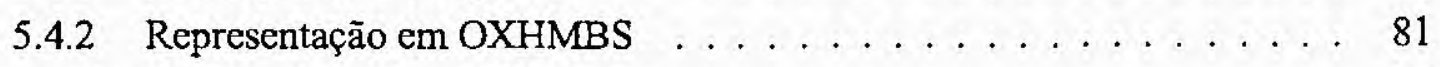

5.5 Análise de Especificações OXHMBS . . . . . . . . . . . . . . . . . . . 94

5.5.1 OXHMBS e os requisitos das aplicações em sistemas hipermídia abertos 94

5.5.2 Utilização de uma abordagem formal - OXHMBS . . . . . . . . 96

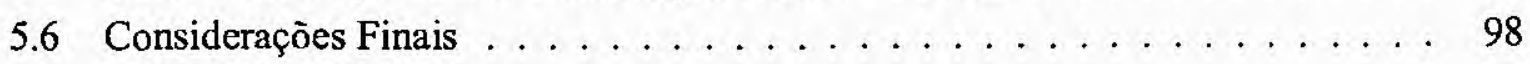

6 Conclusōes $\quad 99$

6.1 Contribuições deste Trabalho . . . . . . . . . . . . . 100

6.2 Sugestões de novas pesquisas . . . . . . . . . . . . . . . . . . 101 
2.1 Arquitetura em Camadas do Sistema Microcosm (Davis et al., 1994) . . . . . . 11

2.2 Arquitetura em Camadas do Modelo Dexter (Halazs e Schwartz, 1990) . . . . . 13

2.3 Arquitetura do Framework Devise Hypermedia (Grønbæk e Trigg, 1999) . . . . 14

2.4 Exemplo de Interface do Sistema Webvise . . . . . . . . . . . . . 16

3.1 Exemplo de um statechart . . . . . . . . . . . . . . . 26

3.2 Exemplo de Transição Temporal (Paulo, 1997) . . . . . . . . . . . . 33

4.1 Proposta de representação para transição bidirecional em Hypercharts Estendido 41

4.2 Transição bidirecional em Hypercharts Estendido representada por transições básicas de Statecharts . . . . . . . . . . . . . . . . . . . 41

4.3 Proposta de representação para transição global em Hypercharts Estendido . . . 43

4.4 Proposta de representação para transição local em Hypercharts Estendido . . . 45

4.5 Especificações OXHMBS em uma Arquitetura Hipermidia Aberta . . . . . . . 53

5.1 Aplicação exemplo especificada no Webvise . . . . . . . . . . . . 81

5.2 Ligações do Documento Introdução ao Diagrama de Transições de Estados . 82

5.3 Ligações do Documento Avaliação_Statecharts . . . . . . . . . . 82

5.4 Ligações do Documento Statecharts . . . . . . . . . . . . . . . . 83

5.5 Ligações do Documento Notas_Statecharts . . . . . . . . . . . . . 83

5.6 Ligações do Documento Statecharts no dia-a-dia . . . . . . . . . . . 84

5.7 Especificação da aplicação exemplo no Modelo OXHMBS . . . . . . . . . 85 
5.1 Tuplas identificadas pela função $M \ldots \ldots \ldots \ldots$

5.2 Tuplas identificadas pela função Doc_Tipo . . . . . . . . . . . . 86

5.3 Tuplas identificadas pela função Doc_Localizacao . . . . . . . . . . . 86

5.4 Tuplas identificadas pela função Visualizacao $\ldots \ldots \ldots \ldots \ldots$

5.5 Tupla identificada pela função Base_Lig .............. 87

5.6 Tupla identificada pela função Autorizacao . . . . . . . . . . . . . 87

5.7 Tuplas identificadas pela função $A n c \_D o c \ldots \ldots \ldots \ldots . \ldots \ldots$

5.8 Tuplas identificadas pela função $A n c_{-}$Localizacao . . . . . . . . . . 89

5.9 Tuplas identificadas pela função Anc_Font . . . . . . . . . . . . . . 89

5.10 Tuplas identificadas pela função Anc_Dest . . . . . . . . . . . . . 89

5.11 Tupla identificada pela função Bidirecional . . . . . . . . . . . . . . . . . . . . . . . . . . . .

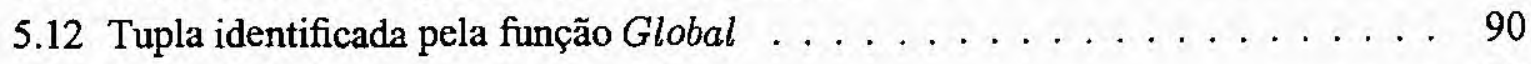

5.13 Tupla identificada pela função Local . . . . . . . . . . . . . . . . . . . 90

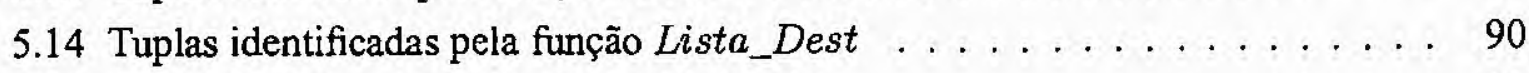

5.15 Tuplas identificadas pela função $L i s t a \ldots$ Anc . . . . . . . . . . . . . . 91

5.16 OXHMBS e os requisitos das aplicações em sistemas hipermídia abertos . . . 94 
U MA tendência no projeto de sistemas hipermidia é o desenvolvimento de sistemas que sejam abertos, extensiveis e distribuidos entre diferentes usuários. Na última década vários sistemas hipermidia abertos foram apresentados na literatura. Nesse contexto, técnicas formais consistem de ferramentas muito úteis para especificação de aplicações hipermídia (e por conseguinte, de aplicações em sistemas hipermidia abertos) por possibilitar que determinada solução especificada seja precisa, não ambígua, independente de sua implementação e reutilizável. Além disso, modelos formais adequados podem oferecer abordagens sistemáticas e confiáveis para a análise e verificação de propriedades estruturais e dinâmicas dessas aplicações. Este projeto de mestrado tem como objetivo verificar a adequação do modelo formal XHMBS (eXtended Hypertext Model Based on Statecharts) em relação à especificação de aplicações em sistemas hipermídia abertos e propor extensões a esse modelo para permitir a especificação de tais aplicações. 


\begin{abstract}
TREND of hypermedia system design is the development of open, extensible and distributed multiuser systems. Therefore, in the last years several Open Hypermedia System (OHS) architectures have been presented in literature. In this context, formal techniques become a very useful tool for specification of hypermedia applications (and OHS applications). Formal techniques allow that a certain specified solution be precise, non-ambiguous, reusable and independent of implementation. Additionally, adequate formal models can offer systematic and reliable approaches to analyze and verify structural and dynamic properties of this kind of applications. This work aims at verifying the adequacy of the formal model XHMBS (eXtended Hypertext Model Based on Statecharts) in relation to the specification of OHS applications and to extend the model in order to allow the specification of such applications.
\end{abstract}




\section{CAPITULO}

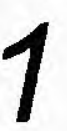

\section{Introdução}

\subsection{Contexto}

A demanda por aplicações que utilizam a tecnologia hipermídia encontra-se em contínua expansão devido, principalmente, à disseminação da World Wide Web $(W W W)^{1}$ (Bieber e Kacmar, 1995; Bieber e Vitali, 1997; Pressman, 2000). Organizações comerciais estão explorando o potencial da $W^{2} b^{2}$ e dos Sistemas de Informações baseados na Web, ou WIS (Web Information Systems), para se apresentar ao público e, ao mesmo tempo vender seus produtos e serviços com mais rapidez, ampliando dessa forma o seu universo de consumidores.

De acordo com Begoray (1990); Hardman et al. (1994), a tecnologia hipermídia consiste de um modelo de organização e recuperação de informações que integra as tecnologias hipertexto e multimídia.

A tecnologia hipertexto se caracteriza por habilitar uma organização não linear da informação e um novo processo de interação que permite aos seus usuários, denominados leitores, navegar um grande aglomerado de informações (Conklin, 1987). Segundo Grønbæk e Trigg (1994), as ligações constituem o centro dessa tecnologia, cuja estrutura navegacional em forma de rede a distingue de outros mecanismos de organização da informação. A tecnologia multimidia, por outro lado, permite criar e manipular documentos como objetos estruturados compostos de dados de natureza distinta, tais como texto, imagem, vídeo, áudio, animação, etc.

\footnotetext{
${ }^{1}$ Sistemas hipertexto sobre a Internet.

${ }^{2}$ Neste trabalho não faremos distinção entre os termos Web e WWW.
} 
Um software ou sistema que apóia as tecnologias hipertexto e multimídia é denominado sistema hipermídia.

De acordo com Grønbæk e Trigg (1999); Østerbye e Wiil (1996), uma tendência no projeto de sistemas hipermídia é o desenvolvimento de sistemas que sejam abertos, extensíveis e distribuídos entre diferentes usuários (OHS - Open Hypermedia System), uma vez que esses fornecem aos usuários modos mais ricos e variados de acessar e integrar informações de um conjunto de dados grande e dinâmico em um ambiente distribuído e heterogêneo. Na última década vários sistemas hipermídia abertos foram apresentados na literatura, dentre esses, pode-se destacar o Sistema Microcosm (Davis et al., 1994) e o Framework Devise Hypermedia (DHM) (Grønbæk e Trigg, 1994).

A aplicação gerenciada e manipulada por um sistema hipermídia aberto é denominada aplicação em sistema hipermídia aberto. Um documento pertencente a uma aplicação em sistema hipermidia aberto possui uma dimensão linear, enquanto a aplicação possui várias dimensões, ou seja, contém referências a outros documentos. Em geral, as aplicações em sistemas hipermídia abertos são compostas por um conjunto de documentos e por um conjunto de ligações entre esses documentos.

Para que aplicações hipermídia e, conseqüentemente, aplicações em sistemas hipermídia abertos possam ser exploradas pelos leitores, é necessário especificar, além de sua estrutura organizacional (conjunto de ligaçōes), a semântica de navegação associada a essa estrutura (Garzotto et al., 1993). Segundo Stotts e Furuta (1990), a semântica de navegação define as propriedades dinâmicas de visualização de uma aplicação em tempo de navegação, permitindo especificar a estrutura navegacional e as transformações associadas a essa quando ligações são ativadas pelo leitor.

\subsection{Motivações e Objetivo}

A exemplo do que acontece com outros produtos de software, as aplicações em sistemas hipermídia abertos demandam modelos de especificação e métodos que sintetizem e suportem a sistemática de seu desenvolvimento. Porém, os métodos e as técnicas tradicionais de desenvolvimento de software não são exatamente adequados para o projeto dessas aplicações, uma vez que essas, assim como as aplicações hipermídia tradicionais, apresentam requisitos próprios, tais como a necessidade de gerenciar um grande volume de tipos de informação e de combinar a navegação controlada por uma grande variedade de potenciais usuários com a natureza das informações multimídia (Garzotto et al., 1994; Hardman et al., 1994; Schwabe et al., 2001; Schwabe e Rossi, 1998).

Tais fatos motivaram a pesquisa de novos métodos e modelos que ofereçam suporte adequado ao gerenciamento sistemático do projeto de aplicações hipermídia e, conseqüentemente 
dc aplicações em sistemas hipermídia abertos, melhorando a atividade de autoria e propiciando o desenvolvimento de aplicações estruturadas (Turine, 1998; ?). De acordo com Cavallaro et al. (1993); Garzotto et al. (1994, 1995), o uso de modelos melhora o processo de projeto e desenvolvimento de aplicações hipermídia e também facilita sua análise e avaliação.

Segundo Courtiat e Oliveira (1996), a utilização de modelos e técnicas formais para a especificação de aplicações hipermídia é uma tendência. Nesse contexto, a adoção de uma abordagem formal (modelo formal) para a descrição de aplicações em sistemas hipermídia abertos permite que essas sejam especificadas de forma precisa, não ambígua e independente de sua implementação.

Adicionalmente, modelos formais adequados podem oferecer abordagens sistemáticas e confiáveis para a análise e verificação de propriedades estruturais e dinâmicas de aplicações em sistemas hipermídia abertos, bem como possibilitar que uma solução especificada seja reutilizada em outras aplicações.

Deve-se ressaltar que o uso de modelos formais deve ser aplicado em conjunto com alguma metodologia para o projeto de aplicações hipermidia (tais como: HMBS/M (An Object Oriented Method for Hypermedia Design) (Carvalho, 1998), HDM (Hypertext Design Model) (Garzotto et al., 1999, 1993), RMM (Relationship Management Methodology) (Isakowitz et al., 1997, 1995), OOHDM (Object Oriented Hypermedia Design Model) (Schwabe e Rossi, 1995, 1998) e WebML (Web Modeling Language) (Ceri et al., 2000)).

No trabalho de Carvalho (1998) é apresentada a metodologia HMBS/M que define uma seqüencia de estágios de projeto (modelagem conceitual, modelagem navegacional, projeto de interface do usuário, implementação e teste) para o desenvolvimento de aplicações hipermídia, e utiliza o modelo formal HMBS (Hyperdocument Model Based on Statecharts) para fornecer uma descrição estrutural e navegacional dessas aplicações (modelagem navegacional).

Diversos modelos formais para especificação de aplicações multimídia e hipermídia foram apresentados na literatura, dentre os quais, pode-se destacar os modelos OCPN (Object Composition Petri Nets) (Little, 1990) e HTSPN (Hierarchical Time Stream Petri Net) (Senac, 1996) baseados em Redes de Petri (Peterson, 1977) e os modelos HMBS (Hyperdocument Model Based on Statecharts) (Oliveira et al., 2001) e XHMBS (eXtended Hypermedia Model Based on Statecharts) (Paulo et al., 1998) baseados em Statecharts (Harel, 1987).

O modelo formal XHMBS, investigado neste trabalho, fornece suporte adequado à especificação de aplicações hipermídia, principalmente àquelas que possuem requisitos temporais $\mathrm{e}$ de sincronização de dados multimídia. No entanto, como pode ser visto no capitulo 4 desta dissertação, esse modelo não oferece suporte adequado à especificação de aplicações em sistemas hipermidia abertos, pois assim como os outros modelos destacados anteriormente, não foi desenvolvido para atender à especificação de tais aplicações. 
Dessa forma, neste trabalho foram inicialmente identificados os requisitos considerados característicos das aplicações em sistemas hipermidia abertos, a partir de revisão da literatura. Com base nesse conjunto de requisitos o objetivo deste trabalho concentrou-se na proposição de extensōes ao XHMBS, culminando no modelo OXHMBS (Open eXtended Hypermedia Model Based on Statecharts), de forma a torná-lo adequado à especificação de aplicações em sistemas hipermídia abertos.

\subsection{Organização do Trabalho}

Neste capitulo foi apresentado o contexto no qual este trabalho está inserido, as motivações para realizá-lo e o objetivo almejado. No capitulo 2 são apresentados os principais aspectos relacionados aos sistemas hipermidia abertos e às aplicações construídas e manipuladas por esses. No capítulo 3 são descritos os modelos XHMBS e seu antecessor HMBS e a técnica Statecharts, subjacente a ambos, com objetivo de apresentar o embasamento necessário para a definição do modelo proposto. No capítulo 4 são apresentadas as propostas de extensão ao XHMBS de forma a tomá-lo adequado à especificação de aplicações em sistemas hipermidia abertos. No capitulo 5 o modelo OXHMBS, com suas novas características incorporadas, é apresentado e discutido. Finalmente, no capítulo 6 são apresentadas as contribuições deste trabalho e as perspectivas de trabalhos futuros. 


\section{Sistemas Hipermídia Abertos}

\subsection{Considerações Iniciais}

Um dos alvos de investigação deste trabalho de mestrado são os sistemas hipermídia abertos que, como já mencionado anteriormente, apresentam-se como uma tendência no projeto de sistemas hipermídia. Dessa forma, neste capítulo é apresentada na Seção 2.2 uma caracterização dos sistemas hipermídia abertos, com base em dois critérios: tipo de suporte oferecido e requisitos desejáveis.

Para oferecer uma visão mais prática desses sistemas, na Seção 2.3 são apresentados o Sistema hipermídia aberto Microcosm e o Framework para sistemas hipermídia abertos Devise Hypermedia. Esses são descritos com base em suas principais características e funcionalidades.

Considerando-se ainda o ponto de vista do suporte oferecido pelos sistemas hipermídia abertos, na seção 2.4 foram apresentados os requisitos característicos das aplicações construídas e manipuladas por esses sistemas. Finalmente, na Seção 2.5 é apresentado o protocolo hipermidia aberto, responsável pela padronização do formato das mensagens de comunicação definidas entre os sistemas hipermídia abertos e os aplicativos ${ }^{1}$ integrados a esses.

\footnotetext{
'Neste trabalho adotamos a seguinte distinção entre os termos aplicativo e aplicação em sistema hipermídia aberto: "aplicativos" podem ser qualquer software do ambiente computacional, tais como: Latex, Word, Excel e Internet Explorer. É através desses aplicativos que os documentos que compõem as aplicações em sistemas hipermidia abertos são criados. Enquanto que as "aplicações" em sistemas hipermidia abertos são compostas pelos documentos criados nesses "aplicativos".
} 


\subsection{Características}

Segundo Davis et al. (1996), um sistema hipermídia aberto é um componente (intermediário) no ambiente computacional que oferece funcionalidades hipermidia para aplicativos em adição às suas funcionalidades de armazenamento e apresentação. Ao utilizarem os serviços de um sistema hipermidia aberto, aplicativos existentes do ambiente computacional podem tornar-se "hipermídia habilitados" (do inglês, hypermedia enabled) suportando, dessa forma, ligações entre informações gerenciadas por esses sem alterá-las.

Ainda de acordo com Davis et al. (1996), para tomarem-se hipermídia habilitados, os aplicativos devem ser estendidos para suportar funcionalidades hipermídia na interface do usuário (tais como: suporte à criação, remoção e modificação de âncoras e ligações e suporte à navegação dessas ligações) e para suportar comunicação com o sistema hipermídia aberto (troca de mensagens com o sistema hipermídia aberto para, por exemplo, instanciação de bases de ligações, inicialização de aplicativos e instanciação de âncoras). Nesse contexto, o termo "ambiente aberto" é usado para englobar tanto o sistema hipermidia aberto quanto o conjunto de aplicativos hipermídia habilitados integrados a esse. Um ambiente hipermídia aberto é, portanto, um subconjunto de todo o ambiente computacional em termos de aplicativos, programas e serviços.

De acordo com Malcon et al. (1991), as principais motivações por trás do desenvolvimento de sistemas hipermidia abertos são a necessidade de reduzir o esforço de autoria em aplicações hipermidia de grande escala e a necessidade de torná-las mais fáceis de serem modificadas, personalizadas e estendidas.

O termo "aberto" tem diferentes significados em diferentes contextos. Geralmente, um software pode ser categorizado como aberto se especifica e publica interfaces entre seus componentes. Contudo, o que significa aberto ou fechado no contex to de sistemas hipermídia? Uma questão importante nesse contexto é a distinção, nas aplicações hipermidia, entre sua estrutura e seu conteúdo. Um sistema hipermídia que impõe um formato de modelo de dados específico (definindo o formato do conteúdo e da estrutura) sobre seus aplicativos hipermídia habilitados é considerado fechado, uma vez que exige que aplicativos sejam completamente modificados para participar desse ambiente. Em contraste, um sistema hipermidia aberto é aquele que apenas impõe formato especifico de estrutura sobre seus aplicativos hipermídia habilitados, ou seja, para que aplicativos participe desse ambiente, basta que atendam a organização estrutural definida pelo sistema hipermídia aberto. Permitir que aplicativos armazenem seus conteúdos em diferentes formatos e externamente ao sistema hipermídia é um requisito básico para integrar e usar aplicativos existentes em um ambiente hipermídia aberto (Malcon et al., 1991; Østerbye e Wiil, 1996).

Em geral, um sistema hipermídia fechado é caracterizado por apenas lidar com um conjunto pré-definido de formatos de conteúdos e por suportar um conjunto pré-definido de aplicati- 
vos hipermídia habilitados que participam ativamente nos serviços hipermídia. Por outro lado um sistema hipermídia aberto permite que um conjunto irrestrito de aplicativos participe dos serviços hipermídia e suporta um conjunto irrestrito de formatos de conteúdos. Os sistemas hipermídia abertos armazenam a estrutura separadamente do conteúdo. Essa estrutura é sobreposta ao conteúdo dos aplicativos hipermídia habilitados em tempo de apresentação. Assim, o conjunto irrestrito de aplicativos que complementa um ambiente hipermídia pode conter documentos disponiveis de várias fontes (incluindo read-only) do ambiente computacional (por exemplo, sistema de arquivos, CD-ROM e bases de dados).

Segundo Davis et al. (1996), apesar do objetivo geral do projeto de sistemas hipermídia abertos estar centrado no suporte a um conjunto de serviços hipermídia, esses sistemas podem ser especificados de diferentes formas, o que faz com que existam variações no tipo de suporte oferecido, tais como:

1. Suporte a diferentes protocolos de comunicação com aplicativos hipermidia habilitados. Alguns sistemas suportam sockets (TCP/IP), outros suportam chamadas a procedimentos remotos (RPC), enquanto outros suportam soluções dependentes de plataforma, como Apple Events (Macintosh) ou OLE (Windows).

2. Suporte a diferentes modelos de dados hipermídia. Modelos de dados hipermídia abertos variam de acordo com o número de pontos finais de uma ligação (dois ou mais) e de acordo com a existência ou não da noção de âncora.

3. Suporte a diferentes serviços hipermídia. Alguns sistemas hipermidia abertos suportam apenas os serviços básicos, ou seja, aqueles serviços que permitem que âncoras e ligações sejam associadas a dados existentes, enquanto outros sistemas suportam caracteristicas mais avançadas, como suporte à autoria cooperativa de estrutura e conteúdo hipermídia.

4. Suporte a diferentes arquiteturas de sistemas hipermídia. O conjunto de arquiteturas hipermidia abertas introduzidas pelos sistemas atuais pode variar de arquiteturas clienteservidor centralizadas, com um único servidor de armazenamento executando em uma rede local, a arquiteturas multi-camadas distribuidas com servidores de armazenamento múltiplos executando em diferentes domínios da Internet.

5. Suporte a diferentes tipos de estruturas. Basicamente, todos sistemas hipermídia abertos suportam estruturas de ligações hipermídia. Alguns sistemas também suportam outros tipos de estrutura, tais como composites $^{2}$, ligações para recuperação de informações e estruturas de classificação.

\footnotetext{
${ }^{2 " C o m p o n e n t e s ~ C o m p o s t o s ", ~ f o r m a d o s ~ p o r ~ v a ́ r i o s ~ c o m p o n e n t e s ~ a t o ̂ m i c o s ~(d o c u m e n t o s ~ q u e ~ p o s s u e m ~ u m ~ u ́ n i c o ~}$ tipo de mídia).
} 
6. São tipicamente divididos em duas categorias gerais: sistemas hiperbase abertas e sistemas servidores de ligações. Ambas as categorias fornecem serviços básicos de ligações hipermídia para um conjunto irrestrito de aplicativos. Sistemas hiperbase abertas também fornecem serviços de armazenamento hipermídia, que podem incluir suporte ao armazenamento de conteúdos no sistema hipermídia aberto (se desejado) e suporte a sessões de autoria cooperativa e multiusuário sobre a estrutura e o conteúdo (controle de acesso, controle de versão, controle de concorrência e notificação de eventos).

Uma questão muito importante das pesquisas sobre hipermídia aberta (tratada pelo Grupo de Trabalho de Sistemas Hipermídia Abertos, OHSWG - Open Hypermedia Systems Working Groups (OHSWG, 2001)) é a identificação de uma arquitetura (ou modelo) hipermidia aberta de referência para sistemas hipermídia abertos. Algumas arquiteturas foram apresentadas na literatura, dentre essas, pode-se destacar a Arquitetura Flag (Østerbye e Wiil, 1996), a Arquitetura em Camadas do Framework Devise Hypermedia (DHM) (Grønbæk et al., 1994), a Arquitetura Shim (Davis et al., 1996), a Arquitetura do Modelo HyperDisco Estendido (Wiil e Whitehead, 1997) e a Arquitetura do Sistema Microcosm (Davis et al., 1994).

Outra questão também muito importante nesse contexto é a identificação dos requisitos desejáveis dos sistemas hipermídia abertos. Alguns trabalhos (Davis et al., 1996; Tai, 1996) enfocaram esse problema e definiram os seguintes requisitos:

1. Os sistemas hipermídia abertos devem suportar ligações a elementos do conteúdo dos documentos. Esses elementos podem ser sentenças em um arquivo texto, regiões em uma imagem ou objetos móveis em um vídeo.

2. Os sistemas hipermídia abertos devem suportar a integração de diversos aplicativos e documentos. Os documentos de dados não precisam ser convertidos em um formato especial (por exemplo, HTML) para participar de um ambiente hipermidia aberto. Documentos de diferentes origens podem fazer parte da mesma rede hipermídia.

3. Os sistemas hipermídia abertos devem permitir ligações em termos da semântica da informação. Ligações a informações com o mesmo significado devem ser suportadas independentemente da identidade dos documentos que encapsulam essas informações. Tais ligações são chamadas de "ligações baseadas em contexto", porque conectam significados ou semânticas, ao invés de localizações ou identificadores de arquivos.

4. Os sistemas hipermídia abertos devem suportar geração de ligações rápidas. Leitores (usuários) não devem precisar criar todas as ligações manualmente. $O$ sistema deve ser capaz de ligar itens de informações relacionados automaticamente, quando esses forem definidos no sistema hipermídia. 
5. Os sistemas hipermídia abertos devem suportar a criação de ligações privadas, além das ligações públicas previamente definidas pelo autor da aplicação.

6. Os sistemas hipermídia abertos devem suportar dados e processos distribuidos através de uma rede e de diferentes plataformas.

7. Deve ser fácil adicionar funcionalidades aos sistemas hipermidia abertos, ou seja, novos módulos de programas devem ser inseridos facilmente.

8. Não deve existir distinção entre usuários leitores e autores nos sistemas hipermidia abertos.

Com o objetivo de oferecer uma visão mais prática desses sistemas, na próxima Seção são descritos o Sistema Microcosm e o Framework Devise Hypermedia.

\subsection{Dois Exemplos: Microcosm e Devise Hypermedia}

\subsubsection{Microcosm}

\subsubsection{Características}

Segundo Davis et al. (1994), o projeto do Sistema hipermidia aberto Microcosm teve como objetivo produzir um workbench completamente aberto e configurável (pelo leitor) para pesquisa hipermidia.

De acordo com Grønbæk e Trigg (1999), a principal contribuição do Sistema Microcosm em termos de uma perspectiva aberta é a definição de um conjunto de ferramentas que permite sua integração com "aplicativos de terceiros" (third-party application), incluindo aqueles que são pouco adaptáveis. O Microcosm suporta a integração de aplicativos de terceiros através de um Visualizador Universal (visualizadores que encapsulam os aplicativos), que adiciona à interface desses funcionalidades para realizar (capturar) seleções e invocar o serviço de ligações. Uma outra contribuição desse sistema envolve a especificação de ligações externas aos dados. Essas ligaçōes são implementadas através de filtros de ligações, que são uma espécie de serviço de ligações para os aplicativos integrados ao Microcosm.

Dessa forma, segundo Davis et al. (1994), os princípios que nortearam o projeto do Microcosm foram:

1. Construir um sistema que separa as ligações dos dados: os relacionamentos (ligações) entre os documentos são separados desses e armazenados em bases de ligações externas. 
2. Construir um sistema fracamente acoplado (com interdependências mínimas), que não deve ser apenas um programa, mas um conjunto de tarefas que se comunicam. Tarefas adicionais podem, dessa forma, ser adicionadas ao sistema ou tarefas existentes podem ser substituídas. Isso faz com que não exista limite nas funcionalidades oferecidas pelo Microcosm.

3. Construir um sistema no qual não exista distinção entre usuários autores e leitores. Todos os leitores do sistema devem conseguir criar ligaçōes.

A abordagem adotada pelo modelo do Microcosm contrasta com abordagens hipermídia que embutem informações sobre ligações em versōes de documentos especializadas e marcadas. O Microcosm armazena informações sobre ligações em objetos chamados de bases de ligações. Em geral, cada ligação consiste de itens, tais como âncora fonte (ponto de início da ligação), âncora destino (ponto destino da ligação) e atributos. No Microcosm, o conceito de âncora foi generalizado de modo a oferecer um conjunto de possibilidades de tipos de ligações, tais como ligações específicas, ligações bidirecionais, ligações locais, ligações globais ${ }^{3}$ e ligações computadas ou dinâmicas (cada uma dessas ligações será descrita detalhadamente na Seção 2.4).

Nesse contexto, a arquitetura do Microcosm (apresentada na Figura 2.1) é baseada em um modelo de quatro camadas, descritas a seguir.

1. Camada de Armazenamento (Hiperbase): também chamada de sistema de gerenciamento de documentos, corresponde à camada de nível mais baixo do modelo. Essa camada é responsável por catalogar informações sobre os documentos registrados no sistema. Também é responsável por armazenar as bases de ligações (separadamente dos documentos). Diferentes bases de ligações (públicas e privadas) podem estar associadas ao mesmo conjunto de documentos.

2. Camada Serviço de Ligações: corresponde à segunda camada do modelo. É responsável pela manipulação das ligações contidas nas bases de ligações. Essa camada tem os seguintes componentes: Sistema de Controle de Documentos, Sistema de Gerenciamento de Filtros e Cadeia de filtros.

Sistema de Controle de Documentos: é responsável pela inicialização dos aplicativos da Camada de Aplicação quando solicitado e também por enviar mensagens que indicam quais documentos devem ser apresentados. As mensagens enviadas pelos aplicativos são transmitidas pelo sistema de controle de documentos para o sistema de gerenciamento de filtros.

\footnotetext{
${ }^{3}$ Também chamadas de ligações genéricas.
} 


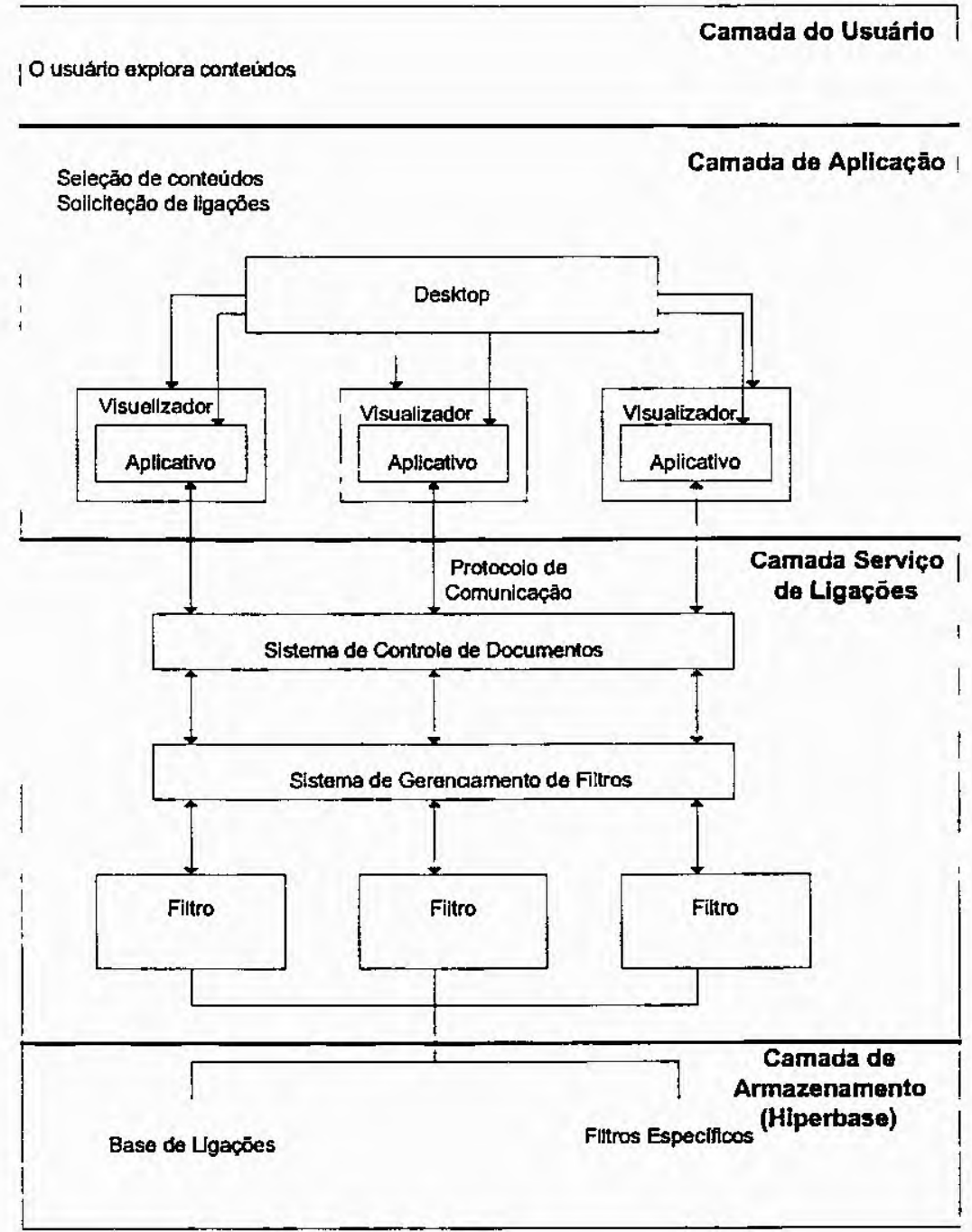

Figura 2.1: Arquitetura em Camadas do Sistema Microcosm (Davis et al., 1994)

Sistema de Gerenciamento de Filtros: é responsável por direcionar as mensagens para os filtros ativos.

Cadeia de Filtros: é um conjunto seqüencial de processos que fornece funcionalidades para os leitores e os aplicativos. Esses filtros recebem mensagens, realizam ações e podem gerar mensagens adicionais para os aplicativos e para outros filtros. A cadeia de filtros ativa no Microcosm define os tipos de ações disponiveis.

3. Camada de Aplicação: corresponde ao conjunto de aplicativos responsáveis pela manipulação de documentos (cada aplicativo é responsável por uma classe de documentos) registrados na camada de armazenamento.

4. Camada do Usuário (Leitor): essa camada oferece para o leitor acesso às funcionalidades do Microcosm. Também permite acesso aos documentos e às ligações que compõem as aplicações hipermídia. 
O Microcosm oferece suporte a três funcionalidades importantes: mais de uma base de ligações pode ser aplicada a uma determinada coleção de documentos, ligações podem ser associadas a midias read-only e ligações podem ser associadas a processos da mesma forma que a documentos.

\subsubsection{Funcionalidades}

No Microcosm, os filtros presentes na Cadeia de Filtros correspondem aos processos responsáveis pelas funcionalidades (hipermidia) oferecidas aos aplicativos e aos leitores.

O conjunto de filtros ativo no Microcosm determina os tipos de ações disponiveis em um determinado instante. As mensagens enviadas aos filtros (pelo Sistema de Controle de Documentos) são processadas seqüencialmente por cada um dos filtros da cadeia, de forma que, após alcançar seus resultados, um filtro comunica-se com os outros através da adição, mudança ou remoção de mensagens.

Segundo Davis et al. (1994), os filtros comumente suportados pelo Microcosm são:

1. Bases de Ligações (Linkbase): uma base de ligações armazena e gerencia todas as informações que se referem a um conjunto particular de ligações sobre um conjunto de documentos. Mais de uma base de ligações pode estar instalada em um determinado instante, possibilitando o suporte a diferentes visões do mesmo conjunto de documentos. As bases de ligações podem ser públicas ou privadas. Uma base de ligações pública contém todas as ligações construídas pelo autor original da aplicação, enquanto uma base de ligações privada contém ligações construidas por um leitor particular dessa aplicação. Os tipos de ligações suportadas pelas bases de ligações são: específicas, bidirecionais, globais, locais e computadas ou dinâmicas.

2. Construtor de Ligações: oferece mecanismos para facilitar a criação dos diferentes tipos de ligações suportadas pelas bases de ligações. No caso de ligações locais e globais, mecanismos de criação automatizada são oferecidos.

3. Visualizador de Ligações: oferece mecanismos para visualização e, conseqüientemente, disponibilização de ligações que não estão correntemente visíveis.

4. Computação de Ligações: oferece mecanismos para busca das âncoras destino de uma ligação computada.

5. Navegação: dois tipos de filtros de navegação são suportados pelo Microcosm: História e Mimic. O filtro História mantém uma lista de todos os documentos que foram visitados, permitindo que o leitor retorne para um documento anteriormente visitado. História pode ser armazenada no final de uma sessão. O filtro Mimic permite que o leitor navegue nos 
documentos através de um caminho pré-definido; todas as ações normais do Microcosm permanecem válidas durante a navegação do caminho pré-definido. Isso significa que o leitor pode sair do caminho pré-definido a qualquer instante, conseguindo ainda retornar ao caminho quando for necessário.

Os leitores podem controlar a ordem na qual cada filtro aparece na cadeia. Filtros podem ser instalados e removidos (dinamicamente), de forma a configurar o sistema conforme as preferências dos leitores. Dessa forma, novas funcionalidades podem ser adicionadas e substituidas facilmente no Microcosm.

\subsubsection{Devise Hypermedia}

\subsubsection{Características}

Segundo Grønbæk e Trigg (1996), o Devise Hypermedia é um framework orientado a objetos para desenvolvimento de sistemas hipermídia avançados, baseado no modelo Dexter (Halazs e Schwartz, 1990). Uma das principais contribuições desse framework foi tornar disponível aos aplicativos hipermídia habilitados integrados a ele um serviço de ligações hipermídia. Outras contribuições importantes foram: suporte a um conjunto rico de composites, suporte ao trabalho cooperativo, suporte a visões diferentes de ligações com zero ou uma extremidade e suporte a diferentes tipos de ligações.

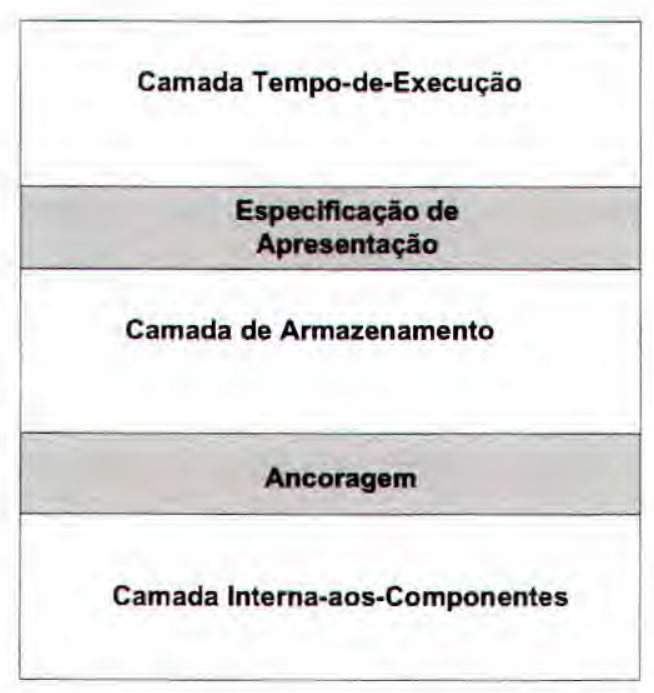

Figura 2.2: Arquitetura em Camadas do Modelo Dexter (Halazs e Schwartz, 1990)

De acordo com Grønbæk e Trigg (1999), o Framework Devise Hypermedia realiza um mapeamento das camadas conceituais do modelo original de Dexter (Figura 2.2) para uma arquitetura (fisica) hipermidia aberta. Esse mapeamento, descrito na Figura 2.3, apresenta os 


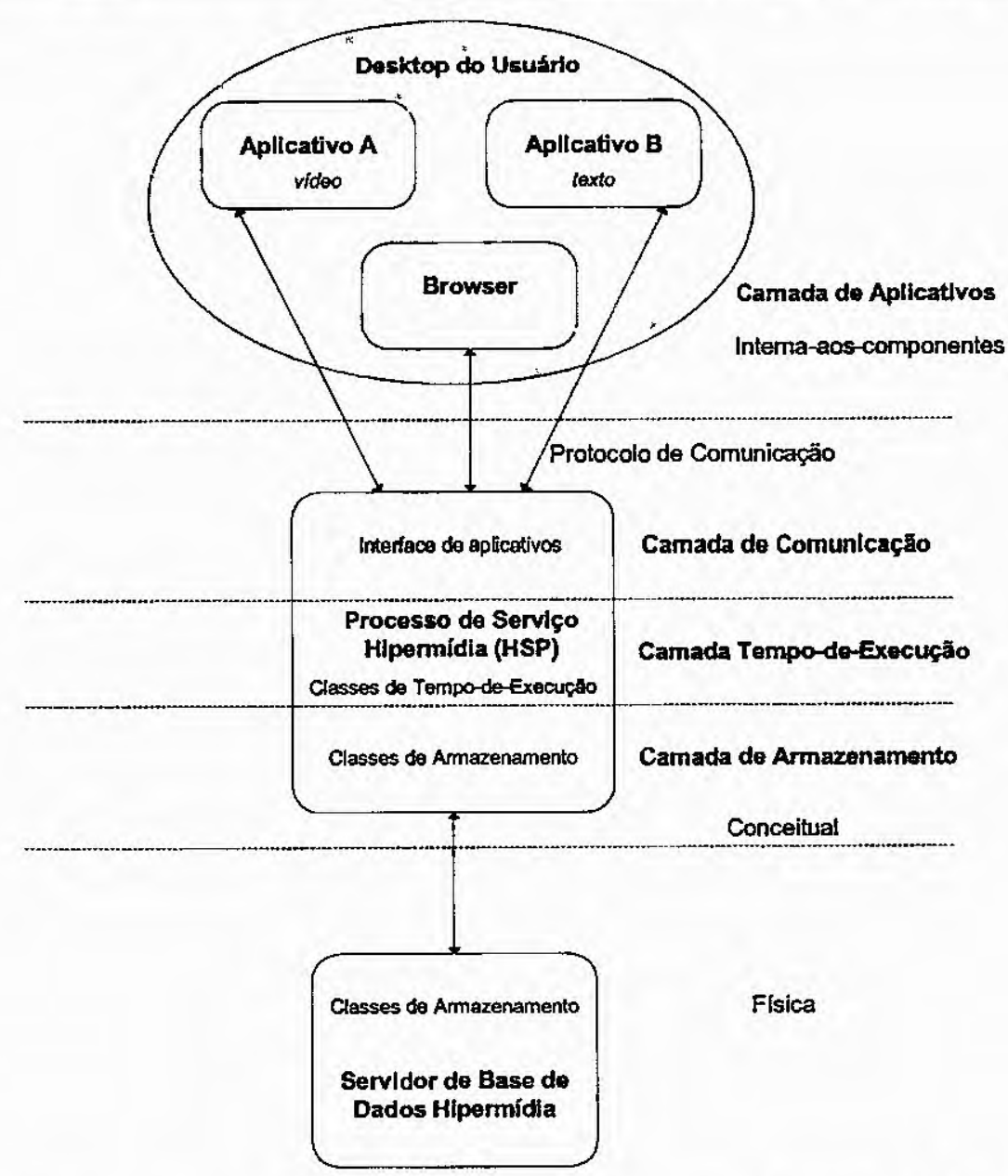

Figura 2.3: Arquitetura do Framework Devise Hypermedia (Grønbæk e Trigg, 1999)

aplicativos, que gerenciam o conteúdo dos componentes, como parte da camada intema-aoscomponentes, ao invés de apresentá-los como clientes do sistema hipermídia e da interface do usuário, como o modelo Dexter sugere (camada Tempo-de-execução de Dexter). Essa mudança faz sentido em um serviço hipermídia aberto, no qual os aplicativos que gerenciam conteúdo são tão importantes quanto o formato dos dados.

Ainda segundo Grønbæk e Trigg (1999), o reconhecimento da importância dos aplicativos em um ambiente hipermídia aberto foi uma das razões para a reorganização arquitetural significativa das camadas conceituais do modelo Dexter para o Modelo Dexter Aberto apresentado no FrameworkDevise Hypermedia. A camada interna-aos-componentes, ao invés de estar no nivel mais baixo da arquitetura e escondida dos usuários do sistema hipermídia, foi passada para o topo e renomeada como camada de aplicativos. Além disso, um novo elemento da camada conceitual foi criado, a camada de comunicação, que modela a comunicação entre os aplicativos e o serviço hipermídia. A camada conceitual é mapeada em três camadas físicas de processos comunicantes, como é mostrado na Figura 2.3. 
Deve-se destacar que o principal elemento da camada conceitual "Tempo-de-Execução" é o Processo de Serviço Hipermídia (HSP - Hypermedia Process Service), que é responsável pelo gerenciamento (incluindo resolução) do conjunto de ligações das aplicações hipermídia.

De acordo com Grønbæk e Trigg (1994, 1999), aplicações desenvolvidas com o Devise Hypermedia são adequadas para o gerenciamento de materiais compartilhados, tais como documentação técnica e material Case.

\subsubsection{Funcionalidades}

As principais funcionalidades oferecidas pelo Framework Devise Hypermedia são:

1. Organização dos nós de informações em redes hipemídia com referências associativas (chamadas de bases de ligações), e utilização da operação seguir ligação para navegar por essas informações. O Devise Hypermedia suporta, com exceção das ligações locais, os mesmos tipos.de ligações suportadas pelo.Microcosm.

2. Suporte a diferentes tipos de nós de informação, tais como texto, gráficos, vídeo, áudio, etc. Partes desses nós, como sentenças em um texto, podem ser especificadas como pontos finais de ligações.

3. Suporte à integração de aplicativos existentes, täís.comoprocessadores de texto, planilhas eletrônicas, browsers da $W W W$, etc.

4. Trabalho cooperativo assíncrono em aplicações hipermídia compartilhadas. O Devise Hypermedia utiliza uma base de dados orientada a objetos (OODB) para fornecer suporte cooperativo a aplicações hipermídia compartilhadas. A OODB suporta transações de longa duração, bloqueios flexíveis e notificação sobre eventos que ocorrem em objetos compartilhados.

\subsubsection{Webvise}

O Sistema Webvise (Grønbæk e Trigg, 1999) é um protótipo de sistema hipermídia aberto desenvolvido com o Framework Devise Hypermedia. Esse protótipo suporta a criação e manutenção de diferentes tipos de estruturas hipermídia abertas, tais como: contextos, ligações, anotações, coleções e roteiros guiados. Também oferece suporte para criação de ligações globais, locais, específicas e bidirecionais.

Uma característica muito importante do Sistema Webvise é o suporte à cooperação, de forma que documentos e ligações podem ser compartilhados. 
Nesse sistema é possível a criação de ligações em documentos nos quais não há permissão de escrita. Essas ligações são armazenadas em bases de ligações externas gerenciadas pelo Webvise.

O conjunto de aplicativos integrado ao Webvise é composto pelos seguintes elementos: Internet Explorer 4.0, Microsoft Word 2000 e Microsoft Excel 2000, o que torna possível a criação de ligações entre documentos nos formatos suportados por esses aplicativos.

É importante ressaltar que o conjunto de aplicativos e, conseqüentemente, formato de documentos integrados ao Webvise é muito restrito. Isso deve-se ao fato desse sistema ser apenas uma implementação protótipo que incorpora algumas características dos sistemas hipermídia abertos.

O conjunto de mensagens que especifica a comunicação entre o Sistema Webvise e os aplicativos integrados a esse é baseado no conjunto de mensagens definido pelo Protocolo Hipermídia Aberto (descrito na Seção 2.5).

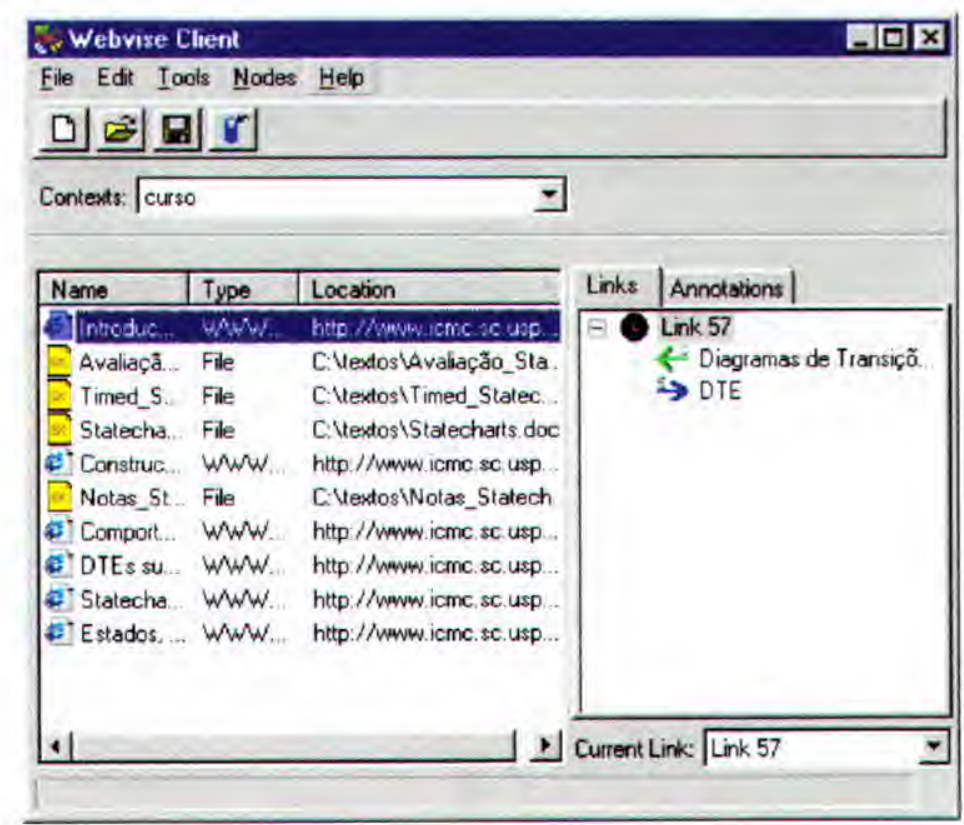

Figura 2.4: Exemplo de Interface do Sistema Webvise

A interface do Webvise, com uma aplicação instanciada, é apresentada na Figura 2.4. Podese observar que a aplicação é composta por um conjunto de documentos (lado esquerdo da Figura) e por uma base de ligações (lado direito da Figura).

Esse protótipo de sistema hipermídia aberto foi utilizado para a especificação do exemplo de uma aplicação em sistema hipermídia aberto real que, por sua vez, também foi especificada no Modelo OXHMBS proposto neste trabalho. Ambas as especificações podem ser observadas na Seção 5.4 . 


\subsection{Aplicações em Sistemas Hipermídia Abertos}

Tendo caracterizado o suporte dos sistemas hipermídia abertos, as aplicações que podem ser construídas e manipuladas por esses sistemas constituem-se basicamente de um conjunto de documentos (criados a partir de diferentes aplicativos) e de um conjunto de ligações armazenadas extemamente a esses documentos (em bases de ligações).

Nesse contexto, o estudo dos requisitos dessas aplicaçōes apresentado em (Miotto e Fortes, 2000) (totalizando oito), descrito a seguir, objetivou a identificação e descrição de quais são efetivamente os requisitos que as aplicações em sistemas hipermídia abertos devem atender, para a partir desses requisitos, posteriormente neste trabalho, indicar quais extensões ao modelo formal XHMBS seriam necessárias para tomá-lo adequado à especificação dessas aplicações.

\subsubsection{Requisitos}

\subsubsection{Separação entre estrutura e conteúdo da informação}

A separação explícita entre a estrutura e o conteúdo das informações é um requisito chave das aplicações em sistemas hipermidia abertos. Nenhuma informação sobre ligações deve ser embutida no conteúdo dos documentos que compõem as aplicações em sistemas hipermidia abertos. Dessa forma, tais documentos continuam sendo analisados, processados e manipulados pelos aplicativos que os criaram, ou seja, o uso desses documentos fora do sistema hipermídia aberto não deve ser comprometido. Os documentos que compõem as aplicações em sistemas hipermidia abertos devem permanecer nos formatos originais de seus aplicativos, o que significa que eles não precisam ser convertidos em um formato especial para participar de um ambiente hipermídia aberto (Davis et al., 1996; Grønbæk e Trigg, 1999).

\subsubsection{Documentos em diferentes formatos}

O suporte a documentos em diferentes formatos é também um requisito indispensável nas aplicações em sistemas hipermidia abertos, uma vez que o objetivo principal dos sistemas hipermídia abertos é produzir um conjunto geral de serviços hipermídia que pode ser usado por um conjunto qualquer de aplicativos existentes (sem alterar seus formatos de dados) no ambiente computacional. Isso conseqüentemente resulta em um conjunto irrestrito de formatos de documentos que compõem as aplicações em sistemas hipermidia abertos (Tai, 1996).

\subsubsection{Bases de ligações externas}

Como conseqüência da necessidade de separação entre o conteúdo e a estrutura das aplicações em sistemas hipermídia abertos, informações sobre ligações são mantidas em bases de ligações 
externas. Essas bases de ligações são gerenciadas pelo sistema hipermidia aberto, e portanto fazem parte das aplicações e devem ser especificadas como parte dessas.

As bases de ligações externas permitem que informações sobre ligações sejam facilmente analisadas, e também permitem a existência de diferentes visões do mesmo conjunto de documentos, ou seja, diferentes bases de ligações sobre o mesmo conjunto de documentos (Davis et al., 1996; Gronbæk e Trigg, 1999). Essas podem ser de dois tipos:

1. Bases de Ligações Públicas: contêm todas as ligações construidas pelo autor original da aplicação hipermídia. Esse conjunto de ligações é visivel por todos os leitores dessa aplicação.

2. Bases de Ligações Privadas: contêm todas as ligações construídas por um leitor particular da aplicação. Esse conjunto de ligações é visivel apenas pelo leitor responsável pela sua criação. Através de bases de ligações privadas, leitores podem configurar conjuntos de ligaçōes de acordo com suas necessidades.

\subsubsection{Ligaçōes "de" e "para" informações read-only}

O suporte a ligações "de" e "para" informações read-only também é uma conseqüência da separação entre estrutura e conteúdo da informação, uma vez que, dessa forma, a estrutura é somente acrescentada ao conteúdo em tempo de apresentação. Assim, é possivel que ligações sejam criadas em documentos de diferentes origens, incluindo read-only (ou seja, mesmo sem permissão de escrita). Esse requisito faz com que não exista nenhuma distinção entre usuários leitores e autores/escritores, o que é um dos requisitos básicos dos sistemas hipermídia abertos (Tai, 1996). Vale ressaltar que essas ligações devem estar contidas nas bases de ligações externas.

\subsubsection{Ligaçōes em termos da semântica da informação}

Ligações a informações com o mesmo significado podem ser suportadas independentemente da identidade dos documentos que encapsulam essas informações. Tais ligações são chamadas de "ligações baseados em contexto" porque conectam significados ou semânticas ao invés de localizaçōes ou identificadores de arquivos (Tai, 1996).

\subsubsection{Documentos relacionados de diversas formas}

As aplicações em sistemas hipermídia abertos podem ter seus documentos relacionados de diversas formas, ou seja, podem suportar diferentes tipos de ligações (Davis et al., 1996; Grønbæk e Trigg, 1999), tais como: 
1. Ligações específicas: são ligações que possuem uma única âncora fonte (que corresponde a uma parte especifica de um documento qualquer) e uma única âncora destino (que também corresponde a uma parte específica de um documento qualquer). Em geral, essas ligaçōes são usadas para fornecer informações detalhadas sobre um assunto particular.

2. Ligações bidirecionais: são semelhantes às ligações específicas, porém, podem ser navegadas em ambas direçòes (fonte para destino e destino para fonte). Isso significa que, nesse tipo de ligação, não há distinção entre âncoras fonte e âncoras destino.

3. Ligaçōes locais: essas ligações são inseridas uma vez e refletidas automaticamente em toda ocorrência da âncora fonte no documento fonte. Podem ser usadas quando a ligação de uma palavra ou frase necessita ser restringida a um documento particular. Por exemplo, para fornecer uma ligação para uma explicação de uma palavra jargão que é usada de um modo particular no documento.

4. Ligaçōes globais: essas ligações são inseridas uma vez e refletidas automaticamente em toda ocorrência da âncora fonte em todo documento que for visualizado. Esse tipo de ligação pode ser usado quando for necessário disponibilizá-la em toda a aplicação, por exemplo, uma ligação para uma explicação de um termo técnico em um glossário.

5. Ligações computadas ou dinâmicas: essas ligaçōes permitem que algum texto seja selecionado a partir de um documento fonte e sejam encontrados outros documentos que contêm uma aita ocorrência das palavras significativas na seleção. Dessa forma, são geradas automaticamente ligações para esses documentos.

\subsubsection{Questões de distribuição}

As aplicações em sistemas hipermidia abertos podem ser armazenadas e executadas em diferentes máquinas em uma rede local ou através de diferentes domínios da Internet. Dessa forma, durante a especificação dessas aplicações, questões relacionadas a distribuição, principalmente de seu armazenamento devem ser consideradas (Davis et al., 1996; Grønbæk e Trigg, 1999).

\subsubsection{Questões de cooperação}

Tanto o conteúdo quanto a estrutura de uma aplicação em sistema hipermídia aberto podem ser desenvolvidos de uma maneira cooperativa (autoria cooperativa). Diferentes tipos de cooperação podem ser suportados pelos sistemas hipermídia abertos, incluindo trabalho assíncrono (dados compartilhados entre um grupo de autores trabalhando em sessões de autoria individuais) e trabalho síncrono (compartilhamento simultâneo e criação de conteúdos e estruturas por um grupo de autores trabalhando em uma única sessão de autoria compartilhada). Embora não 
seja um pré-requisito de sistemas hipermidia abertos (e conseqüentemente das aplicações em sistemas hipermidia abertos), a capacidade de suportar trabalho cooperativo assíncrono, principalmente de conteúdo, é vista por (Davis et al., 1996) como um conceito chave.

\subsection{Protocolo Hipermídia Aberto}

Segundo Grønbæk e Trigg (1999), uma questão critica da pesquisa hipermídia aberta é a definição da forma de comunicação entre os sistemas hipermidia abertos e os aplicativos integrados a esses. Nesse contexto, o Grupo de Trabalho de Sistemas Hipermidia Abertos OHSWG (OHSWG, 2001) definiu o Protocolo Hipermídia Aberto (OHP - Open Hypermedia Protocol) (Davis et al., 1996) baseado em experiências com os Sistemas Microcosm e Multicard (Rizk e Sauter, 1992), e posteriormente em estudos de sua utilização no Framework Devise Hypermedia. Esse protocolo tem como objetivo a padronização do formato das mensagens de comunicação entre os sistemas hipermidia abertos e seus aplicativos hipermídia habilitados.

Na arquitetura do Framework Devise Hypermedia (Seção 2.3.2), o Protocolo Hipermidia Aberto (OHP) encontra-se definido na Camada de Comunicação que é responsável pelas interações entre o HSP (Processo de Serviço Hipermídia) e os aplicativos do ambiente do usuário. Enquanto que na arquitetura do Sistema Microcosm (Seção 2.3.1) esse protocolo encontra-se definido na camada Serviço de Ligações, responsável pelas trocas de mensagens definidas entre o Sistema de Controle de documentos e os aplicativos do ambiente do usuário.

De acordo com Grønbæk e Trigg (1999), o OHP é um protocolo de comunicação ponto a ponto, dessa forma, tanto o sistema hipermídia quanto os aplicativos externos integrados a esse podem receber e enviar mensagens definidas nesse protocolo.

Ainda de acordo com Grønbæk e Trigg (1999), uma implementação simples do protocolo hipermídia aberto poderia usar uma codificação textual de mensagens que, por sua vez poderiam ser "trocadas" (entre os aplicativos e o sistema) através de facilidades de comunicação e ser interpretadas tanto pelo sistema hipermídia aberto quanto pelos aplicativos integrados a esse. Um exemplo de uma codificação textual do OHP é apresentado no trabalho de (Davis et al., 1996), onde é usado um conjunto de comandos em uma sintaxe parecida com a do Latex (Lamport, 1986).

De acordo com suas principais funcionalidades, o protocolo OHP é dividido em quatro subprotocolos:

1. Protocolo de Conexão: responsável pelo estabelecimento de conexões entre os aplicativos (hipermídia habilitados) e o sistema hipermídia aberto. 
2. Protocolo de Ligação Básico: responsável pelo suporte à criação, remoção e travessia de ligações em documentos manipulados por aplicativos integrados ao sistema hipermídia aberto.

3. Protocolo de Navegação Estendida: esse subprotocolo é opcional e permite que comandos de navegação e de gerenciamento sejam manipulados diretamente da interface dos aplicativos integrados ao sistema hipermídia aberto.

4. Protocolo Multiusuário: as mensagens desse protocolo são relevantes quando vários usuários compartilham simultaneamente uma aplicação hipermídia. Basicamente, tais mensagens suportam bloqueios e notificação de eventos.

Uma definição mais detalhada, no contexto do modelo OXHMBS, do formato de cada uma das mensagens definidas pelos sub-protocolos do OHP pode ser observado nas Seções 4.8.1, 4.8.2 e 4.8.3.

\subsection{Considerações Finais}

Neste capitulo foi apresentada, inicialmente, uma visão geral das principais características dos sistemas hipermidia abertos, em termos de suporte oferecido e requisitos desejáveis (Seção 2.2).

Com o objetivo de oferecer uma visão mais prática desses sistemas foram apresentados o Sistema Microcosm e o Framework Devise Hypermedia (Seção 2.3).

Também, foram apresentados os principais requisitos das aplicações construidas e manipuladas pelos sistemas hipermídia abertos (Seção 2.4). Esses requisitos são muito importantes para o trabalho proposto, uma vez que são os responsáveis pela condução das extensões realizadas sobre o modelo formal XHMBS de forma a torná-lo adequado à especificação das aplicações em sistemas hipermídia abertos.

Finalmente, também foi apresentado o Protocolo Hipermidia Aberto (OHP), que define a forma de comunicação padrão existente entre os sistemas hipermidia abertos e os aplicativos integrados a esses (Seção 2.5). O estudo do protocolo OHP foi muito importante para o trabalho proposto, pois esse é utilizado na definição da semântica de navegação do modelo OXHMBS.

No próximo capitulo são apresentadas as principais caracteristicas do modelo XHMBS, bem como de seu antecessor HMBS, com o objetivo de fornecer o embasamento necessário à definição do modelo OXHMBS apresentado nos capitulos 4 e 5 . 


\section{Statecharts, HMBS e XHMBS}

\subsection{Considerações Iniciais}

Como já destacado anteriormente, o objetivo deste trabalho é a proposição de extensões ao modelo XHMBS de forma a tomá-lo adequado à especificação de aplicações em sistemas hipermídia abertos, dessa forma, torna-se necessária a apresentação de uma discussão detalhada sobre esse modelo. O modelo XHMBS é contextualizado na Seção 3.4 deste capitulo.

O XHMBS, por sua vez, é uma extensão do modelo para especificação de aplicações hipermídia HMBS; dessa forma, o HMBS também é descrito na Seção 3.3 deste capitulo.

Finalmente, como Statecharts é a técnica de especificação subjacente a ambos modelos (HMBS, XHMBS e conseqüentemente é a técnica subjacente ao modelo OXHMBS), a mesma é apresentada na Seção 3.2 antes da apresentação dos modelos, para auxiliar no entendimento desses.

\subsection{Statecharts}

Statecharts consistem de uma técnica para especificação do comportamento de sistemas reativos (Harel, 1987; Harel et al., 1987). Segundo Harel et al. (1987), o problema de especificar e projetar sistemas reativos grandes e complexos está na dificuldade de descrever seu comportamento reativo de maneira clara e real, ao mesmo tempo formal e rigorosa o suficiente para permitir sua simulação detalhada. 
O comportamento de um sistema reativo é, na realidade um conjunto de seqüências possíveis de eventos de entrada e saída, condições e ações, além de algumas informaçōes adicionais, tais como restrições de tempo.

A técnica Statecharts constitui uma extensão da técnica Máquinas de Estados Finitos, na qual, além da noção de estados e transições, é possível representar hierarquia entre estados, concorrência entre estados e propagação de eventos (que torna possivel a comunicação entre estados).

A definição de Statecharts é baseada em conjuntos de estados, transições, eventos primitivos, condições primitivas e variáveis. Com base nesses conjuntos de elementos básicos é possivel definir os conjuntos de eventos, condições, expressões, ações e rótulos, bem como os interrelacionamentos entre eles.

Os estados de um statechart representam as situações em que o sistema poderá estar durante sua execução. Esses podem ser básicos, se não forem decompostos em subestados; caso contrário, são não-básicos. Quando um estado é não-básico sua decomposição em subestados pode ser de dois tipos: or ou and. Se um estado $X$ for do tipo or, então quando o sistema sendo especificado estiver em $X$, esse, na verdade, deverá estar em apenas um dos subestados de $X$. Se $X$ for do tipo and, então, quando o sistema sendo especificado estiver em $X$, deverá estar em todos os seus subestados simultaneamente. A noção de hierarquia introduzida pelas decomposições de estados em subestados introduz os termos "estado pai" (estado que é decomposto em subestados) e "estado filho" (estados que são subestados de um "estado pai"). Em todo statechart existe um estado que não possui qualquer "estado-pai", denominado "raiz do statechart". Esses conceitos de hierarquia de estados podem ser melhor observados na Figura 3.1, como é o caso de $A$ ser um estado do tipo and e ser "estado pai" de $A_{1}$ e $A_{2}$.

Um statechart possui um conjunto de expressões que contém variáveis, números e expressões algébricas envolvendo esses elementos. O conjunto de condições de um statechart tem como condições primitivas os valores lógicos true e false. Além disso, sentenças relacionais que envolvem expressões e sentenças lógicas que envolvem outras condiçōes são também consideradas condições.

Os eventos primitivos de um statechart são aqueles que ocorrem no ambiente do sistema sendo especificado. Statecharts também permitem a especificação de um evento nulo (representado por $\lambda$ ) que corresponde a um evento que é gerado a cada passo de execução ou simulação do sistema. Expressões booleanas, ou seja, do tipo true ou false (condições) representam eventos que ocorrem quando o valor de uma condição se torna, respectivamente, verdadeiro ou falso. A expressão changed representa um evento que ocorre quando o valor de uma expressão é modificado. As expressões exit(estado) e entered(estado) representam eventos que ocorrem quando o sistema sai de um estado ou entra em um estado, respectivamente. Qualquer combinação de expressões de eventos através dos operadores lógicos é considerada um evento. Finalmente, a 
cxpressão timeout representa um evento que ocorre quando um determinado número de passos decorre após a ocorrência de um evento observado durante a execução do sistema.

As ações em um statechart podem ser nulas $(\mu)$, expressões de atribuição de valores a variáveis ou condições (na forma $a:=b$ ) ou conjuntos de ações separadas por ";" (na forma $a_{1} ; a_{2} ; \ldots a_{n}$ ).

As transições representam as possibilidades de alterações no estado do sistema quando algum evento que pode ser primitivo/externo (gerado pelo ambiente) ou interno (gerado pelo próprio statechart) ocorrer. Uma transição sempre envolve um conjunto de estados origem, um conjunto de estados destino e um rótulo. O conjunto de rótulos de transições em um statechart é formado por elementos do tipo evento/ação. Por exemplo, se uma transição tem o rótulo evento $1 /$ acao $_{1}$, então essa só será disparada quando o evento evento ocorrer, o que causará a execução da ação $a c a o_{1}$. Nesse contexto, a forma geral do rótulo de uma transição é a seguinte: evento[condição]/ação, no qual evento representa uma expressão de eventos, condição é uma expressão condicional aplicada sobre a transição e ação representa um conjunto de ações.

Informalmente pode-se dizer que uma transição com origem em um conjunto de estados $X$, com destino em um conjunto de estados $Y$ e com um rótulo evento ${ }_{1}\left[\right.$ condicao $\left._{1}\right] /$ acao $_{1}$ irá disparar se o sistema estiver em $X$, o evento evento ${ }_{1}$ ocorrer e a condição condicao $_{1}$ for satisfeita. Dessa forma, as ações em $a c a o_{1}$ serão executadas e o sistema passará a estar nos estados (ou em um estado) determinados pelo conjunto $Y$. As transições são representadas por arcos direcionados que ligam os estados de origem aos estados de destino. Quando mais de um estado estiver envolvido no destino ou na origem de uma transição a extremidade do arco que a representa é ramificada. Esses conceitos sobre transições podem ser melhor observados na Figura 3.1, como é o caso das transições entre os estado $C \rightarrow D, B_{11} \rightarrow B_{12}$ e $B_{21} \rightarrow B_{22}$.

Semelhante a uma transição é o símbolo de estado de fault que também pode ser chamado de transição de fault. Quando um estado do tipo or, por exemplo, o estado $A_{1}$ da Figura 3.1, é decomposto em subestados, por exemplo, $C$ e $D$, de tal forma que o estado $C$ possui o indicador de estado de fault, quando o estado $A_{1}$ for ativado através de alguma transição o subestado $C$ será ativado. Geralmente, sempre que um estado $X$ do tipo or for ativado, o subestado de $X$ que será ativado será aquele no qual o indicador de estado de fault estiver associado.

A partir dos conceitos descritos acima, é possivel definir o comportamento de um sistema através de um statechart. A semântica de execução de Statecharts é baseada em um modelo discreto de tempo, no qual os estados de um sistema possuem duração e as transições são instantâneas. O termo "passo de execução ou de simulação" tem origem nesse modelo de tempo. Pode-se dizer que, cm um passo de execução, o statechart assume uma configuração de estados que corresponde ao conjunto de estados básicos ativos naquele passo. Dessa forma, a cada passo obtém-se uma nova configuração do statechart que pode, dependendo das transições que dispararam, ser igual ou não à configuração anterior. 


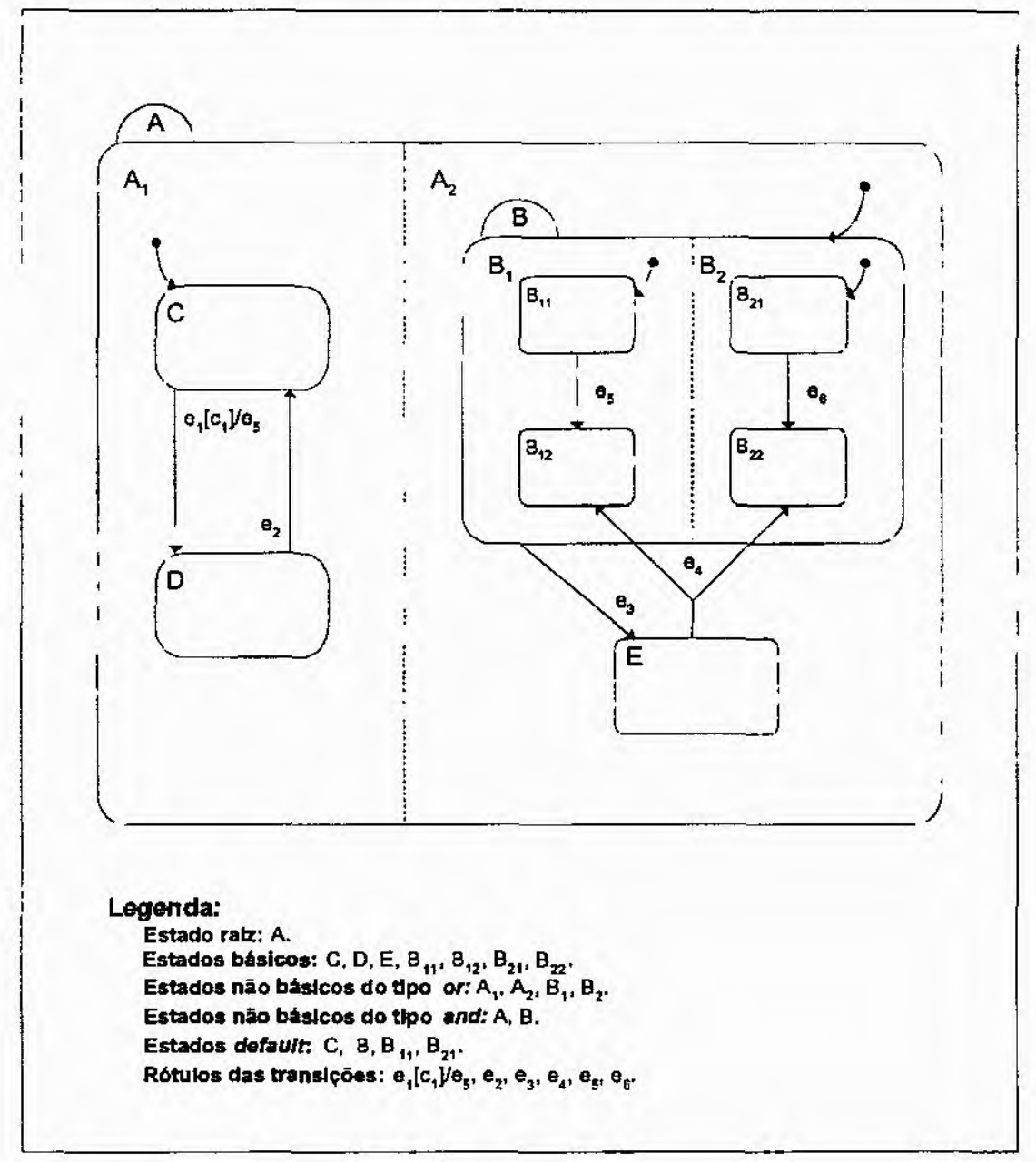

Figura 3.1: Exemplo de um statechart

A configuração inicial de um statechart é obtida pela ativação de seu estado raiz e, recursivamente, de todos os subestados default.

Duas das caracteristicas principais de Statecharts são concorrência entre estados (estados do tipo and) e composição hierárquica de subestados. Porém, um dos mecanismos mais poderosos da técnica Statecharts é a difusão de eventos, que pode ocorrer através da geração de eventos internos. Em termos notacionais, a geração de um evento interno é obtida através da especificação de um evento na expressão de ações contida no rótulo de uma transição. Dessa forma, quando a transição disparar, o evento especificado em sua expressão de ações será gerado e sentido por todos os estados concorrentes que estiverem ativos no passo atual, os quais, se for o caso, poderão reagir e evoluir. Um exemplo da especificação de um evento interno pode ser observado na transição com rótulo $e_{1}\left[c_{1}\right] / e_{5}$ da Figura 3.1 .

Um outro recurso importante da técnica Statecharts é o mecanismo de história. Quando o sistema sendo especificado entra em um estado $X$ do tipo or que possui um símbolo história associado, a configuração de $X$ torna-se igual à configuração encontrada quando o sistema 
esteve em $X$ pela última vez. Essa configuração pode ser diferente da configuração determinada pelos indicadores de estado default, e permite a existência de um mecanismo de recuperação de "memória" de uma configuração anterior de estados.

Com o objetivo de estabelecer a relação entre a especificação comportamental e a especificação funcional de um sistema, Statecharts suportam atividades, que são funções do sistema associadas aos seus estados. Basicamente é possivel que uma atividade seja ativada quando o sistema entra em um estado (on entry), sai de um estado (on exit) ou estiver em um estado (on throughout). Dessa forma, o statechart pode constituir o elemento controlador das funçôes do sistema sendo especificado.

\subsection{Modelo HMBS}

O modelo HMBS, proposto por (Turine, 1998), tem como principal caracteristica a utilização de Statecharts como técnica base para a especificação de aplicações hipermidia, de maneira similar ao uso de Redes de Petri (Peterson, 1977) pelo Modelo Trellis (Stotts e Furuta, 1990).

A idéia principal do modelo HMBS é de utilizar a técnica Statecharts, que oferece facilidades de especificação de concorrência e transição de estados, para especificar a estrutura e a semântica de navegação de uma aplicação hipermídia. A estrutura da aplicação hipermídia é definida pela organização hierárquica de estados de Statecharts, que são mapeados para as respectivas porções de informação (páginas/documentos). Somente os estados do tipo or são mapeados em páginas, ficando os estados do tipo and reservados para a especificação de apresentação concorrente de informações (em geral de mídias diferentes). As transições entre os estados (com os eventos contidos em seus rótulos) correspondem às âncoras e respectivas ligações entre as páginas, definindo os caminhos de navegação disponiveis ao usuário da aplicação.

A navegação de uma aplicação hipermidia no modelo HMBS é realizada com base na execução do statechart (que representa a estrutura dessa) a partir de uma configuração inicial. O resultado do disparo de uma transição corresponde à apresentação da informação contida nas páginas associadas aos estados da nova configuração. A apresentação da informação é realizada através de canais de apresentação. Cada canal de apresentação representa um dispositivo capaz de apresentar um determinado tipo de informação. Dessa forma, deverão ser definidos tantos canais quantas forem as mídias utilizadas na aplicação hipermidia que estiver sendo especificada.

Assim, uma aplicação hipermidia $H$ especificada no modelo HMBS é definida formalmente a seguir:

Definição 1 Seja $H=\langle S T, P, m, L ; p l, a e, N\rangle$ uma aplicação hipermidia, onde: 
- $S T$ representa o statechart que define a estrutura organizacional e navegacional da aplicação hipermídia. O HMBS utiliza apenas um subconjunto da sintaxe original da técnica Statecharts (Harel et al., 1987), ou seja, algumas caracteristicas de Statecharts não foram utilizadas pelo modelo HMBS. Esse subconjunto é definido como uma 10-tupla, tal que $S T=\langle S, \rho, \Psi, \gamma, \delta, V, C, E, A c, T\rangle$, onde:

$S=\left\{s_{1}, s_{2}, \ldots s_{n}\right\}$ representa o conjunto de estados.

$\rho: S \rightarrow 2^{S}$ representa a função de hierarquia, que associa a cada estado o conjunto de seus subestados.

$\Psi: S \rightarrow\{a n d$, or $\}$ representa a função tipo de decomposição, que define para cada estado o seu tipo.

$\gamma: H \rightarrow S$ representa a função de história, responsável pelo mapeamento dos símbolos de história em estados, de forma que: $\gamma(H)=\{y\}$ if $y \in S$ and $\rho(y)=\{o r\}$.

$\delta: S \rightarrow 2^{S \cup H}$ representa a função de fault, que define para cada estado um conjunto de estados iniciais.

$V$ representa o conjunto de expressões que contém nomes de variáveis pertencentes ao conjunto de variáveis lógicas $V_{p}$ (as variáveis desse conjunto possuem valores iniciais conhecidos). O conjunto $V=V_{p}$ é, portanto, dado por $V=V_{t} \cup V_{f}$ onde $V_{t}$ é o conjunto de variáveis cujo valor inicial é true e $V_{f}$ é o conjunto de variáveis cujo valor inicial é false.

$C$ representa o conjunto de condições, que podem ser true, false ou expressões lógicas.

$E$ representa o conjunto de expressões de eventos que podem estar contidas no conjunto de eventos primitivos $E_{p}$, ou combinadas com condições e ações na forma $e[c] / a$.

$A c$ representa o conjunto de ações, que podem ser a ação nula $(\mu)$, um evento primitivo, uma atribuição de valor true ou false a uma condição e uma seqüência qualquer dessas açôes.

$T \subseteq 2^{S} \times E \times 2^{S \cup H}$ representa o conjunto de transições, que são defini das por triplas $t=(X, r, Y)$, onde $X$ é o conjunto de estados de origem, $r$ é o rótulo (expressão de eventos) e $Y$ é o conjunto de estados destino.

- $P=\left\{p_{1}, p_{2}, p_{3}, \ldots p_{n}\right\}$ representa o conjunto de páginas que define o conteúdo da aplicação hipermidia. Cada página $(p \in P$ ), comumente denominada nó de informação, contém uma porção de informação relevante em um determinado contexto da aplicação hipermídia. Essas são definidas conceitualmente pela tripla $\left\langle c, t, A n c_{p}\right\rangle$, onde $c$ é a porção do conteúdo de informação, que pode ser composta por mídias estáticas (texto, gráfico ou 
imagem) ou dinâmicas (vídeo, áudio ou animação); $t$ representa o título associado à página, o qual deve identificar o conceito que melhor descreve a informação contida na página a fim de auxiliar na busca por uma informação específica durante o processo de navegação (ligaçōes dinâmicas ou computadas); e $A n c_{p}=\left\{a_{1}, a_{2}, \ldots a_{m}\right\}$ para $m \geq 0$, define uma coleção de âncoras associadas a uma página. $O$ conjunto de páginas pode incluir uma página nula específica, sem qualquer conteúdo, título e/ou âncora, a qual pode ser associada a estados que não modelam apresentação de informação.

- $m: S_{s} \rightarrow P$ representa a função que mapeia estados $s$ de um subconjunto $S_{s}\left(s \in S_{s}\right)$ a páginas $p(p \in P)$ da aplicação hipermídia. O subconjunto $S_{s}$ é definido por $S_{s}:\{s \in S \mid$ $\Psi(s)=$ or $\vee \rho(s)=\emptyset\}$, ou seja, $S_{s}$ é o conjunto formado pelos estados do tipo or e pelos estados atômicos do statechart. Estados do tipo and não são mapeados em páginas, pois são utilizados para especificar concorrência de informações na apresentação da aplicação hipermídia.

- $L$ representa o conjunto de canais de apresentação, que são abstrações dos dispositivos pelos quais é possível especificar os requisitos relativos à apresentação da informação contida nas páginas da aplicação hipermidia. Os canais são invocados para visualizar as informações contidas nas páginas durante a navegação, atuando como interpretadores de páginas. Dependendo do tipo de midia presente na página a ser apresentada, os canais invocam um determinado aplicativo para visualizar tais informações. Por exemplo, processadores de texto podem ser utilizados como dispositivos para visualizar informações textuais, editores gráficos como dispositivos para imagens estáticas e manipuladores de áudio e video como dispositivos para animação.

- $p l: P \rightarrow L$ define a função de visualização que associa cada página $(p \in P)$ a um único canal $(l \in L)$ capaz de interpretá-la.

- ae $: A n c_{p} \rightarrow E$ define a função que associa elementos $a_{p} \in A n c_{p}$ a eventos do statechart que, por sua vez, definem como as transições serão disparadas. Segundo o HMBS, os elementos do conjunto $A n c_{p}$ de uma página $p \in P$ só ativam as ligações da aplicação hipermídia quando estiverem associados a um único evento pela função ae. O comportamento do mapeamento ae segue a abordagem de programação orientada a eventos, de modo que a ação do leitor selecionar uma âncora é um evento extemo a ser tratado pelo sistema hipermídia que suporta o modelo.

- $N$, onde $(N \in \mathbb{N})$, define o nivel de visibilidade da aplicação hipermídia. O autor da aplicação pode utilizar o valor de $N$ para definir a profundidade da hierarquia, na estrutura especificada pelo statechart subjacente, a ser apresentada durante a navegação. Uma aplicação hipermídia com valor de $N$ igual a zero $(N=0)$ tem, exibidas durante 
a navegação, todas as páginas associadas aos estados atômicos que estiverem ativos na configuração de estados válida. $\operatorname{Com} N$ igual a um $(N=1)$, as páginas exibidas são as definidas por $(N=0)$, além das associadas aos estados ancestrais (do tipo or) imediatos da configuração de estados atual, e assim por diante para $N>1$. Usando a hierarquia de estados de Statecharts, o HMBS permite explorar a hierarquia da aplicação hipermídia. Nesse contexto, o nível de visibilidade trata-se de um mecanismo de navegação, uma vez que ao invés de ativar as âncoras, o leitor pode navegar pelas páginas associadas acima ou abaixo do nível de hierarquia definido pelo autor contribuindo, dessa forma, para minimizar sua eventual desorientação.

Onde $\mathbb{N}$ corresponde ao conjunto dos números naturais.

O suporte à concorrência entre estados em Statecharts possibilita ao modelo HMBS especificar a exibição simultânea de páginas. Dessa forma, o HMBS permite a definição de caminhos concorrentes de navegação, ou seja, podem ser definidas ligações independentes, que podem causar a modificação de apenas uma parte da apresentação. Essa característica enriquece o modelo e o toma flexível para a especificação de vários tipos de aplicações hipermídia.

Segundo Paulo (1997), o HMBS é um modelo abrangente para o domínio de hipertextos, no entanto não se apresenta apropriado para a especificação de aplicações do domínio hipermídia, uma vez que vários requisitos desse tipo de aplicação, principalmente relacionados à sincronização de dados multimídia, não são satisfeitos.

Do ponto de vista das aplicações em sistemas hipermídia abertos, o HMBS deveria sofrer algumas reformulações em suas funções $m, p l$ e $a e$, e em seus conjuntos $P$, renomeado no modelo OXHMBS para $D o c$, e $L$. Algumas das reformulações necessárias, que também não foram definidas no XHMBS, são descritas ao longo dos capítulos 4 e 5.

\subsection{Modelo XHMBS}

O modelo XHMBS, proposto por (Paulo, 1997), é uma extensão do modelo HMBS no qual características foram incorporadas com o objetivo de adequá-lo à especificação de aplicações hipermídia complexas. A característica fundamental do XHMBS é o uso do formalismo Hypercharts (Paulo et al., 1997).

A técnica Hypercharts é uma proposta de técnica de "alto nível" baseada em Statecharts para a especificação de aplicações hipermídia. O principal objetivo dessa técnica é oferecer um conjunto de notações que permita especificar concisamente, e com as mesmas noções de Statecharts, o comportamento de aplicações hipermidia complexas, principalmente àquelas que envolvem requisitos de sincronização de dados multimídia em ambientes distribuidos. 
Hypercharts podem ser considerados um superconjunto de Statecharts de forma que, além de possuírem todas as notações permitidas em Statecharts, introduzem novas notações que permitem a especificação do comportamento temporal de uma aplicação hipermídia. De uma maneira geral, as novas notações introduzidas em Statecharts são: história temporal (Seção 3.4.1), transições temporais (Seção 3.4.2) e mecanismos de sincronização (Seção 3.4.3). Adicionalmente, notações para parametrização de estados e abstrações de transições são introduzidas para permitir uma descrição compacta das aplicações reais.

Nesse contexto, um hyperchart é uma 14-tupla $H Y P=\langle S, \rho, \Psi, \delta, \gamma, V, C, E, A c, T, \tau$, $\left.L S C, T_{\text {L hist. }} T_{S}\right\rangle$, na qual os elementos $\langle S, \rho, \Psi, \delta, \gamma, V, C, E, A c, T\rangle$ representam, respectivamente, conjunto de estados, função de hierarquia, função tipo de decomposição, função default, função de história, conjunto de expressões, conjunto de condições, conjunto de expressões de eventos (rótulos), conjunto de ações, conjunto de transições e conjuntos de símbolos de história, da mesma forma como definido no modelo HMBS.

A semântica da técnica Hypercharts segue a semântica operacional de Statecharts, caracterizada por uma seqüência de passos de execução, cada um definindo uma configuração de estados válida. Uma configuração válida de um statechart é definida como um conjunto ortogonal máximo de estados básicos, representando um conjunto possível de estados correntes ativos. Um relógio global controla os passos de execução, e cada passo de execução deve consistir de vários micro-passos dentro dos quais somente uma transição é ativada, permitindo assim, a evolução das várias máquinas de estado concorrentemente ativas. Essa semântica permite que um componente or de Statecharts evolua somente uma vez a cada passo.

A sintaxe das extensões $\left\langle\tau, L S C, T_{\_}\right.$hist, $\left.T_{S}\right\rangle$ introduzidas em Hypercharts é descrita a seguir:

- $\tau: T \rightarrow$ true, false $\}$ representa a função de história temporal, onde $\tau(t)=$ true implica que a transição $t$ tem um símbolo de história temporal associado.

Também, $\tau^{*}: T \rightarrow\{$ true, false $\}$ representa a função de história temporal recursiva, onde $\tau^{*}(t)=$ true implica que a transição $t$ tem um símbolo de história temporal recursiva associado.

- $L S C: S \rightarrow \mathbb{N}$ representa a função Local Step Counter, que funciona como um contador de passos de execução para um estado $s$, registrando o tempo total de ativação de $s$ em termos de passos de execução. Esse contador é incrementado a cada passo de execução do hyperchart durante todo o tempo em que o estado estiver ativo. O relógio global do sistema é o mecanismo que permite a atualização incremental dos LSCs.

Onde $\mathbb{N}$ corresponde ao conjunto dos números naturais.

- $T \_$hist $: S \rightarrow \mathbb{N}$ representa uma função registradora de tempo, que é responsável por manter o último tempo de ativação de um estado. 
- $T_{S} \subseteq 2^{S \times L} \times 2^{S \times H} \times$ sync $\times(S \cup \emptyset)$ representa o conjunto de transiçōes sincronizadas $M: N$. Essas transições, além de ter um tipo que define a política de sincronização, são rotuladas com eventos temporais $(L)$.

Onde sync representa um tipo de sincronização.

Segundo Paulo et al. (1998), a idéia por trás da técnica Hypercharts é de que alguns novos elementos de sua notação, principalmente aqueles voltados à especificação temporal, podem ter sua semântica descrita em Statecharts e funcionam como componentes notacionais facilitando a especificação de aplicações hipermídia. Esse princípio também é adotado na técnica Hypercharts Estendido, apresentada neste trabalho, na qual todos os novos elementos introduzidos têm sua semântica descrita em termos de Statecharts.

\subsubsection{História Temporal}

Segundo Paulo et al. (1998), a associação do símbolo de história temporal a uma transição que tem como destino um estado $s$ indica que, se $s$ já esteve ativo anteriormente, o disparo da transição recuperará o valor do registro de história temporal de $s$, além de recuperar a última configuração de $s$ (em termos de seus subestados). A versão recursiva do símbolo de história temporal implica que os registradores de história temporal de $s$ e de todos seus subestados também serão recuperados.

A todo estado $s \in S$ no qual história temporal deve ser registrada, existe uma ação de associação "on_exit $T \_h i s t(s):=L S C(s)$ ", garantindo que seu registrador de história temporal será atualizado assim que o sistema sair de $s$. Se existir uma transição com história temporal (recursiva), quando essa for disparada, se os estados pertencentes ao destino da transição já foram ativados uma vez, a operação " $L S C\left(s_{i}\right):=T_{-}$hist $\left(s_{i}\right)$ " é executada em todo estado $s_{i}$ ativado por história convencional. Se não for associado à transição um simbolo de história temporal, a operação " $L S C\left(s_{i}\right):=0$ " é executada para cada estado $s_{i}$ recuperado por história convencional ou ativado por default.

História temporal permite que atividades associadas a estados sejam recuperadas a partir do ponto no qual elas previamente tinham parado. Tão logo o sistema reinicie sua execução, a operação " $L S C(s):=0$ " é realizada para cada estado $s$. Além disso, em cada passo de execução $p$, a operação " $L S C(s):=L S C(s)+1$ " é executada para todos os estados que foram ativados no passo anterior.

\subsubsection{Transições Temporais}

De acordo com Paulo et al. (1998), transições temporais têm seus disparos determinados pela passagem do tempo durante o qual seus estados de origem estiveram ativos. Essas fornecem um 
suporte temporal poderoso para a especificação de comportamentos funcionais dependentes do tempo, suportando a especificação de requisitos de apresentação multimídia, tais como atraso e jitter. As transições temporais possuem eventos temporais que têm a forma $[\alpha, \eta, \beta]$ e devem ter cardinalidade $1: 1$. Além disso, um estado deve ser a origem de apenas uma transição temporal.

A Figura 3.2 apresenta a forma genérica de uma transição temporal e seu evento temporal $([\alpha, \eta, \beta])$ associado, na qual $a$ denota uma ação que pode ser executada após o disparo da transição, de acordo com a semântica de Statecharts. A transição temporal nesse exemplo implica que existe uma atividade principal $A$ sendo controlada pelo estado $X$ (atividade de apresentação de $X$ ), que gera um evento associado end_ $X$ indicando seu término.

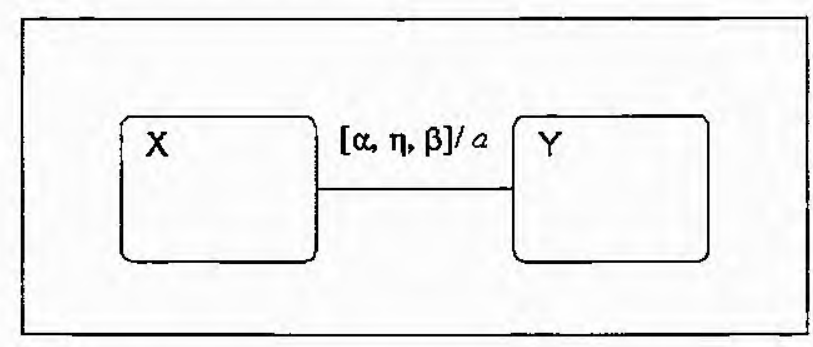

Figura 3.2: Exemplo de Transição Temporal (Paulo, 1997)

A notação $[\alpha, \eta, \beta]$ impõe duas restrições sobre o disparo dessa transição. A primeira referese ao limite temporal mínimo, ou seja, mesmo que a atividade $A$ tenha terminado, isto é, que end_X tenha ocorrido, se o limite temporal mínimo $\alpha$ não tiver sido atingido, mais precisamente, se o sistema não permaneceu ao menos $\alpha$ passos no estado $X$ (respeitadas as implicações semânticas relativas ao uso de história temporal), a transição não disparará. Nesse caso, a transição dispara assim que o limite temporal minimo for atingido. Caso o evento de término end_X ocorra em algum momento relativo entre $\alpha$ e $\beta$, a transição irá disparar imediatamente (idealmente a transição deveria disparar em $\eta$ ). A segunda restrição refere-se ao limite temporal máximo $\beta$. Se o sistema permanecer no estado $X$ até o momento relativo a $\beta$ e o evento end_X não ocorrer, ou seja, se a atividade $A$ não terminar a tempo, a transição irá disparar de qualquer maneira, abortando a execução de todas as atividades associadas ao estado $X$, inclusive, e principalmente $A$.

A semântica das transições temporais está associada à passagem do tempo (modelada pelos passos de execução) e à ocorrência de um evento que indica o final de uma atividade associada internamente a um estado. No caso do uso de Hypercharts no XHMBS, essa atividade representa a apresentação da página associada ao estado pelo canal de apresentação correspondente. A passagem do tempo é especificada semanticamente através de uma combinação de subestados intermediários com eventos de timeout. O evento indicador de término da atividade é um evento primitivo definido para o estado origem da transição temporal. 


\subsubsection{Mecanismos de Sincronização}

Segundo Paulo et al. (1998), em Hypercharts a sincronização é especificada através de transições sincronizadas $M: N$ (as quais envolvem vários estados na origem e no destino), que têm cinco grupos de componentes: estados origem, arcos origem, estados destino, rótulos e um tipo de sincronização. O tipo indica como restrições impostas por eventos temporais associadas a cada arco de origem serão consideradas na geração de uma restrição temporal única para toda a transição. Dessa forma, pode-se dizer que os tipos de sincronização definem a semântica de sincronização entre os hypercharts concorrentes envolvidos, ou, em termos de aplicações hipermídia, da sincronização entre cadeias de dados.

Nove tipos de sincronização estão disponiveis em Hypercharts; cinco básicos: strong_or(so), weak_and(ua), master $(m)$, or e and; e quatro tipos compostos derivados a partir dos básicos: or_master, strong_master, weak_master, e and_master. Esses são os mesmos tipos adotados nos modelo TSPN (Diaz e Senac, 1993; Senac et al., 1994) e TSPNUI (Cooper, 1995).

Uma transição sincronizada $M: N$, que possui $M$ estados origem cujos arcos fontes são rotulados com expressões do tipo $\left[\alpha_{i}, \eta_{i}, \beta_{i}\right](1 \leq i \leq M)$, tem seu momento de disparo relativo $(\theta)$ em um intervalo de tempo definido pelo tipo de sincronização associado a essa. Por exemplo, para um tipo de sincronização or tal intervalo é dado por $\min _{i}\left(\alpha_{i}\right) \leq \theta \leq \max _{i}\left(\beta_{i}\right)$. Isso porque a política de sincronização de or considera a corretitude temporal da primeira das cadeias de dados que terminar com sucesso sua atividade de apresentação. Dessa forma, a transição temporal disparará tão logo algum estado indicar o término de sua atividade de apresentação, ou, tão logo todos os estados atingirem seus limites temporais máximos.

O processo de transformação semântica para derivar um statechart equivalente a partir de uma construção hyperchart baseia-se nas regras de disparo definidas pelas políticas de sincronização.

\subsubsection{Modelo Hipermídia baseado em Hypercharts}

O XHMBS é uma extensão do modelo HMBS cuja principal característica é a capacidade de especificação de requisitos relativos à sincronização da apresentação de dados multimídia.

No XHMBS foram realizadas algumas reformulações nos conjuntos e funções do modelo HMBS, como pode ser observado a seguir. Contudo, a modificação de maior impacto, como já destacado anteriormente, foi a especificação estrutural através de Hypercharts, que passa a substituir a técnica Statecharts como técnica subjacente ao modelo.

O modelo XHMBS usa a estrutura e a semântica de execução da técnica Hypercharts para especificar a estrutura de ligações e a semântica de navegação de uma aplicação hipermídia. Uma aplicação hipermídia $H$ formalmente definida em XHMBS é apresentada a seguir: 
Definição 2 Seja $H=\left\langle H Y P, P, M, A, L, P c h, C c h, V_{p}, V_{a n c}, C h\right\rangle$ uma aplicação hipermídia, onde:

- $H Y P=\left\langle S, \rho, \Psi, \delta, \gamma, V, C, E, A c, T, \tau, L S C, T \_h i s t, T_{S}\right\rangle$ é o hyperchart que representa a estrutura da aplicação hipermídia.

- $P$ : Info ${ }^{2}$ representa um conjunto de páginas que são da forma $\langle c, t\rangle \mid c, t \in \operatorname{Info}$ representando, respectivamente, o conteúdo e o título de uma página. Como definido originalmente no modelo HMBS, o conjunto $P$ inclui a página nula, sem qualquer conteúdo ou título.

Onde Info representa o conjunto das porções básicas de conteúdo da informação de uma aplicação hipermídia.

- Anc $\subseteq$ Info representa o conjunto de âncoras da aplicação hipermídia. Uma âncora é uma unidade de informação que difere de uma página por, normalmente, conter uma porção reduzida de informação.

- $M: S_{s} \rightarrow P$ representa a função que mapeia estados de um subconjunto $S_{s} \subseteq S$ (somente estados do tipo or e estados atômicos) em páginas da aplicação hipermídia.

Onde $S s:\{s \in S \mid \Psi(s)=$ or $\vee \rho(s)=\emptyset\}$

- $A: E \times T \times P \rightarrow A n c$ representa a função que associa uma âncora a cada evento contido no rótulo de uma determinada transição do hyperchart. Além disso, a âncora deve ser contextualizada por uma página.

- $L$, onde $(L \in \mathbb{N})$, representa o nível de visibilidade da aplicação hipermídia, exatamente como definido no modelo HMBS ${ }^{1}$.

Onde $\mathbb{N}$ corresponde ao conjunto dos números naturais.

- Pch representa o conjunto de Pchannels ou canais de apresentação, que são abstrações através das quais é possivel especificar requisitos relativos à apresentação das informações contidas nas páginas.

- Cch representa o conjunto de Channels ou canais de comunicação, que são abstrações da interface com o subsistema de comunicação subjacente. Esse canais são necessários para a especificação de aplicações distribuídas.

- $V_{p}: P \times S_{s} \rightarrow P$ ch representa a função de visualização de páginas, que associa cada página da aplicação hipermídia a um canal de apresentação capaz de interpretá-la.

\footnotetext{
'No modelo HMBS o nivel de visibilidade era representado por N.
} 
- $V_{a n c}: A n c \times P \rightarrow P c h$ representa a função de visualização de âncoras, que associa cada âncora de uma página a um canal de apresentação capaz de interpretá-la.

- $C h: P c h \rightarrow C c h \cup \emptyset$ representa a função que associa um Cchannel a cada Pchannel usado pela aplicação hipermidia. Se a aplicação é local, o Pchannel pode ser associado ao $C$ channel nulo, ou seja, $C h(p c h)=\emptyset$.

Para adequar o modelo XHMBS à especificação de aplicações em sistemas hipermídia abertos alguns elementos de sua sintaxe e semântica de navegação, tais como os conjuntos Anc, $P$ (que como dito anteriormente, foi renomeado no modelo OXHMBS para $D o c$ ), $C c h$ e $P c h$ e as funções $M, A, V_{p}$ e $V_{\text {anc }}$ devem sofrer novas adaptações. Tais adaptações, além da definição de alguns novos elementos, são descritas nos capítulos 4 e 5 .

\subsection{Considerações Finais}

Neste capítulo foram apresentados os modelo HMBS e XHMBS e a técnica Statecharts (subjacente a ambos modelos) com o objetivo de fornecer o embasamento necessário para a definição do modelo OXHMBS proposto neste trabalho.

A apresentação e compreensão desses modelos foi de extrema importância para a especificação do modelo proposto, uma vez que esses formam a base do OXHMBS.

Deve-se observar que o objetivo de extensão tanto do HMBS para o XHMBS, quanto do XHMBS para o OXHMBS concentram-se na evolução desses de forma a adequá-los a características específicas de certos tipos de aplicações.

No contexto do XHMBS, sua proposição teve como objetivo estender o HMBS (adequado para especificação de aplicações hipertexto) de forma a torná-lo adequado à especificação da sincronização de dados multimídia em aplicações hipermídia.

Enquanto que no contexto do OXHMBS, apresentado nos próximos capítulos, sua proposição teve como objetivo tornar o modelo XHMBS (adequado para especificação de aplicações hipermídia) adequado à especificação de aplicações em sistemas hipermídia abertos.

Deve-se destacar que durante o estudo realizado neste capitulo, observou-se que foram incorporadas na definição do modelo XHMBS adaptações na notação e semântica herdadas do modelo HMBS, para sua adequação a novos requisitos. No entanto, outras questões com relação a notação e semântica do XHMBS ainda precisam ser reformuladas para fins da especificação de aplicações em sistemas hipermídia abertos. Essas reformulações são descritas nos capítulos 4 e 5 deste trabalho. 
Capitulo

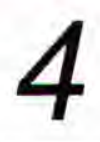

\section{XHMBS e as Aplicações em Sistemas Hipermídia Abertos}

\subsection{Considerações Iniciais}

O modelo OXHMBS é uma proposta de extensão ao modelo XHMBS que tem como objetivo suportar a especificação de aplicações em sistemas hipermídia abertos. Nesse contexto, a técnica Hypercharts Estendido, que tem suas características discutidas neste capitulo, substitui o Hypercharts como técnica de especificação subjacente ao modelo.

Hypercharts Estendido são uma proposta de técnica de "alto nivel" baseada em Statecharts (assim como Hypercharts), que têm como objetivo o suporte à especificação de aplicações em sistemas hipermidia abertos. Dessa forma, essa técnica visa oferecer um conjunto de notações que permita especificar concisamente, e com as mesmas noções de Statecharts, o comportamento dessas aplicações.

A idéia por trás de Hypercharts Estendido é a de que alguns novos elementos de sua notação, tais como transições bidirecionais (Seção 4.2.2), transições globais (Seção 4.2.3) e transições locais (Seção 4.2.4) podem ter sua semântica descrita pelo Statecharts. Assim, o desenvolvedor tem disponível blocos de construção intrinsecos à técnica, os quais podem ser utilizados como componentes notacionais sem que seja necessário um conhecimento prévio deles. Tais notações visam levar a uma diminuição no esforço de desenvolvimento de aplicações. 
Deve-se ressaltar que Hypercharts Estendido podem ser considerados como um superconjunto de Hypercharts (e conseqüentemente de Statecharts), de forma que além de possuirem todas as notações permitidas em Hypercharts, introduzem algumas novas notações apresentadas ao longo deste capitulo.

Nas próximas Seções são apresentados e discutidos os oito requisitos das aplicações em sistemas hipermídia abertos definidos na Seção 2.4. No contexto dos requisitos não suportados pelo XHMBS são apresentadas as propostas de extensão ao modelo (OXHMBS) bem como à técnica que o suporta (Hypercharts Estendido) para adequá-los a esses. Enquanto que para os requisitos suportados pelo XHMBS é apresentada uma descrição de como esse e, conseqüentemente o OXHMBS os suportam.

As definições apresentadas neste capitulo são exemplificadas no capitulo 5 , onde se encontra também a especificação completa do OXHMBS.

A notação utilizada no modelo OXHMBS segue as convenções matemáticas que têm sido amplamente adotadas em notações de especificação, como por exemplo em $Z$ (Nicholls, 1995).

\subsection{Documentos relacionados de diversas formas}

\subsubsection{Ligações Específicas}

O modelo XHMBS suporta a especificação apenas de ligações que têm como destino um documento inteiro. Porém, ligações com destino em pontos específicos de um documento são encontradas na maioria das aplicações em sistemas hipermidia abertos e, dessa forma, é desejável que o modelo OXHMBS permita a especificação de tais ligações. Nesse contexto, para solucionar essa limitação foram propostas as seguintes extensões ao modelo XHMBS:

\section{- Extensōes propostas no modelo OXHMBS}

$A n c \_D o c: A n c, \rightarrow D o c$ (nova função criada no OXHMBS) corresponde a função que associa (contextualiza) cada âncora ao documento no qual essa encontra-se inserida. Caso a âncora seja a "âncora nula" (representada por $a_{\curvearrowleft}$ ) essa é associada ao "documento nulo" (representado por $d_{\mathfrak{g}}$ ).

A definição dos conjuntos $A n c$ e $D o c$ pode ser observada na Seção 5.2, que contém a definição completa do modelo.

Nesse contexto, a função $A n c \_D o c$ é definida da seguinte forma:

Para toda âncora anc $\in A n c$ :

$$
\text { Anc_Doc }(a n c)= \begin{cases}d & \text { se } a n c \neq a_{\curvearrowleft} \\ d_{\mathscr{g}} & \text { caso contrário }\end{cases}
$$


onde $d \in D o c \backslash\left\{d_{\varnothing}\right\}$

Anc_Font : $T \rightarrow$ Anc (função $A$ do XHMBS redefinida pelo OXHMBS) corresponde a função que associa cada transição, cuja abstração é uma ligação hipermídia, a uma âncora fonte. Caso a transição seja apenas de controle (não correspondendo à uma ligação hipermídia) é associado a essa o elemento $a_{\curvearrowleft}$ do conjunto Anc que corresponde a uma âncora nula.

É importante observar as seguintes questões com relação a essa função:

Seja $t \in T$ uma transição de um hyperchart estendido na forma $\left(X_{t}, r_{t}, Y_{t}\right)$, onde $X_{t}$ corresponde ao conjunto de estados origem, $Y_{t}$ corresponde ao conjunto de estados destino e $r_{t}$ corresponde ao rótulo de $t$.

Seja rot : $T \times E \rightarrow$ true, false $\}$ a função que verifica se um evento primitivo $e_{t}$ faz parte do rótulo de um transição $t$, tal que:

$$
\operatorname{rot}\left(t, e_{t}\right)= \begin{cases}\text { true } & \text { se } e_{t} \in E_{p} \text { e } e_{t} \text { faz parte do rótulo de } t \\ \text { false } & \text { caso contrário }\end{cases}
$$

Onde $E_{p}$ corresponde ao conjunto de Eventos Primitivos já definido na técnica Statecharts.

A expressão $\operatorname{rot}\left(t, e_{t}\right)$ será usada como sinônimo de $\operatorname{rot}\left(t, e_{t}\right)=$ true.

Com base nas definições apresentadas acima é possivel a definição completa da função Anc_Font, de forma que para toda transição $t=\left(X_{t}, e_{t}, Y_{t}\right) \in T$ :

Anc_Font $(t)=\left\{\begin{aligned} & a n c \quad \leftrightarrow\left(\exists d \in D o c \mid A n c \_D o c(a n c)=d\right) \wedge\left(\operatorname{rot}\left(t, e_{t}\right)\right) \wedge \\ &\left(\forall s \in X_{t} \rightarrow\left((M(s)=d) \vee\left(\exists s^{\prime} \in \rho^{+}(s) \mid M\left(s^{\prime}\right)=d\right)\right)\right. \\ & a_{\emptyset} \quad \text { caso contrário }\end{aligned}\right.$

onde anc $\in A n c \backslash\left\{a_{\varnothing}\right\}$

Anc_Dest $: T \times$ Ancoras_Fonte $\rightarrow$ Anc (função $A$ do XHMBS redefinida pelo OXHMBS) corresponde a função que associa cada âncora fonte (de uma aplicação hipermídia) associada a uma transição de um hyperchart estendido à uma âncora destino correspondente. É importante observar as seguinte questões com relação à essa função:

Seja Ancoras_Fonte o conjunto que contém apenas as âncoras fonte de uma determinada aplicação hipermidia, tal que:

$$
\text { Ancoras_Fonte }=\text { range }(\text { Anc_Font }) \backslash\left\{a_{\emptyset}\right\}
$$


onde range $R \mid b \in$ range $R \leftrightarrow \exists a \mid(a, b) \in R$

Dessa forma, para toda transição $t=\left(X_{t}, e_{t}, Y_{t}\right) \in T$ e para toda âncora fonte $f \in$ Ancoras_Fonte:

Anc_Dest $(t, f)=\left\{\begin{aligned} & a n c \quad \leftrightarrow\left(\exists d \in D o c \mid A n c \_D o c(a n c)=d\right) \wedge\left(A n c \_F o n t(t)=f\right) \\ & \wedge\left(\forall s \in Y_{l} \rightarrow\left((M(s)=d) \vee\left(\exists s^{\prime} \in \rho^{+}(s) \mid M\left(s^{\prime}\right)=d\right)\right)\right. \\ & a_{\varnothing} \quad \text { caso contrário }\end{aligned}\right.$ onde $a n c \in A n c \backslash\left\{a_{\varnothing}\right\}$

\subsubsection{Ligações Bidirecionais}

O modelo XHMBS não suporta a especificação de ligações bidirecionais diretamente em sua notação. Porém, ligações desse tipo são encontradas na maioria das aplicações em sistemas hipermidia abertos e, dessa forma, é desejável que o modelo OXHMBS permita a especificação de tais ligações. Nesse contexto, para solucionar essa limitação foram propostas as seguintes extensões à técnica Hypercharts e ao modelo XHMBS:

\section{- Extensões propostas na técnica Hypercharts Estendido}

$T_{B}$ (novo conjunto criado em Hypercharts Estendido) corresponde ao conjunto de transições bidirecionais, tal que $T_{B} \subseteq 2^{S} \times E_{p} \times 2^{S}$.

Toda transição $t_{b}=\left(X_{b}, e_{b}, Y_{b}\right) \in T_{B}$ é composta por dois conjuntos de estados "origem_destino" $X_{b}$ e $Y_{b}$ e por um evento primitivo $e_{b}$. As transições bidirecionais são "convertidas", em um nível semântico, em transições básicas (mais precisamente, têm sua semântica descrita através de transições básicas) $t \in T$ de Hypercharts Estendido (e conseqüentemente de Statecharts, uma vez que as transições básicas são fundamentalmente definidas nesse), através da seguinte função:

Seja Bid: $T_{B} \rightarrow T \times T$ (nova função criada em Hypercharts Estendido) a função que associa a cada transição bidirecional de um hyperchart estendido duas transições básicas desse, tal que:

Para toda transição bidirecional $t_{b}=\left(X_{b}, e_{b}, Y_{b}\right) \in T_{B}$ :

$$
\begin{aligned}
& \operatorname{Bid}\left(t_{b}\right)=\left(t^{\prime}, t^{\prime \prime}\right) \leftrightarrow\left(\operatorname{source}\left(t^{\prime}\right)=X_{b} \wedge \text { target }\left(t^{\prime}\right)=Y_{b}\right) \wedge \\
&\left(\operatorname{source}\left(t^{\prime \prime}\right)=Y_{b} \wedge \operatorname{target}\left(t^{\prime \prime}\right)=X_{b}\right)
\end{aligned}
$$

onde $t^{\prime} \in T$ e $t^{\prime \prime} \in T$

source é uma função pré-definida de Statecharts e conseqüentemente herdada pelo Hypercharts Estendido. $O$ resultado dessa função, aplicada sobre uma transição $t$ qualquer, é o conjunto de estados origem de $t$. 
target é uma função pré-definida de Statecharts e conseqüentemente herdada pelo Hypercharts Estendido. O resultado dessa função aplicada sobre uma transição $t$ qualquer, é conjunto de estados destino de $t$.

Um exemplo da notação gráfica proposta para uma transição bidirecional $t_{b}$ na técnica Hypercharts Estendido é apresentado na Figura 4.1.

Seja $t_{b} \in T_{B}$, tal que $t_{b}=(a, e, b)$.

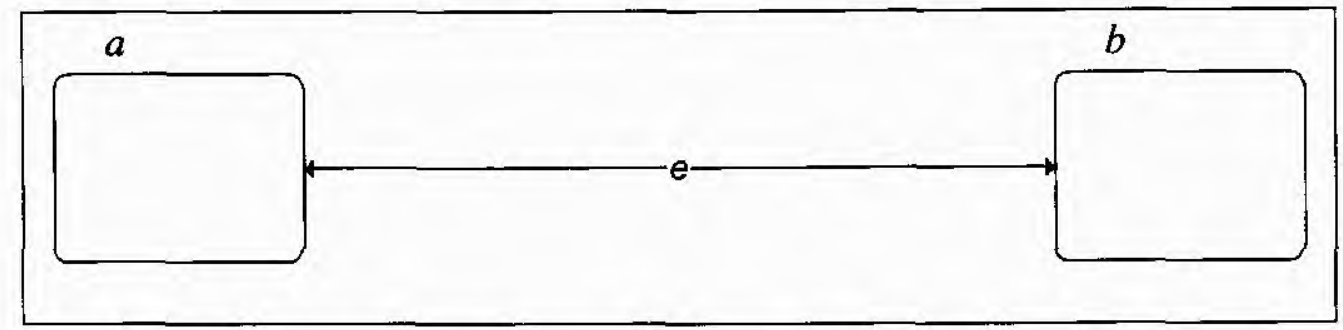

Figura 4.1: Proposta de representação para transição bidirecional em Hypercharts Estendido

Com base na função Bid definida na técnica Hypercharts Estendido, a transição $t_{b}$ (Figura 4.1) teria sua semântica descrita pela representação equivalente em Hypercharts Estendido apresentada na Figura 4.2 (equivalente semanticamente a mesma representação em Statecharts).

Seja $\operatorname{Bid}\left(t_{b}\right)=\left(t^{\prime}, t^{\prime \prime}\right)$, tal que $t^{\prime}=\left(a, e_{1}, b\right) \wedge t^{\prime \prime}=\left(b, e_{2}, a\right)$.

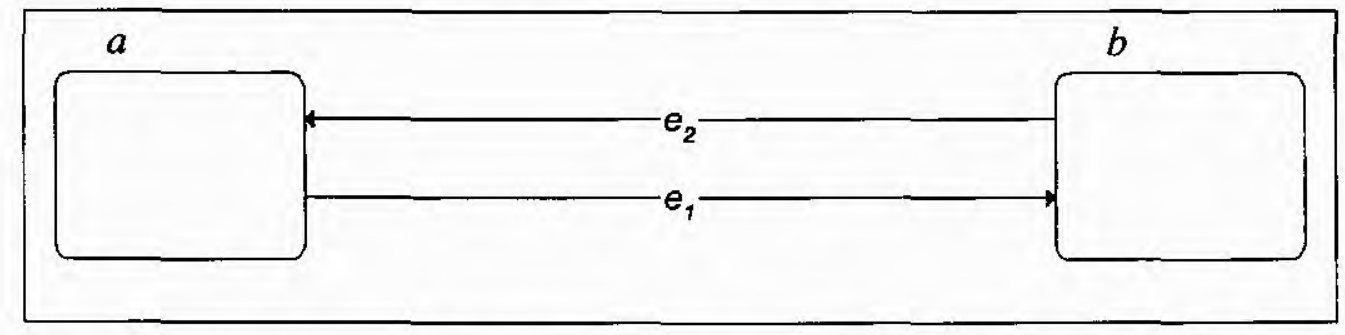

Figura 4.2: Transição bidirecional em Hypercharts Estendido representada por transições básicas de Statecharts

\section{- Extensões propostas no modelo OXHMBS}

Bidirecional : $T_{B} \rightarrow$ Anc $\times$ Anc (nova função criada no OXHMBS) corresponde a função que associa a cada transição bidirecional duas âncoras que correspondem aos pontos nos quais a ligação bidirecional sendo especificada pode ser disparada. Como cada transição bidirecional tem sua semântica descrita através de duas transições básicas $t \in T$ de Hypercharts Estendido (e conseqüentemente de Statecharts), a função Bidirecional define como essas âncoras estarão relacionadas com essas transições básicas.

Dessa forma, para toda transição bidirecional $t_{b}=\left(X_{b}, e_{b}, Y_{b}\right) \in T_{B}$ : 


$$
\begin{aligned}
& \text { Bidirecional }\left(t_{b}\right)=\left(a^{\prime}, a^{\prime \prime}\right) \leftrightarrow\left(\exists t^{\prime}, t^{\prime \prime} \in T \mid \operatorname{Bid}\left(t_{b}\right)=\left(t^{\prime}, t^{\prime \prime}\right)\right) \wedge \\
&\left(\text { Anc_Font }\left(t^{\prime}\right)=a^{\prime} \wedge \text { Anc_Dest }\left(t^{\prime}, a^{\prime}\right)=a^{\prime \prime}\right) \wedge \\
&\left(\text { Anc_Font }\left(t^{\prime \prime}\right)=a^{\prime \prime} \wedge \text { Anc_Dest }\left(t^{\prime \prime}, a^{\prime \prime}\right)=a^{\prime}\right) \\
& \text { onde } a^{\prime} \in A n c \backslash\left\{a_{\varnothing}\right\} \text { e } a^{\prime \prime} \in A n c \backslash\left\{a_{\varnothing}\right\}
\end{aligned}
$$

\subsubsection{Ligações Globais}

O modelo XHMBS não suporta ligações globais diretamente em sua notação. Porém, ligações desse tipo são suportadas na maioria das aplicações em sistemas hipermídia abertos e, dessa forma, é desejável que o modelo OXHMBS permita a especificação de tais ligações. Nesse contexto, para solucionar essa limitação foram propostas extensões à técnica Hypercharts e ao modelo XHMBS, apresentadas abaixo.

Uma questão que deve ser destacada com relação às ligações globais, refere-se ao fato de que no momento da criação de uma ligação global, o sistema que suporta o modelo OXHMBS realizará uma busca em todos os documentos da aplicação sendo especificada, e procurará por palavras que "casem" com o conteúdo da âncora fonte sendo especificada para a ligação global. Para cada uma das palavras resultantes da busca serão identificados: uma âncora com tal conteúdo e com localização física igual a localização física dessa; uma transição, e através da função Anc__Font a nova âncora identificada e a nova transição identificada serão associadas; e para cada novo par identificado (transição, âncora fonte), será associada, através da função Anc_Dest, a âncora destino definida para a ligação global (essas questões são especificadas nas funções definidas a seguir).

\section{- Extensōes propostas na técnica Hypercharts Estendido}

$T_{G}$ (novo conjunto criado em Hypercharts Estendido) corresponde ao conjunto de transições globais, tal que $T_{G} \subseteq 2^{S} \times E_{p} \times 2^{S}$.

Toda transição $t_{g}=\left(X_{g}, e_{g}, Y_{g}\right) \in T_{G}$ é composta por um conjunto de estados origem $X_{g}$, um conjunto de estados destino $Y_{g}$ e por um evento primitivo $e_{g}$. As transições globais são "convertidas", em um nivel semântico, em transições básicas (mais precisamente, têm sua semântica descrita através de transições básicas) $t \in T$ de Hypercharts Estendido (e conseqüentemente de Statecharts, uma vez que as transições básicas são fundamentalmente definidas nesse), através da seguinte função:

Seja $G l: T_{G} \rightarrow 2^{T}$ (nova função criada em Hypercharts Estendido) a função que associa a cada transição global de um hyperchart estendido um conjunto de transições básicas desse, tal que: 
Para toda transição global $t g=\left(X_{g}, e_{g}, Y_{g}\right) \in T_{G}$ :

$$
\begin{aligned}
G l\left(t_{g}\right)=T_{k g} \leftrightarrow & \left(\exists t_{g^{\prime}} \in T_{k g} \mid\left(\operatorname{source}\left(t_{g^{\prime}}\right)=X_{g} \wedge \operatorname{target}\left(t_{g^{\prime}}\right)=Y_{g}\right)\right) \wedge \\
& \left(\forall t^{\prime} \in T_{k g} \rightarrow \operatorname{target}\left(t^{\prime}\right)=Y_{g}\right)
\end{aligned}
$$

onde $T_{k g}$ é um subconjunto de $\mathrm{T}$, ou seja, $T_{k g} \subseteq T$

Um exemplo da notação gráfica proposta para uma transição global $t_{g}$ na técnica Hypercharts Estendido é apresentado na Figura 4.3.

Seja $t_{g} \in T_{G}$, tal que $t_{g}=\left(a, e_{g}, b\right)$.

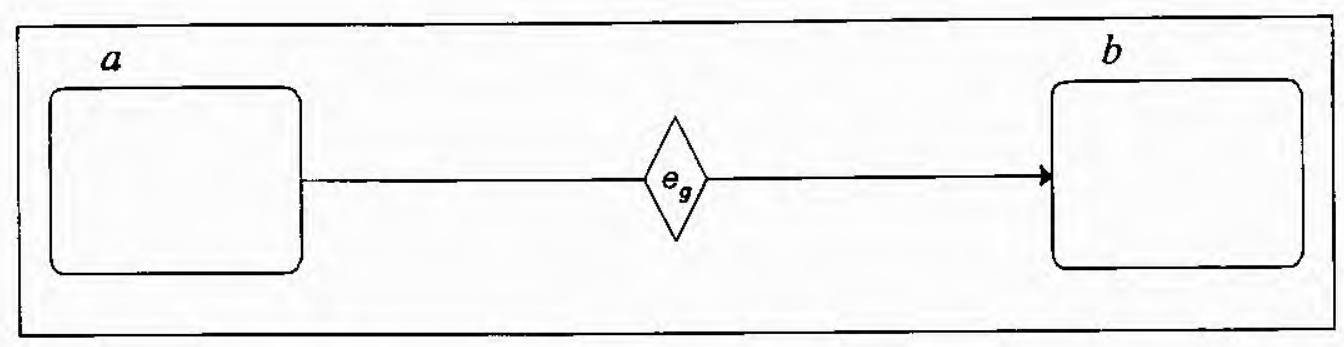

Figura 4.3: Proposta de representação para transição global em Hypercharts Estendido

\section{- Extensões propostas no modelo OXHMBS}

Global $: T_{G} \rightarrow$ Anc $\times$ Anc (nova função criada no OXHMBS) corresponde a função que associa a cada transição global duas âncoras que correspondem aos pontos nos quais a ligação global sendo especificada pode ser disparada. Como cada transição global tem sua semântica descrita através de um subconjunto de transições básicas $t \in T$ de Hypercharts Estendido (e conseqüentemente de Statecharts), a função Global define como essas âncoras estarão relacionadas com essas transições básicas.

Seja Pertence_Global $: T \times I n f o \times A n c \rightarrow\{$ true, false $\}$ a função que verifica se uma âncora (que corresponde a uma das origens da ligação global) associada a uma transição $t$ qualquer, tem um determinado rótulo (ou seja, o conteúdo da âncora cont) e é fonte de uma ligação que tem uma âncora específica anc como destino (destino da ligação global), tal que:

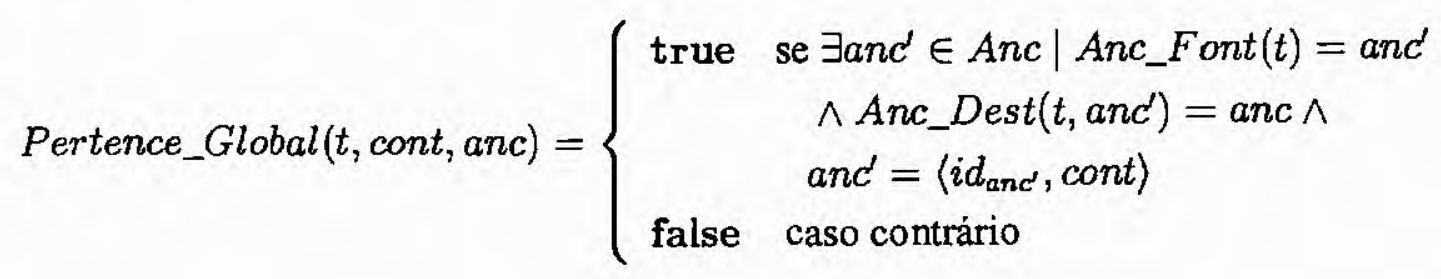


A expressão Pertence_Global $(t$, cont, anc) scrá usada como sinônimo de Pertence_Global $(t$, cont, anc $)=$ true.

Dessa forma, para toda transição global $t_{g}=\left(X_{g}, e_{g}, Y_{g}\right) \in T_{G}$ :

$\operatorname{Global}\left(t_{g}\right)=\left(a_{f}, a_{d}\right) \leftrightarrow\left(\exists T_{k g} \subseteq T \mid G l\left(t_{g}\right)=T_{k g}\right) \wedge\left(\exists t_{g^{\prime}} \in T_{k g} \mid\right.$

$$
\begin{aligned}
& \left.\left(A n c \_F o n t\left(t_{g^{\prime}}\right)=a_{f} \wedge A n c \_D e s t\left(t_{g^{\prime}}, a_{f}\right)=a_{d}\right)\right) \wedge \\
& \left(\forall t \in T \mid \text { Pertence_Global }\left(t, \text { cont } t_{f}, a_{d}\right) \rightarrow t \in T_{k g}\right)
\end{aligned}
$$

onde $t_{g^{\prime}}=\left(X_{g}, e_{g^{\prime}}, Y_{g}\right)$ e $a_{f}=\left\langle i d_{f}\right.$, cont $\left._{f}\right\rangle \in A n c \backslash\left\{a_{\circledast}\right\}$ e $a_{d} \in A n c \backslash\left\{a_{\mathscr{\wp}}\right\}$

Com base na função Global definida no modelo OXHMBS, a transição global $t_{g}$ teria sua semântica descrita por uma representação equivalente em Hypercharts Estendido (equivalente semanticamente a mesma representação em Statecharts). Essa representação deve ser composta pela transição básica $t_{g^{\prime}} \in T$ adicionada de $k(k \geq 0)$ transições básicas que partem de diferentes estados associados a diferentes documentos (possivelmente), $\mathrm{e}$ cujas ligações abstraidas possuem âncora fonte com o mesmo conteúdo da âncora fonte associada à ligação abstraída de $t_{g^{\prime}}$ e âncora destino igual à âncora destino associada à ligação abstraída de $t_{g^{\prime}}$.

\subsubsection{Ligações Locais}

O modelo XHMBS não suporta ligações locais diretamente em sua notação. Porém, ligações desse tipo são suportadas na maioria das aplicações em sistemas hipermídia abertos e, dessa forma, é desejável que o modelo OXHMBS permita a especificação de tais ligações. Nesse contexto, para solucionar essa limitação foram propostas extensões à técnica Hypercharts e ao modelo XHMBS, apresentadas abaixo.

Uma questão que deve ser destacada com relação às ligações locais, refere-se ao fato de que no momento da criação de uma ligação local, o sistema que suporta o modelo OXHMBS realizará uma busca no documento que contextualiza a âncora fonte de tal ligação, e procurará por palavras que "casem" com o conteúdo dessa. Para cada uma das palavras resultantes da busca serão identificados: uma âncora com tal conteúdo e com localização fisica igual a localização fisica dessa; uma transição, e através da função $A n c_{-} F o n t$ a nova âncora identificada e a nova transição identificada serão associadas; e para cada novo par identificado (transição, âncora fonte) será associada, através da função Anc_Dest, a âncora destino definida para a ligação local (essas questões são especificadas nas funções definidas a seguir).

\section{- Extensões propostas na técnica Hypercharts Estendido}


$T_{L}$ (novo conjunto criado em Hypercharts Estendido) corresponde ao conjunto de transições locais, tal que $T_{L} \subseteq 2^{S} \times E_{p} \times 2^{S}$.

Toda transição $t_{l}=\left(X_{l}, e_{l}, Y_{l}\right) \in T_{L}$ é composta por um conjunto de estados origem $X_{l}$, um conjunto de estados destino $Y_{l}$ e por um evento primitivo $e_{l}$. As transições locais são "convertidas", em um nivel semântico, em transições básicas (mais precisamente, têm sua semântica descrita através de transições básicas) $t \in T$ de Hypercharts Estendido (e conseqüentemente de Statecharts, uma vez que as transições básicas são fundamentalmente definidas nesse), através da seguinte função:

Seja $L l: T_{L} \rightarrow 2^{T}$ (nova função criada em Hypercharts Estendido) a função que associa a cada transição local de um hyperchart estendido um conjunto de transições básicas desse, tal que:

Para toda transição local $t_{l}=\left(X_{l}, e_{l}, Y_{l}\right) \in T_{L}$ :

$$
\begin{aligned}
& L l\left(t_{l}\right)=T_{k l} \leftrightarrow\left(\exists t_{l^{\prime}} \in T_{k l} \mid\left(\operatorname{source}\left(t_{l^{\prime}}\right)=X_{l} \wedge \operatorname{target}\left(t_{l^{\prime}}\right)=Y_{l}\right) \wedge\right. \\
&\left(\forall t^{\prime} \in T_{k l} \rightarrow\left(\operatorname{source}\left(t^{\prime}\right)=X_{l} \wedge \operatorname{target}\left(t^{\prime}\right)=Y_{l}\right)\right.
\end{aligned}
$$

onde $T_{k l}$ é um subconjunto de $T$, ou seja, $T_{k l} \subseteq T$

Um exemplo da notação gráfica proposta para uma transição local $t_{l}$ na técnica Hypercharts Estendido é apresentado na Figura 4.4.

Seja $t_{l} \in T_{L}$, tal que $t_{l}=\left(a, e_{l}, b\right)$.

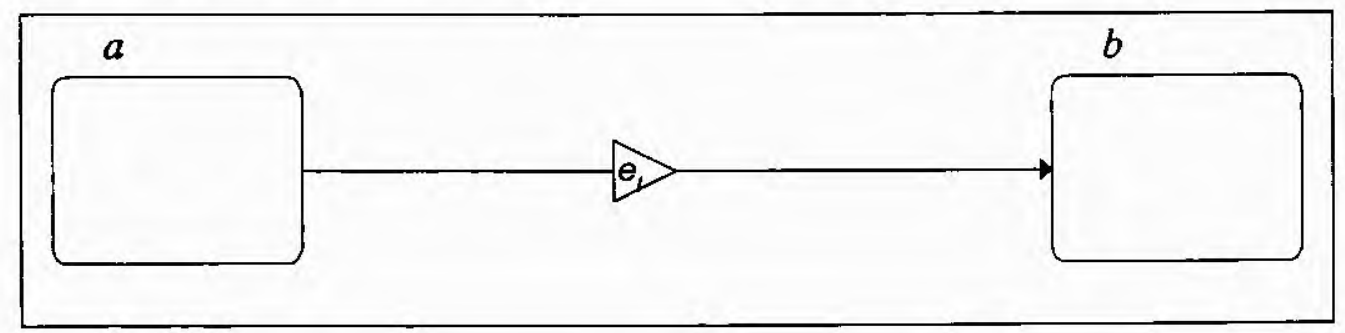

Figura 4.4: Proposta de representação para transição local em Hypercharts Estendido

\section{- Extensões propostas no modelo OXHMBS}

Local : $T_{L} \rightarrow A n s, \times$ Anc (nova função criada no OXHMBS) corresponde a função que associa a cada transição local duas âncoras que correspondem aos pontos nos quais a ligação local sendo especificada pode ser disparada. Como cada transição local tem sua semântica descrita através de um subconjunto de transições básicas $t \in T$ de Hypercharts Estendido (e conseqüentemente de Statecharts), a função Local define como essas âncoras estarão relacionadas com essas transições básicas.

Seja Pertence_Local : Doc $\times T \times I n f o \times A n c \rightarrow\{$ true, false $\}$ a função que verifica se uma âncora (pertencente a um documento especifico $d$ e uma das origens da ligação local) 
associada a uma transição $t$ qualquer, tem um determinado rótulo (ou seja, o conteúdo da âncora cont) e é fonte de uma ligação que tem uma âncora específica anc como destino (destino da ligação local), tal que:

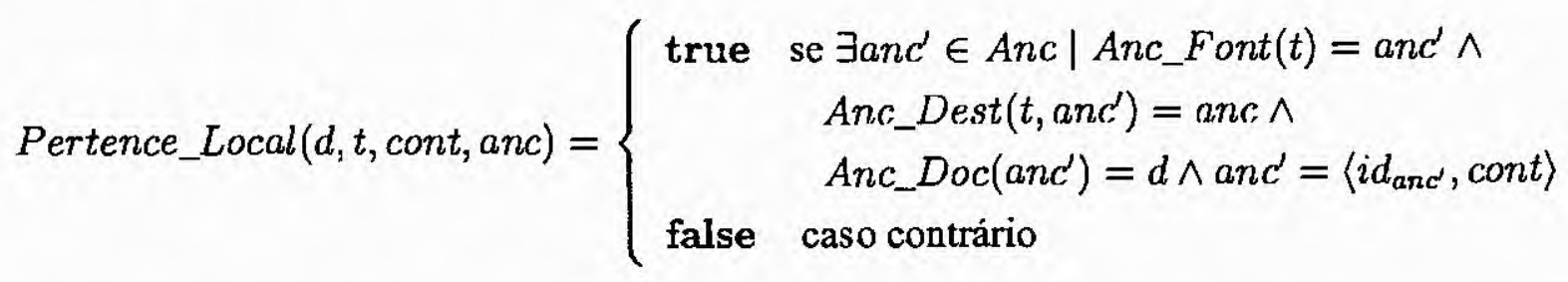

A expressão Pertence_Local $(d, t$, cont,anc) será usada como sinônimo de Pertence_Local $(d, t$, cont, anc $)=$ true.

Dessa forma, para toda transição local $t_{l}=\left(X_{l}, e_{l}, Y_{l}\right) \in T_{L}$ :

$$
\begin{aligned}
& \operatorname{Local}\left(t_{l}\right)=\left(a_{f}, a_{d}\right) \leftrightarrow\left(\exists T_{k l} \subseteq T \mid L l\left(t_{l}\right)=T_{k l}\right) \wedge\left(\exists t_{l^{\prime}} \in T_{k l} \mid\left(A n c \_F o n t\left(t_{l^{\prime}}\right)=a_{f}\right.\right. \\
& \left.\left.\wedge \text { Anc_Dest }\left(t_{l^{\prime}}, a_{f}\right)=a_{d}\right)\right) \wedge\left(\exists d \in \operatorname{Doc} \mid A n c \_D o c\left(a_{f}\right)=d\right) \\
& \wedge\left(\forall t \in T \mid \text { Pertence_Local }\left(d, t, \text { cont }_{f}, a_{d}\right) \rightarrow t \in T_{k l}\right)
\end{aligned}
$$

onde $t_{l^{\prime}}=\left(X_{l}, e_{l^{\prime}}, Y_{l}\right)$ e $a_{f}=\left\langle i d_{f}\right.$, cont $\left._{f}\right\rangle \in A n c \backslash\left\{a_{ø}\right\}$ e $a_{d} \in A n c \backslash\left\{a_{ø}\right\}$

Com base na função Local definida no modelo OXHMBS, a transição $t_{l}$ teria sua semântica descrita por uma representação equivalente em Hypercharts Estendido (equivalente semanticamente a mesma representação em Statecharts). Essa representação deve ser composta pela transição $t_{l^{\prime}}$ adicionada de $k(k \geq 0)$ transições que partem (possivelmente) de diferentes estados associados a um único documento, e cujas ligações abstraídas possuem âncora fonte com o mesmo conteúdo da âncora fonte associada à ligação abstraída da transição $t_{l^{\prime}}$ e âncora destino igual à âncora destino associada à ligação abstraida da transição $t_{l^{\prime}}$.

\subsubsection{Ligações Computadas ou Dinâmicas}

O HMBS e o XHMBS não suportam a especificação de ligações computadas ou dinâmicas diretamente em sua notação, uma vez que esse requisito diz respeito a mecanismos fornecidos pelo sistema hipermidia que os suportem. No entanto, elementos desses modelos, tais como títulos associados aos documentos e semânticas de contexto, permitem que mecanismos de busca (implementados por um sistema hipermídia) criem ligações dinâmicas e índices, levando o usuário a informações específicas de forma não convencional. 
Da mesma forma, não é de responsabilidade do modelo OXHMBS, proposto neste trabalho, suportar a especificação de ligações dinâmicas propriamente em sua notação. Contudo, foi definido um novo elemento em OXHMBS, "palavras-chave" associadas aos documentos (definida na Seção 5.2), com o objetivo de enriquecer os mecanismos de busca e permitir que mais informaçōes possam ser recuperadas quando uma ligação dinâmica é especificada.

\subsection{Ligações em termos da semântica da informação}

Sistemas hipermidia, em geral, utilizam diferentes tipos de mídia, tais como texto, áudio, animação e vídeo. Segundo Tai (1996), para permitir a utilização crescente de diferentes formas de informação não textual em sistemas hipermidia abertos é necessário que esses tenham uma arquitetura que permita que informações sejam tratadas de uma maneira independente do tipo de mídia. Também é importante que informações sejam tratadas independentemente de sua localizaçōes física dentro dos documentos que as contêm.

Nesse contexto, é interessante que o modelo OXHMBS, que tem como objetivo permitir a especificação de aplicações em sistemas hipermidia abertos, permita o suporte a essas características.

Deve-se ressaltar que um suporte completo a tais características dependeria muito mais da existência de um mecanismo de busca adequado implementado por um sistema hipermidia que suportasse o modelo e dos aplicativos hipermídia habilitados integrados a esse sistema do que propriamente do modelo. Dessa forma, neste trabalho apenas foram identificados os elementos do OXHMBS que poderão ser utilizados por um mecanismo de busca que implemente ligações baseadas na semântica da informação.

Um exemplo de ligações baseadas na semântica da informação, ou também chamadas de ligações (recuperação) baseadas em conteúdo, pode ser encontrado quando um leitor qualquer realiza uma consulta sobre um determinado assunto (por exemplo, "Carro") e como resultado é apresentado um conjunto de ligações a documentos de diferentes tipos de mídia cujos conteúdos referem-se ao mesmo assunto (por exemplo, documentos texto sobre carros, documentos áudio sobre carros, documentos vídeo sobre carros, etc).

No OXHMBS, através do uso do título dos documentos e de palavras-chave associadas a esses, é possível estabelecer um cenário inicial no qual recuperação baseada na semântica da informação possa ocorrer. Nesse contexto, a partir de um mecanismo de busca implementado por um sistema que suporte esse modelo seria possivel criar dinamicamente ligações a documentos independentemente do tipo de mídia desses. Dessa forma, para a criação de ligações a informações de um determinado "assunto" em uma aplicação especificada através do modelo OXHMBS, deveria ser realizada uma busca sobre o título e o conjunto de palavras-chave dos documentos que compõem a aplicação, e o resultado dessa busca deveria ser um conjunto de 
ligações (baseadas na semântica da informação) a documentos que possuem palavras-chave e titulo que "casam" com o "assunto" sendo pesquisado.

Também é importante destacar que em nivel de especificação o modelo OXHMBS não trata diretamente da localização fisica de âncoras dentro de um documento, esse controle é deixado principalmente para os aplicativos responsáveis pela apresentação dos documentos que as contêm. As âncoras são descritas por um id e por um conteúdo, que no caso de âncoras associadas a dados textuais correspondem exatamente à porção do texto destacada no documento sendo apresentado, enquanto que no caso de âncoras associadas a dados não textuais, como por exemplo um frame de um vídeo, correspondem a descrições dessas porções de informação. Essa característica do OXHMBS é importante porque, dessa forma, obtém-se uma separação entre o conteúdo das âncoras e sua localização física o que possibilita a criação de ligações estáticas baseadas na semântica (conteúdo) da informação, ao invés de ligações estáticas baseadas na localização fisica dessas.

A localização fisica das âncoras não é de responsabilidade do modelo OXHMBS, esse apenas especifica a associação entre uma âncora (definida logicamente no conjunto de âncoras) e sua posição física definida pelo aplicativo capaz de apresentá-la (a definição da função Anc_Localizacao que é responsável por essas associações pode ser observada na Seção 5.2). Essa informação é transmitida pelos aplicativos para o modelo através de mensagens do protocolo OHP, discutidas detalhadamente na Seção 4.8 .

\subsection{Bases de ligações externas públicas e privadas}

Um dos requisitos das aplicações em sistemas hipermídia abertos é o suporte a bases de ligações públicas e privadas.

No modelo XHMBS os hypercharts que especificam uma aplicação hipermidia podem ser considerados como bases de ligações. Porém, não existem mecanismos que suportem a distinção entre bases de ligações públicas e privadas (ou seja, entre hypercharts públicos e privados), uma vez que nenhum elemento desse modelo especifica o tipo de base que está sendo modelada.

Nesse contexto, a seguir são apresentadas proposições de extensões necessárias ao modelo XHMBS para que este venha a permitir a especificação de bases de ligações públicas e privadas.

\section{- Extensões propostas no modelo OXHMBS}

Raiz (novo conjunto criado no OXHMBS) corresponde ao conjunto formado somente pelo estado raiz de um hyperchart estendido. Esse estado é responsável por encapsular toda base de ligações a que um hyperchart estendido se refere. Dessa forma o conjunto Raiz é tal que: $\{$ Raiz $\subseteq S \mid s \in \operatorname{Raiz} \leftrightarrow(\forall a \in S \rightarrow s \notin \rho(a))\}$. 
Base_Lig: Raiz $\rightarrow$ Tipo (nova função criada no OXHMBS) corresponde a função que associa à raiz do hyperchart estendido, ou seja, à base de ligações, um tipo que pode ser pública ou privada.

Onde, Tipo $=\{$ pública, privada $\}$ corresponde ao conjunto de tipos possíveis de bases de ligações.

Autorizacao: Raiz $\rightarrow$ Info (nova função criada no OXHMBS) corresponde a função que associa às bases de ligações privadas uma senha de acesso (controle de acesso). Dessa forma, Autorizacao é tal que:

$$
\text { Autorizacao }(r)= \begin{cases}x & \text { se Base_Lig }(r)=\text { "privada" } \\ \varnothing & \text { caso contrário }\end{cases}
$$

onde $x \in$ Info $\backslash\{\varnothing\}$

\subsection{Separação entre estrutura e conteúdo da informa- ção}

Como já destacado na Seção 2.4, a separação entre a estrutura e o conteúdo da informação é um requisito chave das aplicações em sistemas hipermídia abertos. Nenhuma informação sobre ligações deve ser embutida no conteúdo dos documentos que compõem as aplicações em sistemas hipermídia abertos, permitindo, dessa forma, que esses sejam analisados, processados e manipulados pelos aplicativos que os criaram, ou seja, o uso desses documentos fora do sistema hipermídia aberto não deve ser comprometido.

Os documentos que compõem as aplicações em sistemas hipermídia abertos devem permanecer nos formatos originais de seus aplicativos, o que significa que eles não precisam ser convertidos em um formato especial, para participar de um ambiente hipermidia aberto.

O modelo XHMBS e conseqüentemente o modelo OXHMBS suportam separação entre conteúdo e estrutura das informações. A existência no OXHMBS de conjuntos distintos para documentos e para âncoras e também o uso de funções distintas para relacionar documentos a estados, âncoras a documentos, transições a âncoras fonte, âncoras fonte a âncoras destino e âncoras a suas localizações fisicas, faz com que toda a estrutura de uma aplicação hipermídia esteja em um nivel diferente daquele em que se encontram as porções de conteúdo da informação.

No contexto das aplicações em sistemas hipermídia abertos, pode-se considerar os hypercharts estendidos como a estrutura das informações, ou seja, como as bases de ligações que contêm o conjunto de ligações de uma determinada aplicação hipermídia. Enquanto que o con- 
teúdo dessas é definido formalmente nos conjuntos de documentos (Doc) e de âncoras (Anc) do OXHMBS.

Durante a identificação das ligações de uma aplicação especificada no modelo OXHMBS nenhuma alteração é feita no conteúdo dos elementos do conjunto Doc, ou seja, o conteúdo dos documentos que compõem uma aplicação hipermídia especificada nesse permanece inalterado quando uma ligação é identificada (mais precisamente, permanece em seu formato original).

A associação entre o hyperchart estendido que representa a estrutura de uma aplicação hipermidia e o conjunto de documentos e âncoras que representam os conteúdos dessa é feita através das funções $M, A n c \_D o c, A n c_{-} F o n t$ e $A n c_{-} D e s t$, definidas pelo OXHMBS. Enquanto que a associação das âncoras às suas localizações fisicas é realizada através da função Anc_Localizacao e não é definida em nivel de especificação (ou seja, pelo leitor da aplicação). Essa associação é definida pelo OXHMBS, com base no valor de localização fisica transmitido pelos aplicativos que são responsáveis pela apresentação dos documentos que encapsulam tais âncoras.

É importante ressaltar que nenhuma dessas funções altera o conteúdo dos documentos (elementos do conjunto $D o c$ ) quando ligações de uma aplicação, ou seja, âncoras fonte e destino são identificadas.

\subsection{Ligações "de" e "para" informações read-only}

Como apresentado na Seção 2.4, esse requisito é uma conseqüência do requisito chave das aplicações em sistemas hipermídia abertos "separação entre estrutura e conteúdo das informações", uma vez que, dessa forma, a estrutura (ou seja, as ligações hipermídia de uma aplicação) é somente acrescentada ao conteúdo (pelos aplicativos hipermídia habilitados) em tempo de apresentação, o que permite que ligações sejam criadas em documentos de diferentes fontes, incluindo fontes read-only.

O modelo XHMBS e conseqüentemente o modelo OXHMBS suportam separação entre conteúdo e estrutura das informações e, dessa forma, a criação de ligações em informações read-only. Como já destacado na Seção 4.5, a existência de conjuntos distintos para documentos e para âncoras e também o uso de funções distintas para relacionar documentos a estados, âncoras a documentos, transições a âncoras fonte, âncoras fonte a âncoras destino e âncoras a suas localizações fisicas, faz com que toda a estrutura de uma aplicação hipermídia esteja em um nível diferente daquele em que se encontram as porções de conteúdo da informação.

Dessa forma, para a especificação de uma ligação específica em um documento (no qual não se tem permissão de escrita) de uma aplicação hipermídia especificada através do modelo OXHMBS, nenhuma alteração é feita no conteúdo desse. Apenas são identificados os seguintes elementos nos conjuntos e funções do modelo OXHMBS: 
1. Uma âncora fonte anc é identificada no conjunto de âncoras | anc $\in$ Anc;

2. Uma âncora destino $a n c^{\prime}$ é identificada no conjunto de âncoras । $a n c^{\prime} \in A n c$;

3. Uma tupla $\langle a n c, d\rangle \mid A n c \_D o c(a n c)=d$ é identificada;

4. Uma tupla $\left\langle a n c^{\prime}, d^{\prime}\right\rangle \mid A n c_{-} D o c\left(a n c^{\prime}\right)=d^{\prime}$ é identificada;

5. Uma tupla $\langle t, a n c\rangle \mid A n c \_F o n t(t)=$ anc é identificada;

6. Uma tupla $\left\langle t, a n c, a n c^{\prime}\right\rangle \mid A n c \_$Dest $(t, a n c)=a n c^{\prime}$ é identificada;

7. Uma tupla $\langle a n c$, localizacao_fonte $\rangle \mid A n c \_L o c a l i z a c a o(a n c)=$ localizacao_fonte é identificada com base nas informações transmitidas pelo aplicativo que apresentará o documento que encapsula a âncora fonte; e

8. Uma tupla $\left\langle a n c^{\prime}\right.$, localizacao_dest $\rangle \mid A n c \_L o c a l i z a c a o\left(a n c^{\prime}\right)=$ localizacao_dest é identificada com base nas informações transmitidas pelo aplicativo que apresentará o documento que encapsula a âncora destino;

Deve-se observar que em nenhum momento foram realizadas alterações nos elementos do conjunto $D o c$, que se referem aos elementos do conjunto de documentos de uma aplicação hipermídia (onde, $\forall d o c \in D o c \mid d o c=$ (identificador, conteúdo, título, palavras-chave)).

Também é importante ressaltar que é de responsabilidade dos aplicativos hipermídia habilitados destacar as âncoras nos documentos que compõem as aplicações hipermídia especificadas no OXHMBS.

\subsection{Documentos em diferentes formatos}

Como dito anteriormente na Seção 2.4, o suporte a documentos em diferentes formatos também é um requisito chave das aplicaçōes em sistemas hipermidia abertos, uma vez que o objetivo principal dos sistemas hipermídia abertos é produzir um conjunto geral de serviços hipermídia (suporte a criação, remoção e modificação de âncoras e ligações e suporte a navegação dessas ligações) que pode ser usado por um conjunto irrestrito de aplicativos existentes no ambiente computacional. Isso conseqüentemente resulta em um conjunto irrestrito de formatos de documentos que podem compor as aplicações em sistemas hipermídia abertos.

Nesse contexto, o OXHMBS deve permitir a especificação de um conjunto irrestrito (ou seja, onde nenhuma restrição seja imposta) de documentos Doc que serão apresentados através de um conjunto de aplicativos. 


\section{- Extensões propostas no modelo OXHMBS}

A função Visualizacao (nova função criada no OXHMBS), definida abaixo, é responsável pela identificação dos relacionamentos entre os documentos presentes no conjunto de documentos e os aplicativos responsáveis por apresentá-los, tal que:

\section{Visualizacao $:\left(D o c \backslash\left\{d_{ø}\right\}\right) \rightarrow$ Aplicativos}

Onde, Aplicativos $\subseteq$ Info $\times$ Info (novo conjunto criado no OXHMBS) corresponde ao conjunto de aplicativos responsáveis pela apresentação dos documentos de uma aplicação hipermídia. Esses aplicativos são da forma (identificador, descrição) | identificador $\epsilon$ Info, descrição $\in$ Info.

É importante ressaltar que o identificador de um aplicativo é único, ou seja: $\forall a_{i}, a_{j} \in$ Aplicativos $\mid a_{i}=\left\langle i d_{i}, d_{i}\right\rangle, a_{j}=\left\langle i d_{j}, d_{j}\right\rangle \rightarrow i d_{i} \neq i d_{j}$.

\subsection{Comunicação, cooperação e distribuição}

Esses requisitos estão relacionados com a existência de um protocolo que realize a comunicação entre os documentos das aplicações hipermídia especificadas através do OXHMBS e os aplicativos responsáveis por sua apresentação.

O modelo XHMBS utiliza o conceito de canais de apresentação Pchanells e canais de distribuição Cchanells para definir a comunicação (e distribuição) entre os documentos de uma especificação XHMBS e os aplicativos responsáveis por sua apresentação. No OXHMBS, porém, optou-se por utilizar o protocolo padrão de comunicação (OHP - Protocolo Hipermídia Aberto) definido pelo Grupo de Trabalho de Sistemas Hipermídia Abertos (OHSWG, 2001).

Nesse contexto, no OXHMBS, que em nivel de implementação deve ser suportado por um sistema hipermídia aberto, mais precisamente por um Processo de Serviço Hipermídia (HSP) ${ }^{1}$ responsável pelo gerenciamento de bases de ligações e âncoras (ou seja, das especificações OXHMBS), a comunicação entre os documentos de uma aplicação hipermídia especificada nesse e os aplicativos responsáveis por sua apresentação deve ser realizada através de mensagens definidas pelo $\mathrm{OHP}$.

Isso significa que através de informações encontradas nas especificações OXHMBS, um HSP que suporte o modelo poderá se comunicar, via protocolo OHP, com os aplicativos responsáveis pela apresentação dos conteúdos dos documentos definidos nessas especificações.

Isso pode ser melhor observado na Figura 4.5, onde as especificações OXHMBS (definidas em uma arquitetura hipermidia aberta) apresentam-se armazenadas em uma Base de Especifi-

\footnotetext{
'Da mesma forma que o HSP definido no Framework Devise Hypermedia e o Serviço de Ligações definido no Microcosm. Em ambos sistemas esse elemento é o componente central da arquitetura.
} 


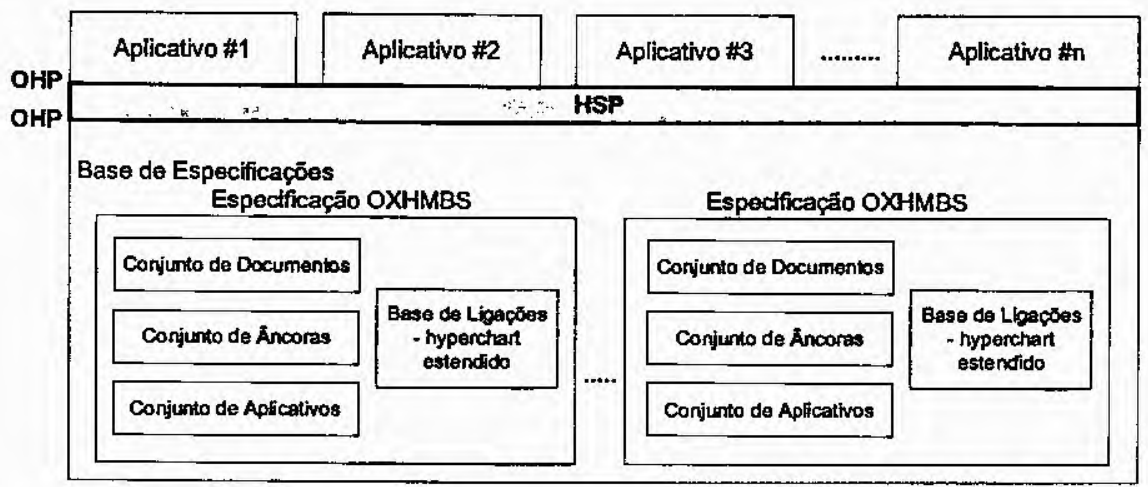

Figura 4.5: Especificações OXHMBS em uma Arquitetura Hipermídia Aberta

cações e comunicam-se via protocolo OHP (através do HSP) com um conjunto de aplicativos responsáveis pela apresentação dos documentos definidos nessa Base de Especificações.

No modelo OXHMBS, com o objetivo de permitir a especificação de aplicações distribuídas e de suportar comunicação e cooperação ${ }^{2}$ foram especificados as mensagens dos seguintes subprotocolos do protocolo OHP (definidos na Seção 2.5): protocolo de conexão, protocolo de ligação básico (comunicação básica e distribuição) e protocolo multiusuário (cooperação). Como já destacado anteriormente (Seção 2.5), o subprotocolo de navegação estendida é opcional e, dessa forma, não será especificado neste trabalho. Nas próximas Seções esses subprotocolos são apresentados mais detalhadamente.

Deve-se ressaltar que a especificação do protocolo OHP é de extrema importância para a definição da semântica de navegação (Seção 5.3) do modelo OXHMBS, porque possibilita a definição da forma com que os documentos serão apresentados e navegados nos aplicativos.

\subsubsection{Protocolo de Conexão}

O protocolo de conexão é composto de duas mensagens que têm como objetivo o estabelecimento e o encerramento de uma conexão (através da alocação de um canal de comunicação) entre os aplicativos hipermídia habilitados e as especificações OXHMBS (aplicações hipermídia) gerenciadas por um HSP que suporte o modelo OXHMBS.

\section{Nome da mensagem: Logon.}

Uso: Usada pelos aplicativos hipermídia habilitados para o estabelecimento de uma conexão com o HSP.

Formato: Nome_usuario, id_aplicativo, senha, id_cliente, num_porta_cliente.

\footnotetext{
${ }^{2}$ No modelo OXHMBS, o termo cooperação será usado para definir um conjunto de documentos sendo utilizado de maneira compartilhada (assíncrona) por um conjunto de leitores.
} 
Resposta: cod_resposta ${ }^{3}$.

Exemplo: amiotto@icmc.sc.usp.br, Latex, ${ }^{* * * * * * *}$, -xapacura.icmc.sc.usp.br, 7666.

Dados extraídos: ${ }^{4}$

Seja aplicativo $=\langle$ Latex, Editor de texto $\rangle$ onde aplicativo $\in$ Aplicativos.

2. Nome da mensagem: Logoff.

Uso: Usada pelos aplicativos hipermídia habilitados para o encerramento de uma conexão com o HSP.

Formato: Nome_usuario, id_aplicativo.

Resposta: cod_resposta.

Exemplo: amiotto@icmc.sc.usp.br, Latex.

Dados extraídos:

Seja aplicativo $=\langle$ Latex, Editor de texto $\rangle$ onde aplicativo $\in$ Aplicativos.

\subsubsection{Protocolo de Ligação Básico}

O protocolo de ligação básico tem como objetivo o suporte à criação, remoção e travessia de ligações em documentos de aplicações especificadas em OXHMBS, e que são manipulados por aplicativos integrados ao HSP que gerencia tais aplicações (especificações OXHMBS). Esse protocolo é dividido em dois tipos de mensagens:

Mensagens do HSP para os aplicativos hipermídia habilitados.

1. Nome da Mensagem: Esta_Aberto.

Uso: Usada para verificar se um determinado documento (definido por alguma especificação OXHMBS) encontra-se sendo apresentado por algum aplicativo hipermídia habilitado.

Formato: id_aplicativo, arquivo_localizacao.

Resposta: $\operatorname{TRUE}(=1)$ ou $\operatorname{FALSE}(=0)$.

Exemplo: Latex, /users/amiotto/teste.tex.

\footnotetext{
${ }^{3}$ Cod_resposta corresponde a um número que codifica o resultado de uma operação, onde 1 corresponde a sucesso e 0 corresponde a falha. Números precedidos por "-" referem-se a mensagens específicas descrevendo o status de uma operação.

${ }^{4} \mathrm{Em}$ um HSP que suporte o OXHMBS, as informações obtidas dessa mensagem (especificada pelo OHP) e utilizadas pela base de especificações serão conforme apresentado.
} 


\section{Dados extraídos: ${ }^{5}$}

Seja doc $\in D o c$ o documento que deseja-se verificar se está aberto, tal que:

Doc_Localizacao $(d o c)^{6}=$ arquivo_localizacao, onde

arquivo_localizacao $=/$ users/amiotto/teste.tex.

Seja aplicativo $\in$ Aplicativos o aplicativo responsável pela apresentação de $d o c$, tal que:

Visualizacao $($ doc $)=$ aplicativo onde aplicativo $=\langle$ Latex, Editor de texto $\rangle$.

\section{Nome da Mensagem: Apresenta_Selecao.}

Uso: Usada para definir a apresentação de uma âncora em um determinado documento.

Formato: id_aplicativo, arquivo_localizacao, ancora_localizacao, especificacao_apresentacao ${ }^{7}$.

Resposta: cod_resposta.

Exemplo: Latex, /users/amiotto/teste.tex, $13 \sharp 14 \sharp^{8}$, [azul].

\section{Dados extraídos:}

Seja anc $\in$ Anc a âncora que deseja-se apresentar e $d o c \in D o c$ o documento em que a âncora a ser apresentada encontra-se contextualizada, tal que: $A n c \_D o c(a n c)=d o c$.

Seja aplicativo $\in$ Aplicativos o aplicativo responsável pela apresentação de doc, tal que: Visualizacao $($ doc $\rangle=$ aplicativo onde aplicativo $=\langle$ Latex, Editor de texto $)$.

A localização física da âncora anc é dada por:

Anc_Localizacao $(a n c)=a n c o r a \_l o c a l i z a c a n$, onde ancora_localizacao $=13 \sharp 14 \sharp$; e

A localização física do documento doc é dada por:

Doc_Localizacao(doc) $=$ arquivo_localizacao, onde arquivo_localizacao = /users/amiotto/teste.tex.

A especificação de apresentação, nesse exemplo, define que a âncora (anc) em questão deve ser apresentada na cor azul.

\section{Nome da Mensagem: Apresenta_Documento.}

\footnotetext{
${ }^{5} \mathrm{Em}$ um HSP que suporte o OXHMBS, as informaçôes obtidas dessa mensagem (especificada pelo OHP) e utilizadas pelos aplicativos serāo conforme apresentado.

${ }^{6}$ A definiçâo da função Doc_Localizacao pode ser observada na Seção 5.2 .

${ }^{7}$ Define alguns atributos de apresentação a serem aplicados sobre um documento ou sobre uma âncora.

${ }^{8}$ Os valores de localização física das âncoras (descrição da localização física) utilizados nesses exemplos são hipotéticos, e dependem da forma de endereçamento das âncoras utilizada pelo aplicativo responsável pela apresentação dos documentos que contextualizam essas.
} 
Uso: Usada para definir a apresentação de um determinado documento.

Formato: id_aplicativo, arquivo_localizacao, especificacao_apresentacao.

Resposta: cod_resposta.

Exemplo: Latex, /users/amiotto/teste.tex, [azul].

\section{Dados extraídos:}

Seja $d o c \in D o c$ o documento a ser apresentado, tal que:

Doc_Localizacao(doc) $=$ arquivo_localizacao, onde arquivo_localizacao $=$ /users/amiotto/teste.tex.

Seja aplicativo $\in$ Aplicativos o aplicativo responsável pela apresentação de doc, tal que:

Visualizacao $($ doc $)=$ aplicativo onde aplicativo $=\langle$ Latex, Editor de texto $\rangle$.

A especificação de apresentação, nesse exemplo, define que o texto do documento (doc) em questão deve ser apresentado na cor azul.

\section{Nome da Mensagem: Documento_Removido.}

Uso: Usada para informar um aplicativo hipermidia habilitado que um determinado documento será removido da especificação OXHMBS (aplicação hipermídia) que esta sendo manipulada correntemente.

Formato: id_aplicativo, arquivo_localizacao.

Resposta: cod_resposta.

Exemplo: Latex,/users/amiotto/teste.tex.

\section{Dados extraídos:}

Seja $d o c \in D o c$ o documento que será removido da especificação OXHMBS, tal que: Doc_Localizacao $(d o c)=$ arquivo_localizacao, onde arquivo_localizacao = /users/amiotto/teste.tex.

Seja aplicativo $\in$ Aplicativos o aplicativo responsável pela apresentação de doc, tal que: Visualizacao $($ doc $)=$ aplicativo onde aplicativo $=\langle$ Latex, Editor de texto $\rangle$.

Esse aplicativo, através dessa mensagem, é informado sobre a remoção de doc da especificação OXHMBS correntemente manipulada.

5. Nome da mensagem: Ancoras_Removidas. 
Uso: Usada para informar um aplicativo hipermídia habilitado que algumas âncoras de um determinado documento serão removidas da especificação OXHMBS (aplicação hipermídia) correntemente manipulada.

Formato:id_aplicativo, arquivo_localizacao, numero_ancoras, $\{\text { ancora_localizacao }\}^{* 9}$.

Resposta: cod_resposta.

Exemplo: Latex, /users/amiotto/teste.tex, $2,13 \sharp 14 \sharp, 23 \sharp 24 \sharp$.

\section{Dados extraídos:}

Sejam $a n c^{\prime}, a n c^{\prime \prime} \in A n c$ as âncoras que serão removidas da especificação OXHMBS, e $d o c \in D o c$ o documento em que essas âncoras encontram-se contextualizadas, tal que: $A n c \_D o c\left(a n c^{\prime}\right)=d o c$ e $A n c \_D o c\left(a n c^{\prime \prime}\right)=d o c$.

Seja aplicativo $\in$ Aplicativos o aplicativo responsável pela apresentação de doc tal que: Visualizacao $($ doc $)=$ aplicativo onde aplicativo $=$ (Latex, Editor de texto).

A localização fisica das âncora $a n c^{\prime}$; $a n c^{\prime \prime}$ é dada por:

Anc_Localizacao $\left(a n c^{\prime}\right)=$ ancora_localizacao onde ancora_localizacao $o^{\prime}=13 \sharp 14 \sharp$; Anc_Localizacao $\left(a n c^{\prime \prime}\right)=$ ancora_localizacao $o^{\prime \prime}$ onde ancora_localizaca $o^{\prime \prime}=23 \sharp 24 \sharp$.

A localização fisica do documento doc é dada por:

Doc_Localizacao(doc) = arquivo_localizacao, onde arquivo_localizacao = /users/amiotto/teste.tex.

O aplicativo responsável pela apresentação do documento que contextualiza anc' e $a n c^{\prime \prime}$, através dessa mensagem, é informado sobre a remoção dessas âncoras da especificação OXHMBS correntemente manipulada.

6. Nome da Mensagem: Envia_Lista_Ancoras.

Uso: Usada para enviar uma lista de âncoras de um determinado documento para o aplicativo hipermídia habilitado responsável por apresentá-las (ou seja, por apresentar o documento que as contextualiza).

Formato: id_aplicativo, arquivo_localizacao, numero_ancoras, \{ancora_localizacao\}*.

Resposta: cod_resposta.

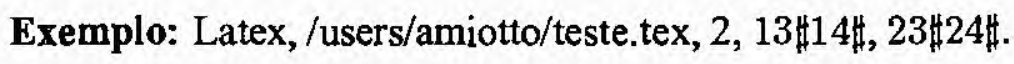

\section{Dados extraídos:}

\footnotetext{
${ }^{9}$ Esta representação $\left(^{*}\right)$ especifica a possibilidade de existir uma ou mais ocorrências de determinada variável, que nesse caso é ancora_localizacao.
} 
Seja Lista_Anc: $D o c \rightarrow 2^{A n c}$ (nova função criada no OXHMBS) a função que define o conjunto de âncoras de um determinado documento, tal que:

$$
\begin{gathered}
\text { Lista_Anc }(\text { doc })=L i s t a \leftrightarrow \\
\text { anc } \in \text { Lista }
\end{gathered}
$$

onde Lista é subconjunto de $A n c$, ou seja, Lista $\subseteq A n c$

Seja doc $\in$ Doc o documento do qual deseja-se enviar uma lista de âncoras, tal que: Doc_Localizacao $(d o c)=$ arquivo_localizacao, onde arquivo_localizacao $=$ /users/amiotto/teste.tex.

Seja aplicativo $\in$ Aplicativos o aplicativo responsável pela apresentação de doc, tal que: Visualizacao $($ doc $)=$ aplicativo onde aplicativo $=\langle$ Latex, Editor de texto $\rangle$.

Seja Lista_Anc(doc) $=\left\{a n c^{\prime}, a n c^{\prime \prime}\right\}$ a lista de âncoras presentes em doc, tal que a localização física dos membros de Lista, que nesse exemplo são $a n c^{\prime}$ e $a n c^{\prime \prime}$, é dada por: Anc_Localizacao $\left(a n c^{\prime}\right)=$ ancora_localizacao onde ancora_localizacao $o^{\prime}=13 \sharp 14 \hbar ;$ Anc_Localizacao $\left(a_{n} c^{\prime \prime}\right)=$ ancora_localizacao" onde ancora_localizacao" $=23 \sharp 24 \sharp$.

7. Nome da Mensagem: Fecha_Canal_Ativo.

Uso: Usada para informar um aplicativo hipermídia habilitado que um canal de comunicação ativo foi fechado pelo HSP que suporta o OXHMBS.

Formato: id_aplicativo.

Resposta: cod_resposta.

Exemplo: Latex.

\section{Dados extraídos:}

Seja aplicativo $\in$ Aplicativos o aplicativo que será informado sobre o canal de comunicação fechado pelo HSP, onde aplicativo = 〈Latex, Editor de texto $\rangle$.

\section{Mensagens dos aplicativos hipermídia habilitados para o HSP. ${ }^{10}$}

\section{Nome da mensagem: Cria_Nova_Ligacao.}

Uso: Usada para criar uma nova ligação de um determinado tipo (específica, bidirecional, local ou global), a partir de um aplicativo hipermidia habilitado, em uma especificação OXHMBS (aplicação hipermídia).

\footnotetext{
${ }^{10} \mathrm{O}$ suporte a esse tipo de mensagens é muito valioso, pois deixa o modelo mais flexível, uma vez que torna-se possivel a manipulação de ligações hipermidia (criação, remoção e navegação) a partir dos aplicativos hipermidia habilitados integrados ao OXHMBS.
} 
Formato:

Nome_usuario,

id_aplicativo_fonte, ancora_fonte_localizacao,

arquivo_fonte_localizacao, id_aplicativo_destino, ancora_destino_localizacao, arquivo_destino_localizacao, tipo_ligacao, aplicacao.

Resposta: aplicacao'.

Exemplo: amiotto@icmc.sc.usp.br, Latex, 13 $\sharp 14 \sharp$, /users/amiotto/testel.tex, Latex, $33 \sharp 34 \sharp$, /users/amiotto/teste2.tex, [específica, bidirecional, local, global], Curso.

Exemplo de Resposta: Curso'.

\section{Dados extraídos: ${ }^{11}$}

Seja $H=\left\langle H y p, D o c, A n c, M, A n c \_D o c, A n c \_\right.$Font, Anc_Dest, Bidirecional, Global, Local, Raiz, Base_Lig, Autorizacao, Aplicativos, Visualizacao, L, Lista_Dest, Lista_Anc,Doc_Tipo,Doc_Localizacao,Anc_Localizacao) a aplicação hipermídia especificada através do OXHMBS (passada como parâmetro); e

$H y p=\left\langle S, \rho, \Psi, \delta, \gamma, \tau, L S C, T\right.$ hist $\left., V, C, E, T, A c, T_{S}, T_{B}, T_{G}, T_{L}, B i d, G l, L l\right\rangle$, o hyperchart estendido que representa a estrutura (base de ligações) dessa aplicação hipermídia (a definição completa de $H$ e $H y p$ pode ser observada na Seção 5.2).

Nesse contexto, de acordo com o tipo de ligação criada, uma nova aplicação hipermídia $H^{\prime}=\left\langle H y p^{\prime}\right.$, Doc',Anc', $M^{\prime}, A n c_{-}$Doc',Anc_Font',Anc_Dest', Bidirecional', Global', Local', Raiz', Base_Lig', Autorizacao', Aplicativos', Visualizacao' ${ }^{\prime}, L^{\prime}$, Lista_Dest',Lista_Anc',Doc_Tipo',Doc_Localizacao',Anc_Localizacao' $\rangle$ será especifcada, tal que:

- Se a nova ligação criada for do tipo específica, então:

Todos os elementos de $H^{\prime}$ permanecem iguais aos de $H$, com exceção de $A n c^{\prime}$ e $H y p^{\prime}$, de forma que:

$A n c^{\prime}=A n c \cup\left\{a n c \_f o n t e, a n c \_d e s t\right\}, \mathrm{e}$

os elementos de $H y p^{\prime}$ permanecem iguais aos de $H y p$ com exceção de $T^{\prime}$, onde $T^{\prime}=T \cup\left\{t_{-}\right.$fonte $\}$.

Com base nesses novos elementos dos conjuntos $A n c^{\prime}$ e $T^{\prime}$, também serão identificadas as seguintes tuplas:

$\left\langle t_{-}\right.$fonte, anc_fonte $\rangle \mid$Anc_Font $\left(t \_f o n t e\right)=a n c \_$fonte.

$\left\langle t_{\_} f o n t e, a n c \_f o n t e, a n c \_d e s t\right\rangle \mid A n c \_D e s t^{\prime}\left(t \_f o n t e, a n c \_f o n t e\right)=a n c \_d e s t$.

Nesse contexto, de acordo com o exemplo ilustrado para a mensagem Cria_Nova_Ligacao, pode-se definir $H$ como sendo Curso, ou seja, a aplicação

\footnotetext{
${ }^{11} \mathrm{Em}$ um HSP que suporte o OXHMBS, as informações obtidas dessa mensagem (especificada pelo OHP) e utilizadas pela base de especificações serāo conforme apresentado.
} 
passada como parâmetro e na qual deseja-se criar uma nova ligação específica. Enquanto que $H^{\prime}$, a aplicação resultante da realização dessa operação, seria definida como Curso', onde:

$\exists a n c \_$fonte, anc_dest $\in A n c^{\prime} \mathrm{e}$

$\exists t$ fonte $\in T^{\prime}$, tal que:

Sejam $d o c^{\prime}, d o c^{\prime \prime} \in D o c^{\prime}$ os documentos nos quais as âncoras anc,_fonte e anc_dest encontram-se contextualizadas, respectivamente, de forma que $A n c \_D o c^{\prime}\left(a n c \_f o n t e\right)=d o c^{\prime}$ e $A n c \_D o c^{\prime}\left(a n c \_d e s t\right)=d o c^{\prime \prime}$. Dessa forma:

A localização física de $d o c^{\prime}$ e $d o c^{\prime \prime}$ é dada por:

Doc_Localizacao $\left(d o c^{\prime}\right)=$ arquivo_fonte_localizacao onde arquivo_fonte_localizacao $=/$ users/amiotto/teste1.tex; $\mathrm{e}$ Doc_Localizacao $\left(\right.$ doc $\left.^{\prime \prime}\right)=$ arquivo_destino_localizacao onde arquivo_destino_localizacao $=/$ users/amiotto/teste2.tex.

A localização física de $a n c \_$fonte e anc_dest é dada por: Anc_Localizacao' (anc_fonte) $=$ ancora_fonte_localizacao onde ancora_fonte_localizacao $=13 \sharp 14 \sharp ; \mathrm{e}$ Anc_Localizacao' (anc_dest $)=$ ancora_destino_localizacao onde ancora_destino_localizacao $=33 \sharp 34$ H.

Finalmente, seja aplicativo $\in$ Aplicativos' o aplicativo responsável pela apresentação de $d o c^{\prime}$ e $d o c^{\prime \prime}$, tal que:

Visualizacao $\left(\right.$ doc $\left.^{\prime}\right)=$ aplicativo e Visualizacao $\left(\right.$ doc $\left.^{\prime \prime}\right)=$ aplicativo onde aplicativo $=$ (Latex, Editor de texto).

\section{- Se a nova ligação criada for do tipo bidirecional, então:}

Todos os elementos de $H^{\prime}$ permanecem iguais aos de $H$, com exceção de $A n c^{\prime}$ e $H y p^{\prime}$, de forma que:

$A n c^{\prime}=A n c \cup\left\{a n c \_\right.$fonte $1, a n c \_$fonte 2$\}, \mathrm{e}$

os elementos de $H y p^{\prime}$ permanecem iguais aos de $H y p$ com exceção de $T_{B}^{v}=$ $T_{B} \cup\left\{t_{-}\right.$bidirecional $\}$e $T^{\prime}$ onde $T^{\prime}=T \cup\left\{t_{-}\right.$fonte $1, t_{-}$fonte 2$\}$ se e somente se $B i d\left(t_{-}\right.$bidirecional $)=\left\{t_{-}\right.$fonte $1_{,} t_{-}$fonte 2$\}$.

Com base nesses novos elementos dos conjuntos $A n c^{\prime}, T_{B}^{\prime}$ e $T^{\prime}$, também serão identificadas as seguintes tuplas:

$\left\langle t_{-}\right.$bidirecional, anc_fonte 1, anc_fonte 2$\rangle \mid$ Bidirecional $^{\prime}\left(t \_b i d i r e c i o n a l\right)=$ \{anc_fonte1, anc_fonte 2$\}$.

$\left\langle t_{-}\right.$fonte1, anc_fonte 1$) \mid A n c_{-} F_{\text {Font }}\left(t_{-}\right.$fonte 1$)=$ anc_fonte 1. 


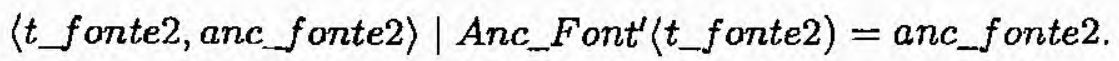

$\left\langle t \_\right.$fonte1,anc_fonte $1, a n c_{-}$fonte 2$\rangle \mid A n c_{-}$Dest $t^{\prime}\left(t_{-}\right.$fonte $1, a n c_{-}$fonte 1$)=$ anc_fonte2.

$\left\langle t \_\right.$fonte 2, anc_fonte $2, a n c \_$fonte 1$\rangle \mid A n c \_D e s t^{\prime}(t$ fonte 2, anc_fonte 2$)=$ anc_fonte 1 .

Nesse contexto, de acordo com o exemplo ilustrado para a mensagem Cria_Nova_Ligacao, pode-se definir $H$ como sendo $C u r$ so, ou seja, a aplicação passada como parâmetro e na qual deseja-se criar uma nova ligação bidirecional. Enquanto que $H^{\prime}$, a aplicação resultante da realização dessa operação, seria definida como Curso', onde:

$\exists a n c \_f o n t e 1, a n c \_$fonte $2 \in A n c^{\prime}$;

$\exists t \_$fonte $1, t$ fonte $2 \in T^{\prime} ; \mathrm{e}$

$\exists t$ bidirecional $\in T_{B}^{\prime}$, tal que:

Sejam $d o c^{\prime}$, doc $c^{\prime \prime} \in D o c^{\prime}$ os documentos nos quais as âncoras anc_fonte1 e anc fonte 2 encontram-se contextualizadas, respectivamente, de forma que $A n c_{-} D o c^{\prime}\left(a n c_{-} f o n t e 1\right)=d o c^{\prime}$ e $A n c_{-} D o c^{\prime}\left(a n c_{-} f o n t e 2\right)=d o c^{\prime \prime}$. Dessa forma: A localização física de $d o c^{\prime}$ e $d o c^{\prime \prime}$ é dada por:

Doc_Localizacao $\left(\right.$ doc $\left.^{\prime}\right)=$ arquivo_fonte_localizacao onde arquivo_fonte_localizacao $=/$ users/amiotto/testel.tex; $\mathrm{e}$ Doc_Localizacao $\left(\right.$ doc $\left.^{\prime \prime}\right)=$ arquivo_destino_localizacao onde arquivo_destino_localizacao $=/$ users/amiotto/teste2.tex.

A localização física de anc_fontel e anc_fonte2 é dada por:

Anc_Localizacao' $\left(a n c \_\right.$fonte 1$)=$ ancora_fonte_localizacao onde ancora_fonte_localizacao $=13 \sharp 14 \sharp$; $\mathrm{e}$ $A n c \_L o c a l i z a c a o^{\prime}\left(a n c \_\right.$fonte 2$)=$ ancora_destino_localizacao onde ancora_destino_localizacao $=33 \sharp 34 \sharp$.

Finalmente, seja aplicativo $\in$ Aplicativos' o aplicativo responsável pela apresentação de $d o c^{\prime}$ e $d o c^{\prime \prime}$, tal que: Visualizacao' $\left(d o c^{\prime}\right)=$ aplicativo e Visualizacao $\left(\right.$ doc $\left.^{\prime \prime}\right)=$ aplicativo onde aplicativo $=$ (Latex, Editor de texto).

\section{- Se a nova ligação criada for do tipo global, então:}

Todos os elementos de $H^{\prime}$ permanecem iguais aos de $H$, com exceção de $A n c^{\prime}$ e $H y p^{\prime}$, de forma que:

$A n c^{\prime}=A n c \cup\left\{a n c \_\right.$fonte, anc_dest $\} \cup\left\{a n c_{1}, \ldots a n c_{n}\right\}(n \geq 0), \mathrm{e}$ 
os elementos de $H y p^{\prime}$ permanecem iguais aos de $H y p$ com exceção de $T_{G}^{\prime}=$ $T_{G} \cup\left\{t_{\text {global }}\right\}$ e $T^{\prime}$ onde $T^{\prime}=T \cup\left\{t_{g^{\prime}}\right\} \cup\left\{t_{1}, \ldots t_{n}\right\}(n \geq 0)$ se e somente se $G l(t$ global $)=\left\{t_{g^{\prime}}\right\} \cup\left\{t_{1}, \ldots t_{n}\right\}$.

A notação $\left\{x_{1}, \ldots, x_{n}\right\}$ define "extensão de conjunto", que especifica o conjunto formado por $x_{1}, x_{2}, x_{3}, \ldots x_{n}$. Onde, se $n=0$, o conjunto corresponde ao conjunto vazio; e se $n=1$, o conjunto corresponde ao conjunto unitário (Nicholls, 1995).

Com base nesses novos elementos dos conjuntos $A n c^{\prime}, T^{\prime}$ e $T_{G}^{\prime}$, também serão identificadas as seguintes tuplas:

$\left\langle t_{-} g l o b a l, a n c \_\right.$fonte, anc_dest $\rangle \mid G l o b a l '\left(t \_g l o b a l\right)=\left\{a n c \_\right.$fonte, anc_dest\}.

$\left\langle t_{g^{\prime}}, a n c_{-}\right.$fonte $\rangle,\left\langle t_{1}, a n c_{1},\right\rangle, \ldots\left\langle t_{n}, a n c_{n}\right\rangle \mid A n c_{-} F o n t^{\prime}\left(t_{g^{\prime}}\right)=$ anc_fonte, Anc_Font $\left(t_{1}\right)=a n c_{1}, \ldots$ Anc_Font $\left(t_{n}\right)=a n c_{n}$.

$\left\langle t_{g^{\prime}}, a n c \_\right.$fonte, $a n c_{\_}$dest $\rangle,\left\langle t_{1}, a n c_{1}, a n c \_d e s t\right\rangle, \ldots\left\langle t_{n}, a n c_{n}, a n c_{-}\right.$dest $\rangle \mid$ $A n c_{-} D e s t^{\prime}\left(t_{g^{\prime}}, a n c_{-}\right.$fonte $)=a n c \_d e s t, A n c_{-} D e s t^{\prime}\left(t_{1}, a n c_{1}\right)=a n c \_d e s t, \ldots$ Anc_Dest $\left(t_{n}, a n c_{n}\right)=$ anc_dest.

Nesse contexto, de acordo com o exemplo ilustrado para a mensagem Cria_Nova_Ligacao, pode-se definir $H$ como sendo Curso, ou seja, a aplicação passada como parâmetro e na qual deseja-se criar uma nova ligação global. Enquanto que $H^{\prime}$, a aplicação resultante da realização dessa operação, seria definida como Curso', na qual:

$\exists a n c_{-}$fonte, anc_dest, $a n c_{1}, \ldots a n c_{n} \in A n c^{\prime}$,

$\exists t g^{\prime}, t_{1}, \ldots t_{n} \in T^{\prime} \mathrm{e}$

$\exists t \_$global $\in T_{G}^{\prime}$, tal que:

Sejam $d o c^{\prime}, d o c^{\prime \prime} \in D o c^{\prime}$ os documentos nos quais as âncoras anc_fonte e anc_dest encontram-se contextualizadas, respectivamente, de forma que $A n c_{\_} D o c^{\prime}\left(a n c_{-} f o n t e\right)=d o c^{\prime}$ e $A n c_{-} D o c^{\prime}\left(a n c_{-} d e s t\right)=d o c^{\prime \prime}$. Dessa forma:

A localização fisica de $d o c^{\prime}$ e $d o c^{\prime \prime}$ é tal que:

$D o c \_L o c a l i z a c a o^{\prime}\left(d o c^{\prime}\right)=$ arquivo_fonte_localizacao onde arquivo_fonte_localizacao $=/$ users/amiotto/teste1.tex; $\mathrm{e}$ Doc_Localizacao $\left(d o c^{\prime \prime}\right)=$ arquivo_destino_localizacao onde arquivo_destino_localizacao $=/$ users/amiotto/teste2.tex.

A localização física de $a n c_{-}$fonte e anc_dest é tal que:

Anc_LLocalizacao' (anc_fonte) $=$ ancora_fonte_localizacao onde ancora_fonte_localizacao $=13 \sharp 14 \sharp ; \mathrm{e}$ 
Anc_Localizacao $\left(a n c \_d e s t\right)=$ ancora_destino_localizacao

onde ancora_destino_localizacao $=33 \sharp 34 \sharp$.

Finalmente, seja aplicativo $\in$ Aplicativos' o aplicativo responsável pela apresentação de $d o c^{\prime}$ e $d o c^{\prime \prime}$ tal que $V$ isualizacao' $\left(d o c^{\prime}\right)=$ aplicativo e Visualizacao $\left(\right.$ doc $\left.^{\prime \prime}\right)=$ aplicativo onde aplicativo $=\langle$ Latex, Editor de texto $\rangle$.

Deve-se observar que para as âncoras restantes $\left(a n c_{1}, \ldots a n c_{n}\right)$ sua localização fisica, bem com sua identificação no conjunto de âncoras será resultado de uma busca realizada em todos os documentos da especificação OXHMBS correntemente manipulada. Essa busca tem como objetivo identificar todas as ligações que possuem âncoras fonte cujo conteúdo é igual ao da âncora fonte especificada (anc_fonte), e cujo destino é igual a anc_dest.

\section{- Se a nova ligação criada for do tipo local, então:}

Todos os elementos de $H^{\prime}$ permanecem iguais aos de $H$, com exceção de $A n c^{\prime}$ e $H y p^{\prime}$, de forma que:

$A n c^{\prime}=A n c \cup\left\{a n c_{-}\right.$fonte, anc_dest $\} \cup\left\{a n c_{1}, \ldots a n c_{n}\right\}(n \geq 0)$, e os elementos de $H y p^{\prime}$ permanecem iguais aos de $H y p$ com exceção de $T_{L}^{\prime}=T_{L} \cup\left\{t_{-}\right.$local $\}$ e $T^{\prime}$ onde $T^{\prime}=T \cup\left\{t_{l^{\prime}}\right\} \cup\left\{t_{1}, \ldots t_{n}\right\}(n \geq 0)$ se e somente se $L l\left(t_{-}\right.$local $)=$ $\left\{t_{l^{\prime}}\right\} \cup\left\{t_{1}, \ldots t_{n}\right\}$.

Com base nesses novos elementos dos conjuntos $A n c^{\prime}, T^{\prime}$ e $T_{L}^{\prime}$, também serão identificadas as seguintes tuplas:

$\left\langle t_{-}\right.$local, anc_fonte, anc_dest $\rangle \mid$Local $^{\prime}\left(t_{-}\right.$local $)=\left\{a n c \_\right.$fonte, anc_dest\}.

$$
\left\langle t_{l^{\prime}}, a n c_{\text {f fonte }}\right\rangle,\left\langle t_{1}, a n c_{1},\right\rangle, \ldots\left\langle t_{n}, a n c_{n}\right\rangle \mid A n c_{-} F o n t^{\prime}\left(t_{l^{\prime}}\right)=a n c_{-} \text {fonte, }
$$
$A n c_{-} F o n t^{\prime}\left(t_{1}\right)=a n c_{1}, \ldots$ Anc_Font ${ }^{\prime}\left(t_{n}\right)=a n c_{n}$.

$\left\langle t_{l^{\prime}}, a n c \_\right.$fonte, anc_dest $\rangle,\left\langle t_{1}, a n c_{1}, a n c \_d e s t\right\rangle, \ldots\left\langle t_{n}, a n c_{n}, a n c \_d e s t\right\rangle \mid$ $A n c \_D e s t^{\prime}\left(t_{l^{\prime}}, a n c \_\right.$fonte $)=a n c \_d e s t, A n c \_D e s t^{\prime}\left(t_{1}, a n c_{1}\right)=a n c \_d e s t, \ldots$ $A n c \_D e s t^{\prime}\left(t_{n}, a n c_{n}\right)=a n c \_d e s t$.

Nesse contexto, de acordo com o exemplo ilustrado para a mensagem Cria_Nova_Ligacao, pode-se definir $H$ como sendo Curso, ou seja, a aplicação passada como parâmetro e na qual deseja-se criar uma nova ligação local. Enquanto que $H^{\prime}$, a aplicação resultante da realização dessa operação, seria definida como Curso', na qual:

$\exists a n c \_$fonte, anc_dest, $a n c_{1}, \ldots a n c_{n} \in A n c^{\prime}$, 
$\exists t_{l^{\prime}}, t_{1}, \ldots t_{n} \in T^{\prime} \mathrm{e}$

$\exists t \_l o c a l \in T_{L}^{\prime}$, tal que:

Sejam $d o c^{\prime}, d o c^{\prime \prime} \in D o c^{\prime}$ os documentos nos quais as âncoras anc_fonte e anc_dest encontram-se contextualizadas, respectivamente, de forma que $A n c \_D o c^{\prime}\left(a n c \_\right.$fonte $)=d o c^{\prime}$ e $A n c_{-} D o c^{\prime}\left(a n c_{-} d e s t\right)=d o c^{\prime \prime}$. Dessa forma:

A localização física de $d o c^{\prime}$ e $d o c^{\prime \prime}$ é tal que:

Doc_Localizacao $\left(d o c^{\prime}\right)=$ arquivo_fonte_localizacao onde arquivo_fonte_localizacao $=/$ users/amiotto/testel.tex; $\mathrm{e}$ Doc_Localizacao $\left(\right.$ doc $\left.^{\prime \prime}\right)=$ arquivo_destino_localizacao onde arquivo_destino_localizacao $=$ /users/amiotto/teste2.tex.

A localização fisica de anc_fonte e anc_dest é tal que:

Anc_Localizacao $\left(a n c \_f o n t e\right)=$ ancora_fonte_localizacao onde ancora_fonte_localizacao $=13 \sharp 14 \sharp$; $\mathrm{e}$ Anc_Localizacao $\left(a n c \_d e s t\right)=a n c o r a \_d e s t i n o \_l o c a l i z a c a o$ onde ancora_destino_localizacao $=33 \sharp 34 \sharp$.

Finalmente, seja aplicativo $\in$ Aplicativos' $^{\prime}$ o aplicativo responsável pela apresentação de $d o c^{\prime}$ e doc' tal que Visualizacao $\left(d o c^{\prime}\right)=$ aplicativo e Visualizacao $\left(\right.$ doc $\left.^{\prime \prime}\right)=$ aplicativo onde aplicativo $=\langle$ Latex, Editor de texto $\rangle$.

Deve-se observar que para as âncoras restantes $\left(a n c_{1}, \ldots a n c_{n}\right)$ sua localização fisica, bem com sua identificação no conjunto de âncoras, será resultado de uma busca realizada no documento $(d o c)$ em que a âncora fonte (anc_fonte) encontra-se contextualizada. Essa busca tem como objetivo identificar todas as ligações que possuem âncoras fonte cujo conteúdo é igual ao da âncora fonte (anc_fonte) especificada e cujo destino é igual a anc_dest.

\section{Nome da Mensagem: Seguir_Ligacao.}

Uso: Usada pelos aplicativos hipermídia habilitados para a obtenção da(s) âncora(s) destino de uma determinada âncora fonte.

Formato: Nome_usuario, id_aplicativo, arquivo_localizacao, ancora_localizacao.

Resposta: $\{\text { id_aplicativo,arquivo_localizacao,ancora_localizacao }\}^{*}$.

Exemplo: amiotto@icmc.sc.usp.br, Latex, /users/amiotto/teste1.tex, 13\#14\#.

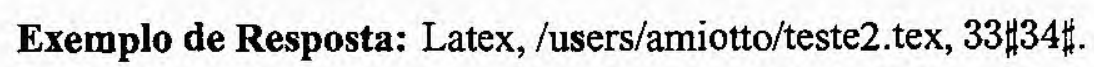

\section{Dados extraídos:}


Seja Lista_Dest $:$ Ancoras_Fonte $\rightarrow 2^{\text {Anc }}$ (nova função criada no OXHMBS) a função que define o conjunto de âncoras destino de uma determinada âncora fonte, tal que:

Lista_Dest $(a n c)=\operatorname{Lista}_{d} \leftrightarrow \forall t \in T \mid\left(\right.$ Anc_Dest $(t, a n c)=a n c \_d e s t \wedge$

$$
\left.a n c \_ \text {dest } \neq a_{\emptyset}\right) \rightarrow a n c_{-} \text {dest } \in \text { Lista }_{d}
$$

onde Lista $_{d} \subseteq$ Anc e Ancoras_Fonte $=$ range $\left(A n\right.$ An_Font $\left._{-}\right) \backslash\left\{a_{\emptyset}\right\}$

Seja anc $\in$ Anc a âncora fonte (cuja localização fisica é $13 \sharp 14 \sharp$, passada como parâmetro) que deseja-se seguir. Dessa forma, através da função Lista_Dest é possível obter o conjunto de âncoras destino de anc, de forma que (particularmente para o exemplo apresentado acima):

Seja Lista_Dest $(a n c)=\left\{a n c^{\prime}\right\}$, onde $\left\{a n c^{\prime}\right\}$ corresponde ao conjunto de âncoras destino de anc que será retornado como resposta dessa mensagem.

A localização fisica da âncora destino de $a n c$, é dada por:

Anc_Localizacao $\left(a n c^{\prime}\right)=$ ancora_localizacao onde ancora_localizacao $=33 \sharp 34 \sharp$.

Seja $d o c \in D o c$ o documento no qual $a n c^{\prime}$ encontra-se contextualizada, de forma que $A n c_{-} D o c\left(a n c^{\prime}\right)=d o c$. A localização fisica de doc, dessa forma, é definida por:

Localizacao_Doc $($ doc $)=$ arquivo_localizacao, onde (nesse exemplo) arquivo_localizacao $=/$ users/amiotto/teste2.tex.

Finalmente, seja aplicativo $\in$ Aplicativos o aplicativo responsável pela apresentação de doc, tal que:

Visualizacao $($ doc $)=$ aplicativo onde aplicativo $=($ Latex, Editor de texto $)$.

\section{Nome da Mensagem: Ancora_Removida.}

Uso: Usada pelos aplicativos hipermídia habilitados para a remoção de uma âncora fonte (e conseqüentemente a remoção da ligação associada a essa) de um determinado documento.

Formato: Nome_usuario, id_aplicativo, arquivo_localizacao, ancora_localizacao, aplicacao.

Resposta: aplicacao'.

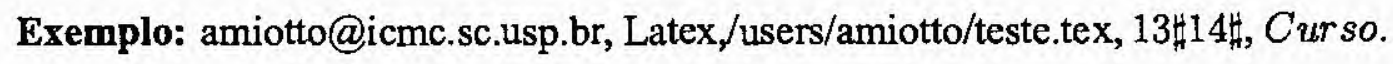

Exemplo de Resposta: Curso'.

Dados extraídos: 
Seja $H=\langle$ Hyp,Doc, Anc, M, Anc_Doc,Anc_Font, Anc_Dest, Bidirecional, Global, Local, Raiz, Base_Lig, Autorizacao, Aplicativos,Visualizacao, L, Lista_Dest, Lista_Anc,Doc_Tipo,_Doc_Localizacao,Anc_Localizacao) a aplicação hipermídia especificada através do OXHMBS (passada como parâmetro); e

$H y p=\left\langle S, \rho, \Psi, \delta, \gamma, \tau, L S C, T \_\right.$hist $\left., V, C, E, T, A c, T_{S}, T_{B}, T_{G}, T_{L}, B i d, G l, L l\right\rangle$, o hyperchart estendido que representa a estrutura (base de ligações) dessa aplicação hipermidia.

Nesse contexto, após a realização da remoção de uma âncora, uma nova aplicação hiper-

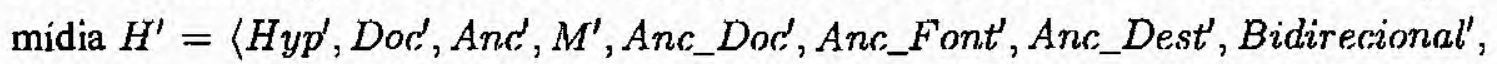
Global', Local', Raiz', Base_Lig', Autorizacao', Aplicativos', Visualizacad', L', Lista_Dest', Lista_Anc',Doc_Tipo',Doc_Localizacao', Anc_Localizacao $\left.{ }^{\prime}\right\rangle$ será especificada, tal que:

Todos os elementos de $H^{\prime}$ permanecem iguais aos de $H$, com exceção de $A n c^{\prime}$ e $H y p^{\prime}$, de forma que:

$A n c^{\prime}=A n c-\left\{a n c \_\right.$fonte $\}$onde anc_fonte corresponde a âncora que será removida; e

Os elementos de $H y p^{\prime}$ permanecem iguais aos de $H y p$ com exceção de $T^{\prime}$, onde $T^{\prime}=$ $T-\left\{t_{-}\right.$fonte $\mid$Anc_Font $\left(t_{-}\right.$fonte $)=a n c \_$fonte $\}$onde $t_{-}$fonte corresponde a ligação associada a âncora removida.

É importante ressaltar que a remoção da ligação associada a âncora fonte retirada do documento previne a existência de ligações inconsistentes.

Obviamente, todas as tuplas que tenham como elemento anc_fonte ou $t$ f fonte não serão mais identificadas.

Nesse contexto, de acordo com o exemplo ilustrado para a mensagem Remove_Ancora, pode-se definir $H$ como sendo Curso, ou seja, a aplicação passada como parâmetro e na qual deseja-se remover uma âncora fonte (e conseqüentemente a ligação associada a essa). Enquanto que $H^{\prime}$, a aplicação resultante da realização dessa operação, seria definida como Curso'.

A localização fisica de anc_fonte é passada como parâmetro, e é definida como $13 \sharp 14$, tal que:

Anc_Localizacao $($ anc_fonte $)=13 \sharp 14 \sharp$.

A localização fisica do documento $d o c \in D o c$ que contextualiza anc_fonte (Anc_Doc $\left(a n c \_f o n t e\right)=d o c$ ) também é passada como parâmetro e é definida como /users/amiotto/teste.tex, tal que: 
Doc_Localizacao $($ doc $)=/$ users/amiotto/teste.tex.

Dessa forma, tanto a âncora fonte (anc_fonte) quanto a ligação associada ( $t$ _fonte) a essa, deverão ser removidas da especificação OXHMBS.

4. Nome da Mensagem: Solicita_Lista_Ancoras.

Uso: Usada pelos aplicativos hipermidia habilitados para solicitação da lista de âncoras de um determinado documento.

Formato: Nome_usuario, id_aplicativo, arquivo_localizaao.

Resposta: $\{\text { ancora_localizacao }\}^{*}$.

Exemplo: amiotto@icmc.sc.usp.br, Latex, /users/amiotto/teste.tex.

Exemplo de Resposta: $23 \sharp 24 \sharp, 33 \sharp 34 \sharp$.

Dados extraídos:

Seja $d o c \in D o c$ o documento (passado como parâmetro da mensagem) do qual a lista de âncoras esta sendo solicitada, tal que: Localizacao_Doc(doc) $=$ arquivo_localizacao, onde arquivo_localizacao $=$ /users/amiotto/teste.tex.

Seja aplicativo $\in$ Aplicativos o aplicativo responsável pela apresentação de doc, tal que: Visualizacao $($ doc $)=$ aplicativo onde aplicativo $=\langle$ Latex, Editor de texto $\rangle$.

Dessa forma, através da função Lista_Anc é possivel a obtenção do conjunto de âncoras de doc, de forma que (particularmente para o exemplo apresentado acima):

Seja Lista_Anc(doc) $=\left\{a n c^{\prime}, a n c^{\prime \prime}\right\}$, ou seja o conjunto de âncoras de doc é dado por $\left\{a n c^{\prime}, a n c^{\prime \prime}\right\}$. Onde, a localização fisica de $a n c^{\prime}$ e $a n c^{\prime \prime}$, é tal que:

Anc_Localizacao $\left(a n c^{\prime}\right)=$ ancora_localizacao onde ancora_localizacao ${ }^{\prime}=23 \sharp 24 \sharp$; Anc_Localizacao $\left(a n c^{\prime \prime}\right)=$ ancora_localizacao ${ }^{\prime \prime}$ onde ancora_localizacao" $=33 \sharp 34 \sharp$.

\subsubsection{Protocolo Multiusuário}

As mensagens do protocolo Multiusuário são relevantes quando vários usuários estão simultaneamente compartilhando as mesmas especificações OXHMBS (ou seja, as mesmas aplicações hipermídia). Basicamente esse protocolo oferece suporte para bloqueios e notificação de eventos.

As mensagens do protocolo Multiusuário são divididas em dois tipos:

Mensagens do HSP para os aplicativos hipermídia habilitados. 
1. Nome da Mensagem: Define_Modo_Acesso.

Uso: Usada para informar aos aplicativos hipermídia habilitados sobre o status do bloqueio de um determinado documento.

Formato: id_aplicativo,arquivo_localizacao.

Resposta: cod_resposta.

Exemplo: Latex, /users/amiotto/teste.tex.

Dados extraídos: ${ }^{12}$

Seja $d o c \in$ Doc o documento do qual deseja-se informar para os aplicativos hipermídia habilitados o tipo de bloqueio, tal que:

Doc_Localizacao $(d o c)=$ arquivo_localizacao, onde (nesse exemplo) arquivo_localizacao $=/$ users/amiotto/teste.tex.

Seja aplicativo $\in$ Aplicativos o aplicativo responsável pela apresentação de doc e que será informado sobre o tipo de bloqueio desse, tal que:

Visualizacao $($ doc $)=$ aplicativo onde aplicativo $=($ Latex, Editor de texto $)$.

2. Nome da Mensagem: Alteracao_Documento.

Uso: Usada para informar aos aplicativos hipermídia habilitados que um determinado documento foi alterado por um outro cliente hipermídia.

Formato: id_aplicativo,arquivo_localizacao.

Resposta: cod_resposta.

Exemplo: Latex, /users/amiotto/teste.tex.

\section{Dados extraídos:}

Seja $d o c \in D o c$ o documento que foi alterado por outro cliente hipermídia, tal que: Doc_Localizacao(doc) $=$ arquivo_localizacao, onde (nesse exemplo) arquivo_localizacao $=/$ users/amiotto/teste.tex.

Seja aplicativo $\in$ Aplicativos o aplicativo responsável pela apresentação de doc, tal que: Visualizacao $($ doc $)=$ aplicativo onde aplicativo $=\langle$ Latex, Editor de texto $\rangle$.

Esse aplicativo deve ser informado sobre qualquer alteração realizada em doc.

\section{Mensagens dos aplicativos hipermídia habilitados para o HSP.}

\footnotetext{
${ }^{12} \mathrm{Em}$ um HSP que suporte o OXHMBS, as informações obtidas dessa mensagem (especificada pelo OHP) e utilizadas pelos aplicativos serão conforme apresentado.
} 
1. Nome da Mensagem: Inicializa_Documentos.

Uso: Usada para solicitar a inicialização dos documentos de uma determinada especificação OXHMBS (aplicação hipermídia).

Formato: Nome_usuario,id_aplicativo, $\{\text { arquivo_localizao }\}^{*}$.

Resposta: cod_resposta.

Exemplo: amiotto@icmc.sc.usp.br, Latex, /users/amiotto/teste.tex.

Dados extraídos: ${ }^{13}$

Seja doc $\in$ Doc o documento que deve ser inicializado pelo HSP, tal que:

Doc_Localizacao $($ doc $)=$ arquivo_localizacao onde arquivo_localizacao =/users/amiotto/testel.tex (a localização física desse documento é passada como parâmetro da mensagem pelos aplicativos hipermidia habilitados).

Seja aplicativo $\in$ Aplicativos o aplicativo responsável pela apresentação de doc, tal que:

Visualizacao $($ doc $)=$ aplicativo onde aplicativo $=\langle$ Latex, Editor de texto $\rangle$.

2. Nome da Mensagem: Assina_Informacoes_Doc.

Uso: Usada quando um cliente hipermidia deseja receber informações sobre operações realizadas em conjunto de documentos.

Formato: Nome_usuario,id_aplicativo, $\{\text { arquivo_localizacao }\}^{*}$.

Resposta: cod_resposta.

Exemplo: amiotto@icmc.sc.usp.br, Latex, /users/amiotto/teste.tex.

\section{Dados extraídos:}

Seja doc $\in D o c$ o documento do qual o usuário "amiotto@icmc.sc.usp.br" deseja receber informações, tal que: Doc_Localizacao $($ doc $)=$ arquivo_localizacao, onde arquivo_localizacao $=/$ users/amiotto/teste.tex (a localização física desse documento é passada como parâmetro da mensagem pelos aplicativos hipermidia habilitados).

Seja aplicativo $\in$ Aplicativos o aplicativo responsável pela apresentação de doc, tal que: $V$ isualizacao $(d o c)=$ aplicativo onde aplicativo $=\langle$ Latex, Editor de texto $\rangle$.

3. Nome da Mensagem: Cancela_Assinatura_Informacoes.

Uso: Usada quando um cliente hipermídia não deseja mais receber informações sobre operações realizadas em um conjunto de documentos.

\footnotetext{
${ }^{13}$ Em um HSP que suporte o OXHMBS, as informações obtidas dessa mensagem (especificada pelo OHP) e utilizadas pela base de especificações serão conforme apresentado.
} 
Formato: Nome_usuario,id_aplicativo, $\{\text { arquivo_localizacao }\}^{*}$.

Resposta: cod_resposta.

Exemplo: amiotto@icmc.sc.usp.br, Latex, /users/amiotto/teste.tex.

\section{Dados extraídos:}

Seja doc $\in$ Doc o documento do qual o usuário "amiotto@icmc.sc.usp.br"não deseja mais receber informações, tal que:

Doc_Localizacao $(d o c)=$ arquivo_localizacao onde arquivo_localizacao =/users/amiotto/teste.tex (a localização física desse documento é passada como parâmetro da mensagem pelos aplicativos hipermídia habilitados).

Seja aplicativo $\in$ Aplicativos o aplicativo responsável pela apresentação de $d o c$, tal que: Visualizacao $($ doc $)=$ aplicativo onde aplicativo $=\langle$ Latex, Editor de texto $\rangle$.

4. Nome da Mensagem: Modifica_bloqueio.

Uso: Usada pelos aplicativos hipermidia habilitados para alterar o bloqueio de um determinado documento.

Formato: Nome_usuario,id_aplicativo, arquivo_localizacao,valor_bloqueio.

Resposta: cod_resposta.

Exemplo: amiotto@icmc.sc.usp.br, Latex, /users/amiotto/teste.tex, 1.

\section{Dados extraídos:}

Seja $d o c \in D o c$ o documento que terá seu bloqueio alterado, tal que:

Doc_Localizacao $($ doc $)=$ arquivo_localizacao onde arquivo_localizacao $=$ /users/amiotto/teste.tex (a localização fisica desse documento é passada como parâmetro da mensagem pelos aplicativos hipermídia habilitados).

Seja aplicativo $\in$ Aplicativos o aplicativo responsável pela apresentação de doc, tal que: Visualizacao $($ doc $)=$ aplicativo onde aplicativo $=\langle$ Latex, Editor de texto $\rangle$.

5. Nome da Mensagem: Solicita_Bloqueio.

Uso: Usada pelos aplicativos hipermídia habilitados para solicitar o status do bloqueio de um determinado documento.

Formato: Nome_usuario,id_aplicativo,arquivo_localizacao.

Resposta: cod_resposta.

Exemplo: amiotto@icmc.sc.usp.br, Latex, /users/amiotto/teste.tex. 


\section{Dados extraídos:}

Seja $d o c \in D o c$ o documento do qual se deseja verificar o status do bloqueio, tal que: Doc_Localizacao $($ doc $)=$ arquivo_localizacao, onde arquivo_localizacao $=$ /users/amiotto/teste.tex (a localização fisica desse documento é passada como parâmetro da mensagem pelos aplicativos hipermidia habilitados).

Seja aplicativo $\in$ Aplicativos o aplicativo responsável pela apresentação de doc, tal que: Visualizacao $($ doc $)=$ aplicativo onde aplicativo $=\langle$ Latex, Editor de texto $)$.

\section{Nome da Mensagem: Solicita_Usuarios_Ativos.}

Uso: Usada pelos aplicativos hipermídia habilitados para solicitar a lista de usuários correntemente ativos em uma determinada especificação OXHMBS (aplicação hipermídia).

Formato: Nome_usuario,id_aplicativo, aplicacao.

Resposta: $\{\text { Nome_usuario }\}^{*}$.

Exemplo: amiotto@icmc.sc.usp.br, Latex, Curso.

Exemplo de Resposta: renata@icmc.sc.usp.br, aline@icmc.sc.usp.br.

\section{Dados extraídos:}

Seja Curso a especificação OXHMBS, ou seja, a aplicação hipermídia que deseja-se verificar quais são os usuários correntemente ativos.

Sejam renata@icmc.sc.usp.br e aline@icmc.sc.usp.br os usuários que estão correntemente utilizando tal aplicação e que serão enviados como resposta dessa mensagem.

\subsection{Considerações Finais}

Neste capitulo foram apresentadas as principais propostas de extensão ao XHMBS e à técnica Hypercharts para torná-los adequados à especificação de aplicações em sistemas hipermidia abertos.

Dessa forma, no contexto dos requisitos das aplicações em sistemas hipermidia abertos descritos na Seção 2.4, foram apresentadas para cada um dos requisitos não suportados pelo XHMBS as propostas de extensões para a adequação do modelo OXHMBS a esses. Enquanto que para os requisitos suportados foi apresentada uma descrição de como o XHMBS e, conseqüentemente o OXHMBS, os suportam.

As reformulações realizadas no XHMBS podem ser classificadas em dois niveis: 
- Referente a técnica Hypercharts subjacente ao modelo (Hypercharts Estendido), na qual foram incorporados elementos para possibilitar a especificação de ligações bidirecionais, globais e locais, presentes na maioria das aplicações em sistemas hipermídia abertos.

- Referente ao modelo XHMBS propriamente (OXHMBS), no qual foram reformulados alguns elementos de sua notação, tais como: a função $A$ que foi substituída pelas funções Anc_Font e Anc_Dest, com o objetivo de permitir a especificação de ligações especificas; e a substituição dos canais de apresentação e distribuição, utilizados na definição da semântica de navegação do XHMBS, pela especificação de mensagens do protocolo OHP.

Também foram definidos novos elementos no modelo (tais como: o conjunto Raiz e as funções Base_Lig e Autorizacao), com o objetivo de adaptá-lo a algumas necessidades específicas das aplicações em sistemas hipermídia abertos.

No próximo capitulo será apresentada uma definição detalhada e completa do modelo OXHMBS com base nas extensões (propostas) apresentadas ao longo deste capitulo. Como exercício de validação será apresentado um exemplo de uma aplicação em sistema hipermídia aberto real especificada em OXHMBS. Também será apresentada uma análise das especificações OXHMBS em termos dos requisitos das aplicações em sistemas hipermídia abertos. Além disso, foi observado como as propriedades inerentes ao formalismo subjacente ao modelo efetivamente auxiliam a especificação das aplicações em sistemas hipermídia abertos. 


5

\section{Especificação do modelo OXHMBS}

\subsection{Considerações Iniciais}

O modelo OXHMBS é uma extensão do modelo XHMBS e sua principal característica é a capacidade de especificação de aplicações em sistemas hipermídia abertos. Além disso, outros requisitos relativos às aplicações hipermídia se tornam passíveis de especificação pelo OXHMBS devido às inovações incorporadas a esse modelo. Entre as inovações apresentadas pelo modelo OXHMBS estão a possibilidade de especificação de ligações especificas, bidirecionais, locais e globais, e também a possibilidade de especificação de bases de ligações públicas e privadas. Como modificações de maior impacto, estão a substituição da técnica Hypercharts por Hypercharts Estendido e a substituição dos canais de apresentação (Pchanells) e distribuição (Cchanells) pela especificação de mensagens do protocolo OHP.

O modelo OXHMBS continua a ser, como o HMBS e o XHMBS, um modelo para o projeto estrutural e navegacional de aplicações hipermídia (com um escopo voltado à aplicações em sistemas hipermídia abertos). Dessa forma, para a especificação de uma aplicação de forma mais completa, é necessário um processo mais abrangente que parta da modelagem semântica da informação e inclua o OXHMBS como modelo da estrutura e da semântica de navegação de uma aplicação hipermídia.

Em termos de notação, o OXHMBS conta com os recursos gráficos de Hypercharts Estendido (e conseqüentemente alguns recursos herdados de Hypercharts e de Statecharts). E para refletir as informações desenvolvidas em Hypercharts Estendido, tabelas representam os 
mapeamentos definidos pelas funções Anc_Doc,Anc_Font, Anc_Dest, Lista_Dest, Global, Local, Lista_Anc, Doc_Tipo, Bidirecional, Autorizacao, Visualizacao, Anc_Localizacao, Doc_Localizacao, Base_Lig.

$\mathrm{Na}$ Seção 5.2 o modelo OXHMBS é definido e suas novas características apresentadas. Com o objetivo de apresentar uma definição completa do OXHMBS, também é apresentada na Seção 5.3 a semântica de navegação desse. Para demonstrar o uso do modelo, na Seção 5.4 é apresentado um exemplo de uma especificação OXHMBS. Finalmente, na Seção 5.5 é apresentada uma análise sobre especificações OXHMBS.

\subsection{Aplicação hipermídia especificada em OXHMBS}

As aplicações em sistemas hipermídia abertos, segundo o modelo OXHMBS, são extensões de aplicações hipermídia definidas pelo modelo XHMBS. As idéias básicas de estruturação e semântica de navegação do XHMBS (e conseqüentemente do HMBS) foram mantidas, de modo que a filosofia de especificação permaneceu a mesma. Dessa forma, uma aplicação hipermídia $H$ em OXHMBS é definida como:

Definição 3 Seja $H=\left\langle H y p, D o c, A n c, M, A n c_{-}\right.$Doc,Anc_Font,Anc_Dest,Bidirecional, Global, Local, Raiz, Base_Lig, Autorizacao, Aplicativos, Visualizacao, L, Lista_Dest, Lista_Anc,Doc_Tipo,Doc_Localizacao, Anc_Localizacao) uma aplicação hipermidia, onde:

- Hyp é um hyperchart estendido definido como a 20-tupla $H y p=\langle S, \rho, \Psi, \delta, \gamma, \tau, L S C$, $\left.T_{\text {Lhist }} V, C, E, T, A c, T_{S}, T_{B}, T_{G}, T_{L}, B i d, G l, L l\right\rangle$ representando, respectivamente, conjunto de estados, função de hierarquia, função de tipo de decomposição, função default, função de história, função história temporal, função relógios locais, função registradores de história temporal, conjunto de expressões, conjunto de condições, conjunto de expressões de eventos, conjunto de transições, conjunto de ações, conjunto de transições sincronizadas, conjunto de transições bidirecionais, conjunto de transições globais, conjunto de transições locais, função de conversão semântica de transições bidirecionais, função de conversão semântica de transições globais e função de conversão semântica de transições locais. Deve-se destacar que os novos elementos introduzidos em Hypercharts Estendido são: $T_{B}, T_{G}, T_{L}, B i d, G l, L l$.

- $D o c \subseteq \mathbb{N} \times M i d i a \times I n f o \times 2^{\text {Info }}$ corresponde ao conjunto de documentos ${ }^{1}$ de uma aplicação hipermídia, que são da forma:

\footnotetext{
${ }^{1}$ Nos modelos HMBS e XHMBS (antecessores do OXHMBS) é utilizado o conceito de páginas ao invés de documentos. Porém, o conceito de documentos é mais amplo e genérico do que o de páginas e mais adequado ao modelo proposto.
} 
〈identificador, conteúdo, título, palavras-chave) $\mid$ identificador $\in \mathbb{N}$, conteúdo $\in$ Midia, título $\in$ Info, palavras-chave $\in 2^{\text {Info }}$. Onde:

$\mathbb{N}$ corresponde ao conjunto dos números Naturais;

Midia corresponde ao conjunto de conteúdos dos documentos que compõem as aplicações hipermídia; e

Info corresponde a um conjunto de sentenças textuais.

É importante ressaltar que o identificador de um documento é único, ou seja:

$\forall d o c_{i}, d o c_{j} \in \operatorname{Doc} \mid\left(d o c_{i}=\left\langle i d_{i}, c_{i}, t_{i}, p_{i}\right\rangle \wedge d o c_{j}=\left\langle i d_{j}, c_{j}, t_{j}, p_{j}\right\rangle\right) \wedge(i \neq j) \rightarrow i d_{i} \neq$ $i d_{j}$.

Como definido originalmente no XHMBS (e no HMBS), o conjunto Doc inclui o documento nulo ou vazio (sem qualquer conteúdo, título ou palavras-chave), representado explicitamente no modelo OXHMBS por $d_{\emptyset}$. Esse documento pode ser associado a estados que não modelam a apresentação da informação, funcionando como artificios de especificação, modelando (por exemplo) a passagem do tempo.

Formalmente, $d_{\emptyset}$ é definido da seguinte forma: $\exists d_{\varnothing} \in D o c \mid d_{\emptyset}=\left\langle i d_{d_{\emptyset}}, \emptyset, \emptyset, \emptyset\right\rangle$.

- Anc $\subseteq \mathbb{N} \times$ Info corresponde ao conjunto de âncoras de uma aplicação hipermídia que são da forma 〈identificador, conteúdo) | identificador $\in \mathbb{N}$, conteúdo $\in$ Info. O conteúdo de uma âncora, normalmente, contém uma porção reduzida de informação como, por exemplo, uma palavra. Para âncoras que não são textuais, o conteúdo dessa refere-se a uma descrição da mesma.

É importante ressaltar que o identificador de uma âncora é único, ou seja:

$\forall a_{i}, a_{j} \in A n c \mid\left(a_{i}=\left\langle i d_{i}, c_{i}\right\rangle \wedge a_{j}=\left\langle i d_{j}, c_{j}\right\rangle\right) \wedge(i \neq j) \rightarrow i d_{i} \neq i d_{j}$.

O conjunto $A n c$ inclui a âncora nula, representada explicitamente nesta extensão por $a_{\mathscr{\emptyset}}$. Da mesma forma que o documento nulo $\left(d_{\emptyset}\right)$, a âncora nula $\left(a_{\emptyset}\right)$ pode estar associada a transições que não modelam ligações hipermídia funcionando, dessa forma, como artificios de especificação.

Formalmente, $a_{\emptyset}$ é definida da seguinte forma: $\exists a_{\varnothing} \in A n c \mid a_{\emptyset}=\left\langle i d_{a_{\emptyset}}, \emptyset\right\rangle$.

- Seja $S_{s}$ um subconjunto de $S$ de forma que $\left\{S_{s} \subseteq S \mid s \in S_{s} \leftrightarrow \Psi(s)=o r \vee \rho(s)=\emptyset\right\}$, tal que $M: S_{s} \rightarrow 2^{D o c}$ corresponde à função que associa a cada estado do subconjunto $S_{s}$ (ou seja, estados básicos ou do tipo or) documentos de uma aplicação hipermídia. Informalmente, a função $M$ representa o mapeamento de correspondência dos estados (elementos de $S_{s}$ ) aos documentos (elementos de Doc) de uma aplicação hipermídia. 
- Anc_Doc $: A n c \rightarrow D o c$ corresponde à função que associa (contextualiza) cada âncora ao documento no qual essa encontra-se inserida (uma definição completa dessa função pode ser observada na Seção 4.2.1).

- Anc_Font : $T \rightarrow$ Anc corresponde à função que associa cada transição, cuja abstração é uma ligação hipermidia, a uma âncora fonte (uma definição completa dessa função pode ser observada na Seção 4.2.1).

- Anc_Dest $: T \times$ Ancoras_Fonte $\rightarrow$ Anc corresponde à função que associa cada âncora fonte (de uma aplicação hipermídia) associada a uma transição de um hyperchart estendido a uma âncora destino correspondente (uma definição completa dessa função pode ser observada na Seção 4.2.1).

- Bidirecional : $T_{B} \rightarrow A n c \times A n c$ corresponde à função que associa a cada transição bidirecional duas âncoras que correspondem aos pontos nos quais a ligação bidirecional sendo especificada pode ser disparada (uma definição completa dessa função pode ser observada na Seção 4.2.2).

- Global : $T_{G} \rightarrow A n c \times A n c$ corresponde à função que associa a cada transição global duas âncoras que correspondem aos pontos nos quais a ligação global sendo especificada pode ser disparada (uma definição completa dessa função pode ser observada na Seção 4.2.3).

- Local : $T_{L} \rightarrow$ Anc $\times$ Anc corresponde à função que associa a cada transição local duas âncoras que correspondem aos pontos nos quais a ligação local sendo especificada pode ser disparada (uma definição completa dessa função pode ser observada na Seção 4.2.4).

- Raiz corresponde ao conjunto formado somente pelo estado raiz de um hyperchart estendido. Esse estado é responsável por encapsular toda base de ligações a que um hyperchart estendido se refere. Dessa forma, o conjunto Raiz é tal que: $\{$ Raiz $\subseteq S \mid s \in R a i z \leftrightarrow$ $(\forall a \in S \rightarrow s \notin \rho(a))\}$.

- Base_Lig : Raiz $\rightarrow$ Tipo corresponde à função que associa à raiz de um hyperchart estendido, ou seja, à base de ligações, um tipo que pode ser pública ou privada.

Onde Tipo $=\{$ pública, privada $\}$ corresponde ao conjunto de tipos possiveis de bases de ligações.

- Autorizacao : Raiz $\rightarrow$ Info corresponde à função que associa às bases de ligações privadas uma senha de acesso (uma definição completa dessa função pode ser observada na Seção 4.4). 
- Aplicativos $\subseteq$ Info $\times$ Info corresponde ao conjunto de aplicativos responsáveis pela apresentação dos documentos de uma aplicação hipermídia. Esses aplicativos são da for$\mathrm{ma}$ 〈identificador, descrição〉 | identificador $\in$ In fo, descrição $\in$ Info (uma definição completa desse conjunto pode ser observada na Seção 4.7).

- Visualizacao $:\left(\operatorname{Doc} \backslash\left\{d_{\mathfrak{g}}\right\}\right) \rightarrow$ Aplicativos corresponde à função que associa a cada documento presente no conjunto de documentos um aplicativo responsável por apresentálo.

- $L$, onde $(L \in \mathbb{N})$, corresponde ao nivel de visibilidade de uma aplicação hipermídia, exatamente como definido pelos modelos HMBS e XHMBS. O autor da aplicação hipermídia pode utilizar o valor de $L$ para definir a profundidade da hierarquia na estrutura especificada pelo hyperchart estendido subjacente a ser apresentada durante a navegação.

- Lista_Dest : Ancoras_Fonte $\rightarrow 2^{\text {Anc }}$ corresponde à função que define o conjunto de âncoras destino de uma determinada âncora fonte (uma definição completa dessa função pode ser observada na Seção 4.8.2 - Mensagem Seguir_Ligacao).

- Lista_Anc $: D o c \rightarrow 2^{A n c}$ corresponde à função que define o conjunto de âncoras de um determinado documento (uma definição completa dessa função pode ser observada na Seção 4.8.2 - Mensagem Envia_Lista_Ancoras).

- Doc_Tipo : $\left(D o c \backslash\left\{d_{g}\right\}\right) \rightarrow$ Tipo_Midia corresponde à função que associa a cada documento de uma aplicação hipermídia um tipo, de acordo com o conteúdo dessa.

Onde Tipo_Midia $=$ \{texto, gráfico, áudio, vídeo, imagem $\}$ corresponde ao conjunto dos tipos possiveis de mídia que podem estar associados aos documentos do OXHMBS.

- Doc_Localizacao : $\left(D o c \backslash\left\{d_{g}\right\}\right) \nrightarrow$ Info corresponde à função ${ }^{2}$ que associa a cada documento de uma aplicação hipermídia (com exceção do documento nulo $d_{\mathfrak{g}}$ ) uma descrição de sua localização física.

- Anc_Localizacao : $\left(A n c \backslash\left\{a_{\emptyset}\right\}\right) \succ I n f o$ corresponde à função que associa a cada âncora (com exceção da âncora nula $a_{\mathfrak{g}}$ ) uma descrição de sua localização física.

\subsection{Semântica de Navegação do modelo OXHMBS}

Uma vez apresentadas as novas características do modelo OXHMBS, também é necessário definir a sua semântica de navegação. Dessa forma, nesta Seção são apresentadas as modificações

\footnotetext{
${ }^{2}$ A cardinalidade dessa função é um para um $(1: 1)$, porque um documento só pode ter uma localização fisica e sua localização fisica refere-se a um único documento.

${ }^{3} \mathrm{~A}$ cardinalidade dessa função é um para um $(1: 1)$, porque uma âncora só pode ter uma localização fisica $\mathrm{e}$ sua localização fisica refere-se a uma única âncora.
} 
realizadas na semântica de navegação do modelo XHMBS que suportam as definições apresentadas pelo OXHMBS.

A diferença básica entre a semântica de navegação dos dois modelos é o uso de Hypercharts pelo XHMBS e o uso de Hypercharts Estendido pelo OXHMBS como técnica de especificação subjacente ao modelo. A idéia central de que as informações são apresentadas conforme as configurações assumidas pela técnica subjacente (neste caso, um hyperchart estendido) permanece inalterada. Porém, a forma com que as informações associadas a um hyperchart estendido são apresentadas foi essencialmente modificada, uma vez que os canais de apresentação e distribuição foram retirados do modelo e substituídos pela definição de um conjunto de mensagens do protocolo OHP (descritas na Seção 4.8).

Dessa forma, as informações contidas nas aplicações especificadas através do modelo OXHMBS são apresentadas pelos aplicativos hipermídia habilitados através de trocas de mensagens definidas pelo protocolo OHP e especificadas no modelo OXHMBS, ou seja, a comunicação entre os documentos e âncoras definidos em uma especificação OXHMBS e os aplicativos responsáveis por sua apresentação é realizada através de seqüências de mensagens.

Deve-ser ressaltar que a utilização dessa nova abordagem possibilitou o suporte de funcionalidades hipermídia a partir dos aplicativos integrados ao modelo (habilitando-os, dessa forma, a criar, remover e navegar ligações de uma especificação OXHMBS), uma vez que foram especificadas tanto as mensagem que são enviadas pelo modelo OXHMBS para os aplicativos hipermídia habilitados, quanto as mensagens enviadas pelos aplicativos hipermídia habilitados para esse.

Assim como nos modelos HMBS e XHMBS, a noção mais elementar da semântica de navegação do OXHMBS é de visitar um documento, uma vez que a apresentação das informações contidas no conteúdo dos documentos de uma aplicação hipermidia é determinada unicamente pela decisão do leitor em seguir uma ligação pela ativação de uma âncora. Dessa forma, o conceito convencional de navegação de aplicações hipermídia, satisfeito no HMBS e no XHMBS, também é satisfeito no OXHMBS.

Para a apresentação das informações de uma aplicação hipermídia, são realizadas trocas de mensagens entre o HSP que suporta o modelo e os aplicativos integrados a esse. Vários documentos podem ser exibidos concorrentemente. O conjunto de documentos exibidos durante um determinado momento da navegação define uma "configuração de contexto corrente de uma aplicação hipermídia $(C C)^{\text {" }}$.

A configuração de contexto corrente $(C C)$ é formada pelos documentos associados aos estados da configuração de estados corrente do hyperchart estendido, além dos documentos que satisfazem o nível de visibilidade $L$ especificado pelo autor da aplicação hipermídia. No trabalho de (Turine, 1998) são apresentadas as implicaçōes semânticas que o nivel de visibilidade 
$L$ impõe sobre uma configuração de contexto qualquer. Essas implicações são herdadas pelo modelo OXHMBS.

Com base na semântica operacional de Hypercharts Estendido, que é descrita em termos da semântica operacional de Statecharts, a semântica de navegação de uma aplicação hipermidia definida pelo modelo OXHMBS é interpretada da seguinte maneira:

Quando o leitor seleciona uma âncora fonte de um documento sendo apresentado por algum aplicativo, através do envio da mensagem Seguir_Ligacao, o HSP realiza as seguintes ações:

1. Identifica o conjunto de âncoras destino da âncora fonte selecionada (através da função Lista_Dest) e apresenta-as aos leitores para que esses decidam por qual destino desejam navegar (resposta da mensagem Seguir_Ligacao).

2. Identifica a transição (ligação abstraída) que associa as âncoras, fonte e destino, selecionadas pelo leitor (através das funções $A n c \_F o n t$ e $A n c \_D e s t$ ) e gera o evento associado a essa transição ${ }^{4}$. Dessa forma, a transição que associa as âncoras selecionadas (fonte $e$ destino) é disparada.

3. Ativa todos os estados que fazem parte do conjunto destino da transição disparada, gerando a próxima configuração de estados e desabilitando a configuração atual. Em seguida, remove da apresentação todas as "janelas lógicas" associadas aos documentos correspondentes aos estados da configuração atual e seus estados ancestrais, segundo o nivel de visibilidade $L$. Essa ação é realizada através do envio da mensagem Fecha_Canal_Ativo para os aplicativos que estavam apresentando os documentos da configuração de estados atual.

4. Define a nova configuração de contexto da aplicação hipermídia como sendo formada pelos documentos associados aos estados da nova configuração de estados, além dos documentos que obedecem ao escopo estabelecido pelo nível de visibilidade $L$ definido pelo autor. Em seguida, através do envio da seqüência de mensagens: Esta_Aberto, Apresenta_Documento, Envia_Lista_Ancoras, Apresenta_Selecao ${ }^{5}$ para cada um dos aplicativos responsáveis pela apresentação de cada um dos documentos da nova configuração de estados, tais documentos (e âncoras contextualizadas nesses) são apresentados.

\footnotetext{
${ }^{4}$ Deve-se observar que para transições bidirecionais, globais e locais, somente as transições básicas associadas a essas (ou seja, a representação com transições básicas equivalente a essas) têm sua semântica descrita e, dessa forma, podem ser disparadas. Os disparos das transições básicas corresponderão semanticamente a disparos das transiçōes bidirecionais, globais e locais a que essas se referem.

${ }^{5}$ Para cada documento, o número de vezes que essa mensagem será enviada depende do número de âncoras contextualizadas nesse, sendo que, é enviada uma mensagem para cada âncora.
} 
É importante ressaltar que foi especificado no modelo OXHMBS um conjunto de mensagens do protocolo OHP, mais amplo do que as mensagens identificadas nesta Seção, necessárias para o estabelecimento de qualquer tipo de comunicação que ocorra entre o modelo OXHMBS e os aplicativos integrados a esse, e necessárias para oferecer suporte ao compartilhamento de documentos por um grupo de leitores.

\subsection{Exemplo de Especificação OXHMBS}

Para um melhor entendimento do modelo OXHMBS e como exercício de validação do mesmo, nesta Seção é apresentado o uso do OXHMBS para a especificação de um exemplo real de uma aplicação em sistema hipermídia aberto.

A aplicação exemplo, apresentada a seguir, foi previamente especificada no protótipo de Sistema Hipermídia Aberto Webvise e, dessa forma, sua especificação nesse também será apresentada.

Apesar do potencial do modelo OXHMBS (herdado dos modelos HMBS e XHMBS) para suportar a especificação de decomposição hierárquica e paralelismo, no exemplo a seguir não abordamos tais características, somente procuramos demonstrar a capacidade de especificação do OXHMBS em termos dos requisitos destacados como relevantes para as aplicações em sistemas hipermidia abertos. Exemplos que abordem essas outras características do OXHMBS podem ser observados em (Paulo, 1997; Turine, 1998).

\subsubsection{Descrição do Exemplo}

O exemplo especificado consiste de uma aplicação típica de sistemas hipermídia abertos, que é composta por um conjunto de documentos em vários formatos ${ }^{6}$ e por um conjunto de ligações sobre esses documentos.

Essa aplicação especifica um conjunto de material de um curso sobre Statecharts, no qual o "professor" deseja manter todo seu material (mais precisamente, referências a ele), que envolve arquivos da $W W W(h t m l)$, arquivos texto $(d o c)$ e planilhas eletrônicas $(x l s)$, em uma Base de Especificações comum, e também deseja criar ligações nesse material (especificas, bidirecionais, globais e locais) sem alterar o conteúdo desses documentos.

Na Figura 5.1 é apresentada a interface da aplicação exemplo no Webvise, onde o conjunto de documentos dessa (nome e localização) pode ser observado à esquerda. À direita, de acordo com o documento selecionado (no exemplo em questão, "Introdução ao Diagrama de Transições de Estados”), pode ser observado o conjunto de ligações desse. O Webvise permite que

\footnotetext{
${ }^{6} \mathrm{Nesse}$ exemplo apenas documentos dos formatos $d o c$, xls e $h t m l$ foram utilizados por causa de limitações do Webvise, que ainda é um protótipo de sistema hipermidia aberto.
} 
algum documento seja selecionado como nó inicial (ou seja, o nó que inicializará a navegação). Nesse exemplo, foi selecionado o documento Statecharts no dia-a-dia (arquivo html) como nó inicial de navegação.

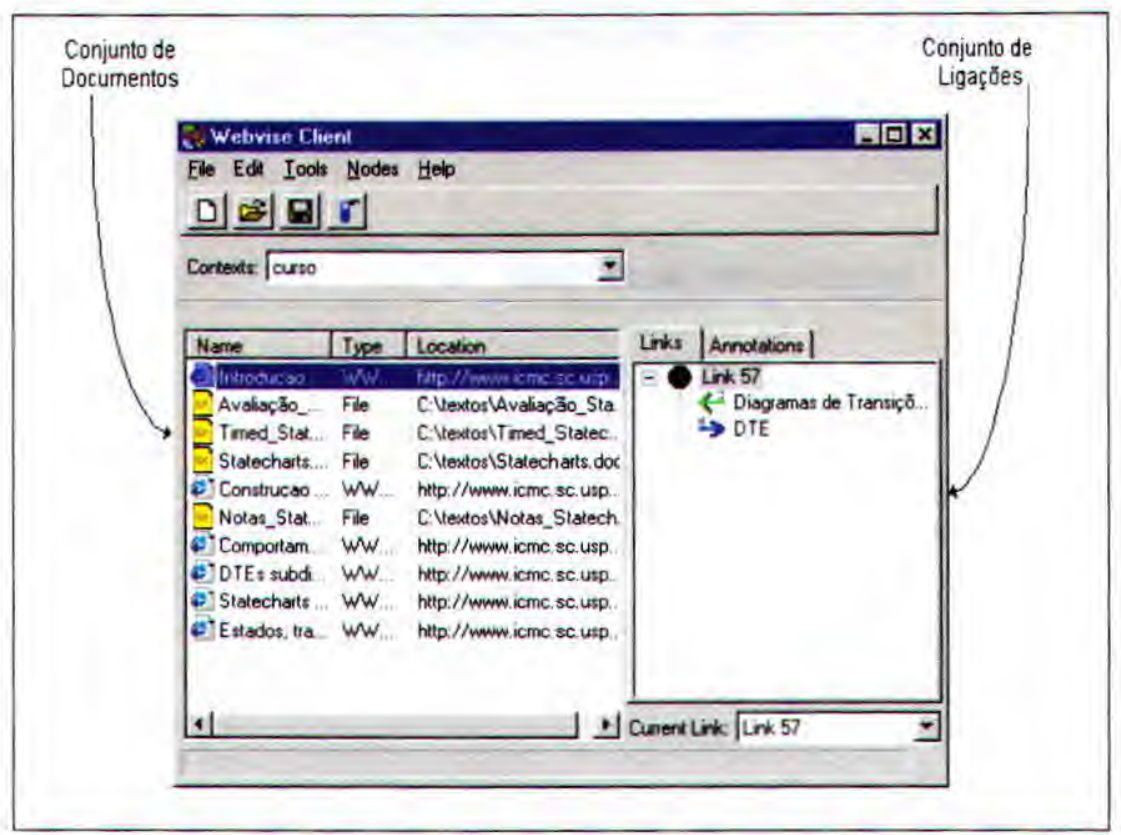

Figura 5.1: Aplicação exemplo especificada no Webvise

A seguir, para cada documento que compõe a aplicação exemplo, é apresentada uma Figura que mostra o conjunto de ligações desse, bem como uma identificação do tipo de cada ligação (Figuras 5.2, 5.3, 5.4, 5.5 e 5.6). Deve-se observar que para alguns documentos não é apresentada nenhuma Figura, uma vez que referências a esses documentos foram inseridas na Base de Especificações, mas nenhuma ligação "de" ou "para" eles foi criada.

É importante ressaltar que como as ligações globais e locais são computadas, suas âncoras fonte só são disponibilizadas durante a apresentação/navegação dos documentos e, dessa forma, não ficam visivelmente disponíveis na Base de Especificações.

\subsubsection{Representação em OXHMBS}

Para a especificação em OXHMBS do exemplo de aplicação em sistema hipermidia aberto descrito na Seção 5.4.1, inicialmente foi definido o hyperchart estendido da Figura 5.7 (ou seja, a base de ligações) relativo à estrutura da aplicação exemplo.

É importante ressaltar que para o leitor (ou usuário) que encontra-se utilizando o OXHMBS como modelo de especificação, as transições pontilhadas não estarão visíveis. Esses poderão observar somente as transições em traço contínuo. As transições pontilhadas são importantes para a execução do hyperchart estendido (ou seja, para a semântica de navegação do modelo) 


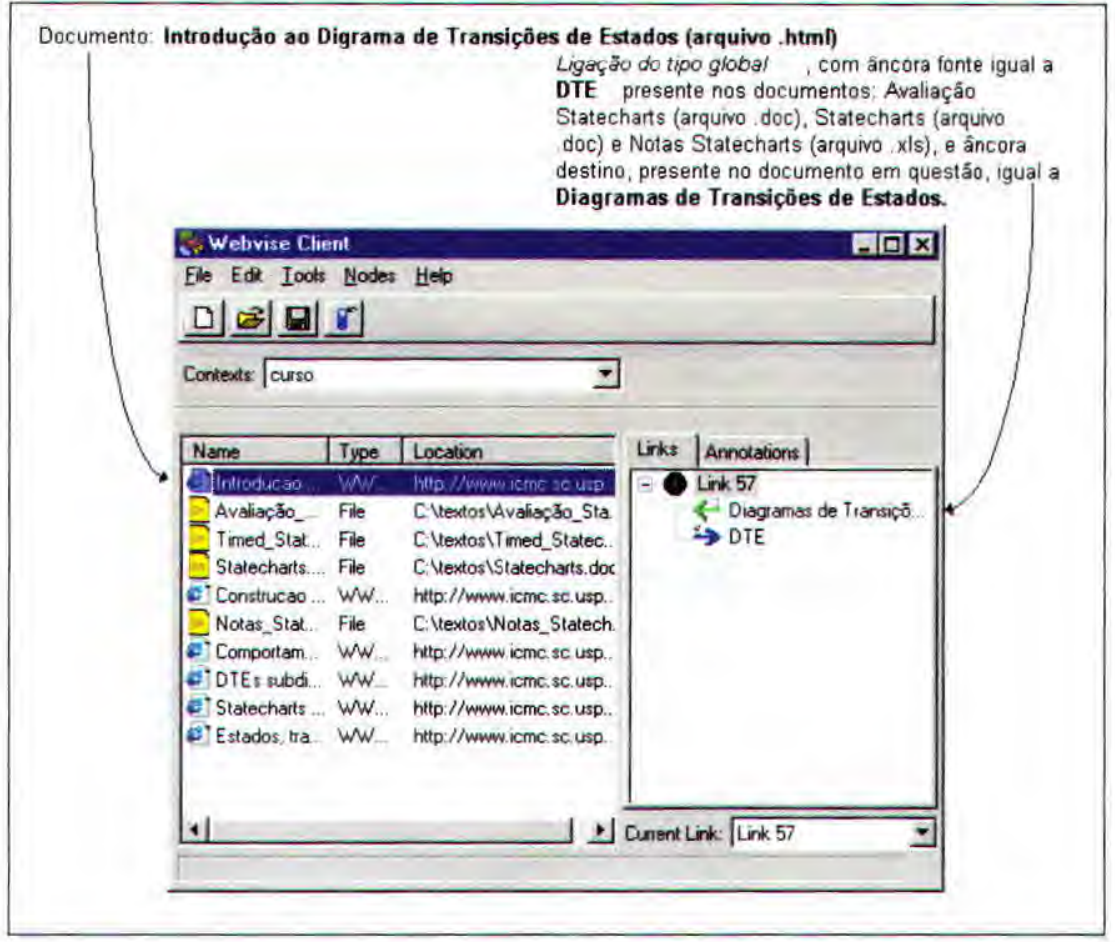

Figura 5.2: Ligações do Documento Introdução ao Diagrama de Transições de Estados

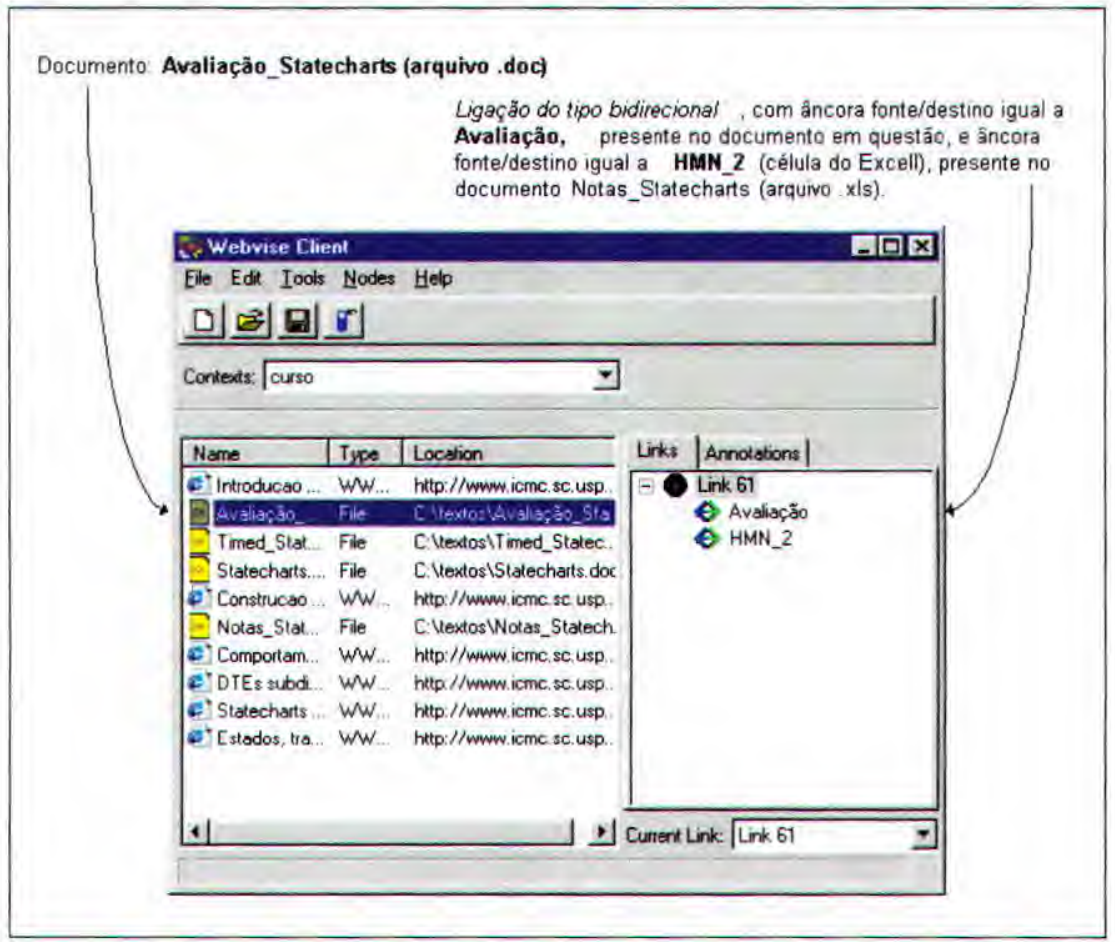

Figura 5.3: Ligações do Documento Avaliação_Statecharts

que especifica a aplicação exemplo, uma vez que serão essas transições que definirão a execução das transições globais, locais e bidirecionais definidas em um nível mais alto de abstração. 


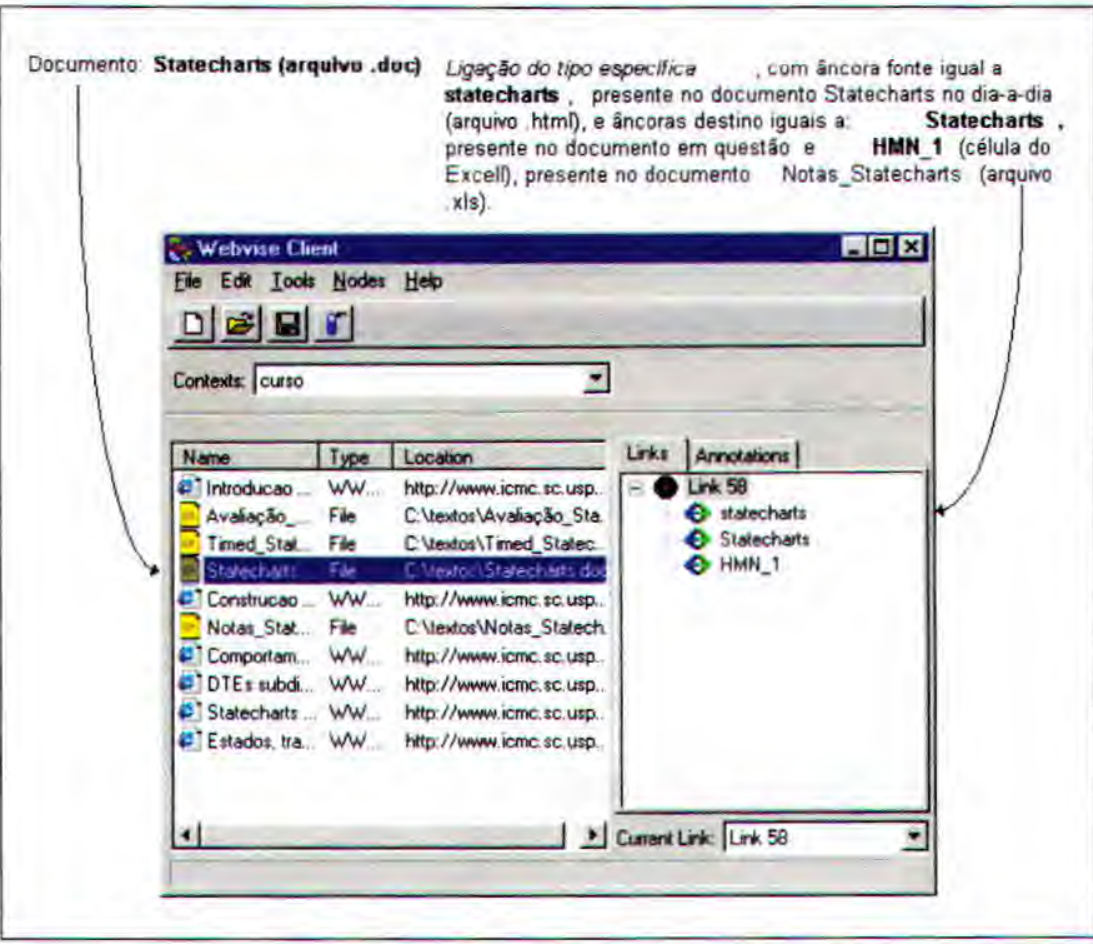

Figura 5.4: Ligações do Documento Statecharts

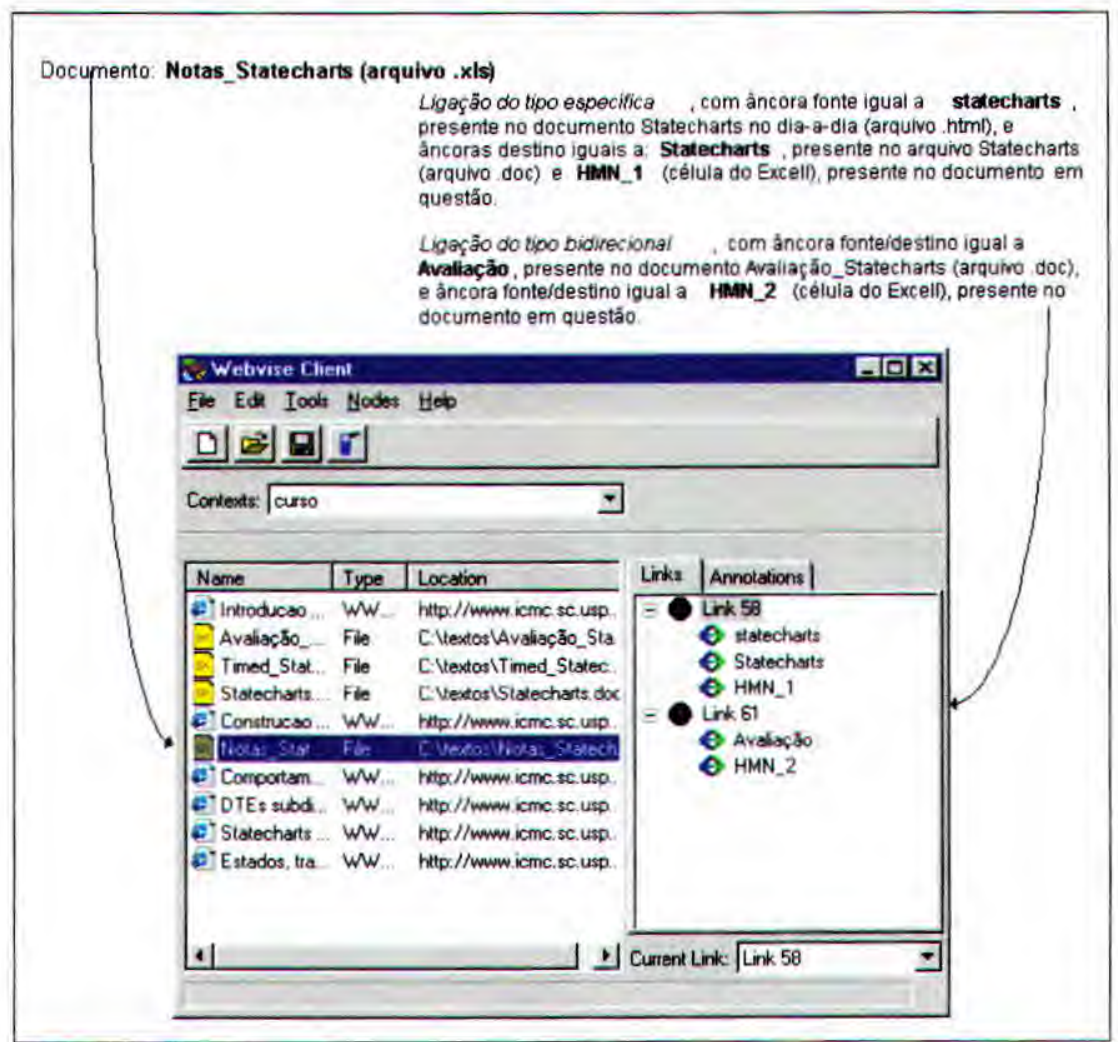

Figura 5.5: Ligações do Documento Notas_Statecharts 


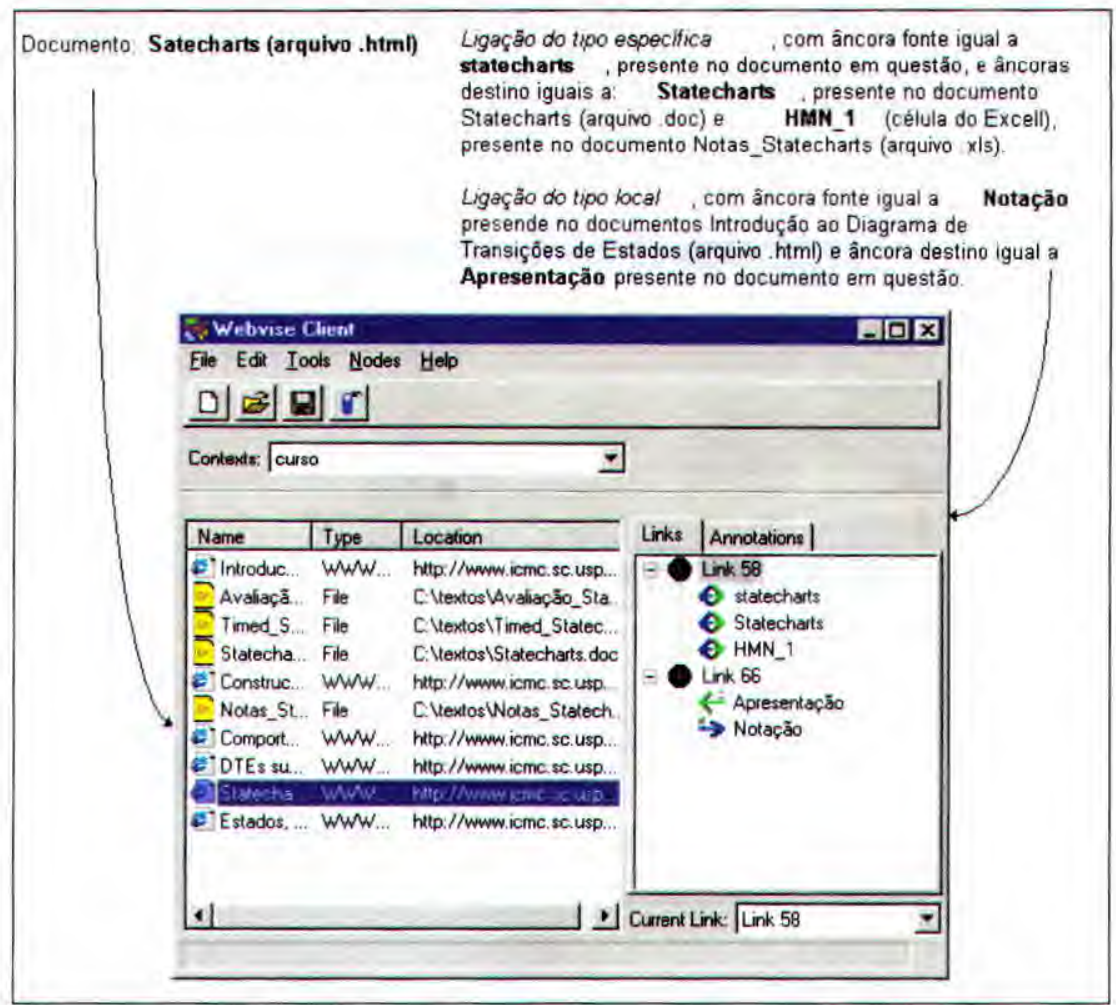

Figura 5.6: Ligações do Documento Statecharts no dia-a-dia

De acordo com o hyperchart estendido especificado na Figura 5.7, foram identificados os seguintes elementos nos conjuntos do OXHMBS e as seguintes tuplas nas funções do OXHMBS:

1. No conjunto Doc foram identificados os seguinte elementos:

Doc $=\left\{d_{\varnothing}, d_{1}, d_{2}, d_{3}, d_{4}, d_{5}, d_{6}, d_{7}, d_{8}, d_{9}, d_{10}\right\}$, onde:

$d_{\varnothing}=\left\langle i d_{d_{\varnothing}}, \varnothing, \varnothing, \varnothing\right\rangle$;

$d_{1}=\left\langle 1\right.$, "Introdução ao Diagrama de Transições de Estados", $c_{1},\{$ DTE, Statecharts $\left.\}\right\rangle$;

$d_{2}=\left\langle 2\right.$, "Avaliação_Statecharts", $c_{2},\{$ Prova, Statecharts $\left.\}\right\rangle ;$

$d_{3}=\left\langle 3\right.$, "Timed Statecharts", $c_{3},\{$ Temporal, Statecharts $\left.\}\right\rangle$;

$d_{4}=\left\langle 4\right.$, "Statecharts", $c_{4},\{$ Técnica Formal, Máquina de Estados Finitos $\left.\}\right\rangle ;$

$d_{5}=\left\langle 5\right.$, "Construção do Diagrama de Transições de Estados", $c_{1},\{$ DTE, Statecharts $\left.\}\right\rangle$;

$d_{6}=\left\langle 6\right.$, "Notas_Statecharts", $c_{6},\{$ Notas, Avaliação, Statecharts $\left.\}\right\rangle$;

$d_{7}=\left\langle 7\right.$, "Comportamento Dependente do Tempo", $c_{7},\{$ Statecharts $\left.\}\right\rangle$;

$d_{8}=\left\langle 8\right.$, "DTEs subdivididos", $c_{8},\{$ DTE, Statecharts, Refinamento $\left.\}\right\rangle ;$

$d_{9}=\left\langle 9\right.$, "Statecharts no dia-a-dia", $c_{9},\{$ Statecharts, Introdução $\left.\}\right\rangle ;$ 


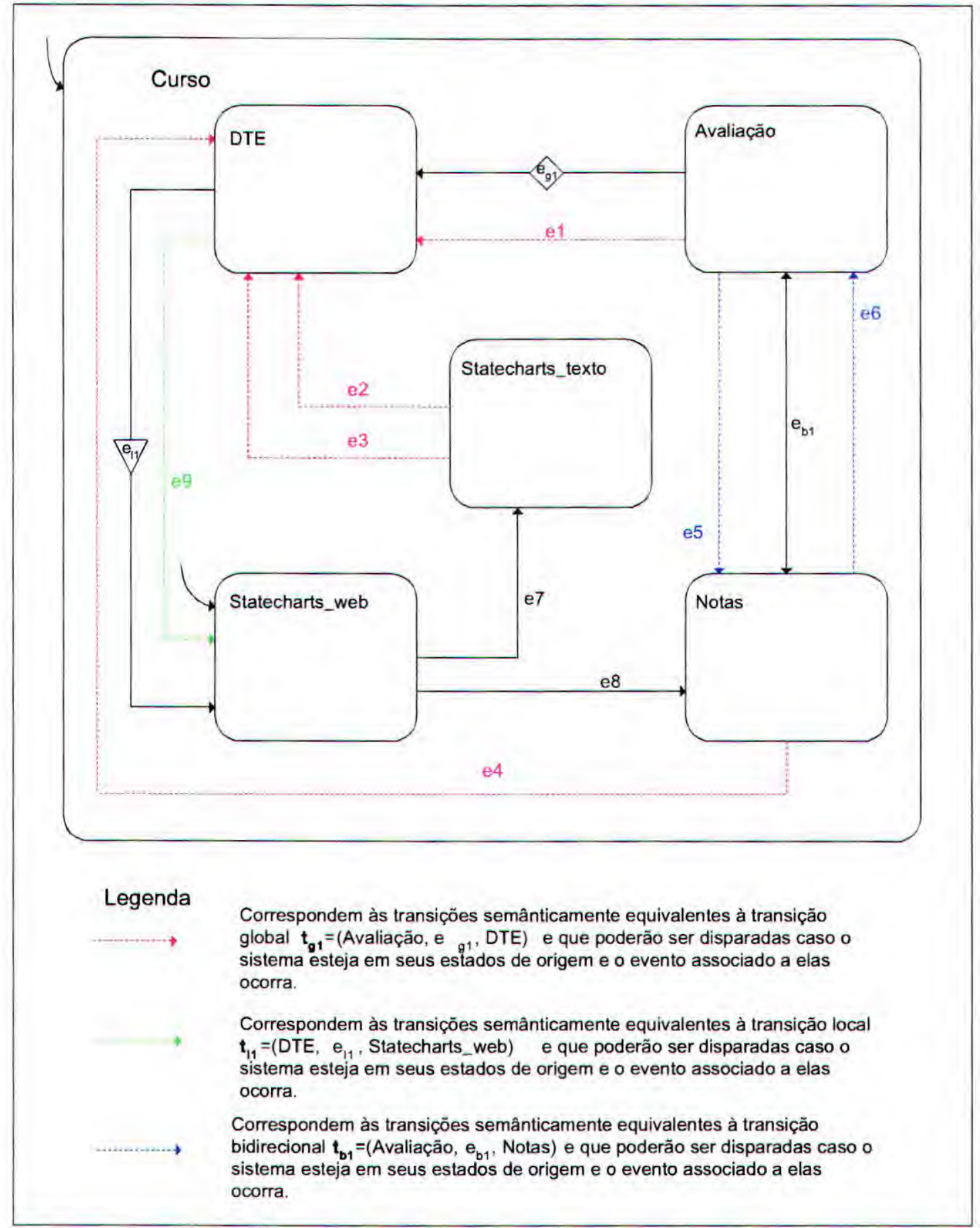

Figura 5.7: Especificação da aplicação exemplo no Modelo OXHMBS

$d_{10}=\left\langle 10\right.$, "Estados, transições, eventos e ações", $c_{10},\{$ Statecharts $\left.\}\right\rangle$.

2. Com base na função $M$ foram identificadas as tuplas apresentadas na Tabela 5.1. 
Tabela 5.1: Tuplas identificadas pela função $\cdot M$

\begin{tabular}{|l|c|}
\hline \hline Estado do hypercharts estendido & Documento \\
\hline Curso & $d_{\varnothing}$ \\
DTE & $d_{1}$ \\
Avaliação & $d_{2}$ \\
Statecharts_texto & $d_{4}$ \\
Notas & $d_{6}$ \\
Statecharts_web & $d_{9}$ \\
\hline \hline
\end{tabular}

3. Com base na função $D o c \_T i p o$ foram identificadas as tuplas apresentadas na Tabela 5.2.

Tabela 5.2: Tuplas identificadas pela função Doc_Tipo

\begin{tabular}{|c|c|}
\hline \hline Documento & Tipo do Documento \\
\hline$d_{1}$ & texto $(. \mathrm{html})$ \\
$d_{2}$ & texto $(. \mathrm{doc})$ \\
$d_{3}$ & texto $(. \mathrm{doc})$ \\
$d_{4}$ & texto $(. \mathrm{doc})$ \\
$d_{5}$ & texto $(. \mathrm{html})$ \\
$d_{6}$ & texto $(. \mathrm{xsl})$ \\
$d_{7}$ & texto $(. \mathrm{html})$ \\
$d_{8}$ & texto $(. \mathrm{html})$ \\
$d_{9}$ & texto $(. \mathrm{html})$ \\
$d_{10}$ & texto $(. \mathrm{html})$ \\
\hline \hline
\end{tabular}

4. Com base na função Doc_Localizacao foram identificadas as tuplas apresentadas na Tabela 5.3 .

Tabela 5.3: Tuplas identificadas pela função $D o c \_L o c a l i z a c a o$

\begin{tabular}{|c|l|}
\hline \hline Documento & \multicolumn{1}{|c|}{ Localização Física do Documento } \\
\hline$d_{1}$ & http://www.icmc.sc.usp.br/curso.html \\
$d_{2}$ & c:/textos/Avaliação_Statecharts.doc \\
$d_{3}$ & c:/textos/Timed_Statecharts.doc \\
$d_{4}$ & c:/textos/Statecharts.doc \\
$d_{5}$ & http://www.icmc.sc.usp.br/curso/construçãoDTE.html \\
$d_{6}$ & c:/textos/Notas_Statecharts.xls \\
$d_{7}$ & http://www.icmc.sc.usp.br/curso/tempo.html \\
$d_{8}$ & http://www.icmc.sc.usp.br/curso/subdivididos.html \\
$d_{9}$ & http://www.icmc.sc.usp.br/curso/curso.html \\
$d_{10}$ & http://www.icmc.sc.usp.br/curso/conceitoDTE.html \\
\hline \hline
\end{tabular}

5. No conjunto Aplicativos foram identificados os seguintes elementos: 
Aplicativos $=\left\{\right.$ aplicativo $_{1}$, aplicativo $_{2}$, aplicativo $\left._{3}\right\}$, onde:

aplicativo $_{1}=\langle$ Microsoft Word, Editor de Texto $\rangle$;

aplicativo $_{2}=\langle$ Microsoft Excel, Planilha Eletrônica $\rangle$;

aplicativo $_{3}=\langle$ Internet Explorer, Browser $\rangle$.

6. Com base na função Visualizacao foram identificadas as tuplas apresentadas na Tabela 5.4 .

Tabela 5.4: Tuplas identificadas pela função $V$ isualizacao

\begin{tabular}{|c|c|}
\hline \hline Documento & Aplicativo \\
\hline$d_{1}$ & aplicativo $_{3}$ \\
$d_{2}$ & aplicativo $_{1}$ \\
$d_{3}$ & aplicativo $_{1}$ \\
$d_{4}$ & aplicativo $_{1}$ \\
$d_{5}$ & aplicativo $_{3}$ \\
$d_{6}$ & aplicativo $_{2}$ \\
$d_{7}$ & aplicativo $_{3}$ \\
$d_{8}$ & aplicativo $_{3}$ \\
$d_{9}$ & aplicativo $_{3}$ \\
$d_{10}$ & aplicativo $_{3}$ \\
\hline \hline
\end{tabular}

7. O nível de visibilidade $L$ dessa aplicação exemplo é 0 . Dessa forma, serão exibidos durante a navegação todos os documentos associados aos estados atômicos que estiverem ativos na configuração de estados válida.

8. No conjunto Raiz foi identificado o seguinte elemento:

Raiz $=\{$ Curso $\}$

9. Com base na função Base__Lig foi identificada a tupla apresentada na Tabela 5.5.

Tabela 5.5: Tupla identificada pela função Base_Lig

\begin{tabular}{|c|c|}
\hline \hline Base de Ligaçōes & Tipo \\
\hline Curso & pública \\
\hline \hline
\end{tabular}

10. Com base na função Autorizacao foi identificada a tupla apresentada na Tabela 5.6.

Tabela 5.6: Tupla identificada pela função Autorizacao

\begin{tabular}{|c|c|}
\hline \hline Base de Ligações & Senha \\
\hline Curso & $\varnothing$ \\
\hline
\end{tabular}


11. No conjunto Anc foram identificados os seguintes elementos:

$$
\begin{aligned}
& A n c=\left\{a_{\emptyset}, a n c_{1}, a n c_{2}, a n c_{3}, a n c_{4}, a n c_{5}, a n c_{6}, a n c_{7}, a n c_{8}, a n c_{9}, a n c_{10}\right\}, \text { onde: } \\
& a_{\emptyset}=\left\langle i d_{a}, \emptyset\right\rangle \\
& a n c_{1}=\langle 1, \text { diagrama de transições de estados }\rangle ; \\
& a n c_{2}=\langle 2, \text { DTE }\rangle ; \\
& a n c_{3}=\langle 3, \text { DTE }\rangle ; \\
& a n c_{4}=\langle 4, \text { DTE }\rangle ; \\
& a n c_{5}=\langle 5, \text { DTE }\rangle ; \\
& a n c_{6}=\langle 6, \text { Avaliação }\rangle ; \\
& a n c_{7}=\langle 7, \text { HMN_2 }\rangle ; \\
& a n c_{8}=\langle 8, \text { statecharts }\rangle ; \\
& a n c_{9}=\langle 9, \text { Statecharts }\rangle ; \\
& a n c_{10}=\langle 10, \text { HMN_1 }\rangle . \\
& a n c_{11}=\langle 11, \text { Apresentação }\rangle . \\
& a n c_{12}=\langle 12, \text { Notação }\rangle .
\end{aligned}
$$

12. Com base na função $A n c \_D o c$ foram identificadas as tuplas apresentadas na Tabela 5.7.

Tabela 5.7: Tuplas identificadas pela função Anc_Doc
\begin{tabular}{|c|c|}
\hline \hline Ancora & Documento que a contextualiza \\
\hline$a_{\varnothing}$ & $d_{\varnothing}$ \\
$a n c_{1}$ & $d_{1}$ \\
$a n c_{2}$ & $d_{2}$ \\
$a n c_{3}$ & $d_{4}$ \\
$a n c_{4}$ & $d_{4}$ \\
$a n c_{5}$ & $d_{6}$ \\
$a n c_{6}$ & $d_{2}$ \\
$a n c_{7}$ & $d_{6}$ \\
$a n c_{8}$ & $d_{9}$ \\
$a n c_{9}$ & $d_{4}$ \\
$a n c_{10}$ & $d_{6}$ \\
$a n c_{11}$ & $d_{9}$ \\
$a n c_{12}$ & $d_{1}$ \\
\hline \hline
\end{tabular}

13. Com base na função Anc_Localizacao foram identificadas as tuplas ${ }^{\top}$ apresentadas na Tabela 5.8.

\footnotetext{
${ }^{7}$ Os valores definidos como localização física das âncoras são hipotéticos, uma vez que esses dependem dos aplicativos responsáveis por apresentá-las.
} 
Tabela 5.8: Tuplas identificadas pela função Anc_Localizacao

\begin{tabular}{|c|c|}
\hline \hline Ancora & Localização Física da Ancora \\
\hline$a n c_{1}$ & $\sharp 13 \sharp 14$ \\
$a n c_{2}$ & $\sharp 05 \sharp 06$ \\
$a n c_{3}$ & $\sharp 10 \sharp 09$ \\
$a n c_{4}$ & $\sharp 23 \sharp 24$ \\
$a n c_{5}$ & $\sharp 27 \sharp 28$ \\
$a n c_{6}$ & $\sharp 33 \sharp 34$ \\
$a n c_{7}$ & $\sharp 56 \sharp 57$ \\
$a n c_{8}$ & $\sharp 93 \sharp 94$ \\
$a n c_{9}$ & $\sharp 02 \sharp 01$ \\
$a n c_{10}$ & $\sharp 66 \sharp 67$ \\
$a n c_{11}$ & $\sharp 79 \sharp 49$ \\
$a n c_{12}$ & $\sharp 17 \sharp 23$ \\
\hline \hline
\end{tabular}

14. Com base na função Anc_Font foram identificadas as tuplas apresentadas na Tabela 5.9.

Tabela 5.9: Tuplas identificadas pela função Anc_Font

\begin{tabular}{|l|c|}
\hline \hline \multicolumn{1}{|c|}{ Transição } & Ancora Fonte \\
\hline$t_{1}=$ (Avaliação, $\left.e 1, \mathrm{DTE}\right)$ & $a n c_{2}$ \\
$t_{2}=$ (Statecharts_texto, $\left.e 2, \mathrm{DTE}\right)$ & $a n c_{3}$ \\
$t_{3}=$ (Statecharts_texto, e3, DTE) & $a n c_{4}$ \\
$t_{4}=$ (Notas, $\left.e 4, \mathrm{DTE}\right)$ & $a n c_{5}$ \\
$t_{5}=$ (Avaliação, e5, Notas) & $a n c_{6}$ \\
$t_{6}=$ (Notas, e6, Avaliação) & $a n c_{7}$ \\
$t_{7}=$ (Statecharts_web,e7, Statecharts_texto) & $a n c_{8}$ \\
$t_{8}=$ (Statecharts_web,e8, Notas) & $a n c_{8}$ \\
$t_{9}=(\mathrm{DTE}, e 9$, Statecharts_web) & anc $c_{12}$ \\
\hline \hline
\end{tabular}

15. Com base na função $A n c \_$Dest foram identificadas as tuplas apresentadas na Tabela 5.10.

Tabela 5.10: Tuplas identificadas pela função Anc_Dest

\begin{tabular}{|c|c|c|}
\hline Transição & Ancora Fonte & Ancora Destino \\
\hline$t_{1}=($ Avaliação, $e 1$, DTE $)$ & $a n c_{2}$ & $a n c_{1}$ \\
\hline$t_{2}=($ Statecharts_texto, $e 2, \mathrm{DTE})$ & $a n c_{3}$ & $a_{n} c_{1}$ \\
\hline$t_{3}=($ Statecharts_texto, $e 3, \mathrm{DTE})$ & $a_{n} c_{4}$ & anc $c_{1}$ \\
\hline$t_{4}=($ Notas $, e 4, \mathrm{DTE})$ & $a n c_{5}$ & anc $c_{1}$ \\
\hline$t_{5}=($ Avaliação, $e 5$, Notas $)$ & $a n c_{6}$ & anc $_{7}$ \\
\hline$t_{6}=($ Notas, $e 6$, Avaliação $)$ & $a n c_{7}$ & $a_{n} c_{6}$ \\
\hline$t_{7}=($ Statecharts_web, $e 7$, Statecharts_texto $)$ & $a n c_{8}$ & anc.9 \\
\hline$t_{8}=($ Statecharts_web,$e 8$, Notas $)$ & $a n c_{8}$ & $a n c_{10}$ \\
\hline$t_{9}=(\mathrm{DTE}, e 9$, Statecharts_web $)$ & $a_{n} c_{12}$ & $a n c_{11}$ \\
\hline
\end{tabular}


16. Com base na função Bidirecional foi identificada a tupla apresentada na Tabela 5.11.

Tabela 5.11: Tupla identificada pela função Bidirecional

\begin{tabular}{|c|c|c|}
\hline \hline Transição Bidirecional & Ancora Fonte $\backslash$ Destino & Ancora Fonte $\backslash$ Destino \\
\hline$t_{b 1}=\left(\right.$ Avaliação, $e_{b 1}$, Notas $)$ & $a n c_{6}$ & $a n c_{7}$ \\
\hline \hline
\end{tabular}

17. Com base na função Global foi identificada a tupla apresentada na Tabela 5.12.

Tabela 5.12: Tupla identificada pela função Global

\begin{tabular}{|c|c|c|}
\hline \hline Transição Global & Ancora Fonte & Ancora Destino \\
\hline$t_{g 1}=\left(\right.$ Avaliação, $e_{g 1}$, DTE $)$ & $a n c_{2}$ & $a n c_{1}$ \\
\hline
\end{tabular}

18. Com base na função Local foi identificada a tupla apresentada na Tabela 5.13.

Tabela 5.13: Tupla identificada pela função Local

\begin{tabular}{|c|c|c|}
\hline \hline Transição Local & Ancora Fonte & Ancora Destino \\
\hline$t_{l 1}=\left(\mathrm{DTE}, e_{l 1}\right.$, Statecharts_web) & $a n c_{12}$ & $a n c_{11}$ \\
\hline
\end{tabular}

19. Com base na função Lista_Dest foram identificadas as tuplas apresentadas na Tabela 5.14 .

Tabela 5.14: Tuplas identificadas pela função Lista_Dest

\begin{tabular}{|c|c|}
\hline \hline Ancora Fonte & Ancoras Destino \\
\hline$a n c_{2}$ & $\left\{a n c_{1}\right\}$ \\
$a n c_{3}$ & $\left\{a n c_{1}\right\}$ \\
$a n c_{4}$ & $\left\{a n c_{1}\right\}$ \\
$a n c_{5}$ & $\left\{a n c_{1}\right\}$ \\
$a n c_{6}$ & $\left\{a n c_{7}\right\}$ \\
$a n c_{7}$ & $\left\{a n c_{6}\right\}$ \\
$a n c_{8}$ & $\left\{a n c_{9}, a n c 10\right\}$ \\
$a n c_{12}$ & $\{a n c 11\}$ \\
\hline
\end{tabular}

20. Com base na função Listn_Anc foram identificadas as tuplas apresentadas na Tabela 5.15 .

Também é necessário exemplificar a semântica de navegação do OXHMBS para a aplicação exemplo através da especificação da seqüência de mensagens necessárias para a apresentação dos documentos dessa aplicação exemplo, e da especificação da seqüência de mensagens necessárias para a navegação das âncoras dessa. Obviamente, os documentos $d_{3}, d_{5}, d_{7}, d_{8}$ e $d_{10}$ não poderão ser apresentados durante a execução do hyperchart estendido, uma vez que não estão associados a estados desse. 
Tabela 5.15: Tuplas identificadas pela função Lista_Anc

\begin{tabular}{|c|c|}
\hline \hline Documento & Ancoras \\
\hline$d_{\mathfrak{g}}$ & \{\} \\
$d_{1}$ & $\left\{a n c_{1}, a n c_{12}\right\}$ \\
$d_{2}$ & $\left\{a n c_{2}, a n c_{6}\right\}$ \\
$d_{3}$ & \{\} \\
$d_{4}$ & $\left\{a n c_{3}, a n c_{4}, a n c_{9}\right\}$ \\
$d_{5}$ & \{\} \\
$d_{6}$ & $\left\{a n c_{5}, a n c_{7}, a n c_{10}\right\}$ \\
$d_{7}$ & \{\} \\
$d_{8}$ & \{\} \\
$d_{9}$ & $\left\{a n c_{8}, a n c_{11}\right\}$ \\
$d_{10}$ & \{\} \\
\hline
\end{tabular}

Considerando que o estado DTE faça parte da configuração de contexto corrente do hyperchart estendido e, dessa forma, o documento $d_{1}$ associado a esse deve ser apresentado. Um HSP que suporte o modelo deve enviar as seguintes mensagens para o aplicativo responsável pela apresentação de $d_{1}$ :

Esta_Aberto(Internet Explorer, http://www. icmc.sc.usp.br/curso.html). Apresenta_Documento(Internet Explorer, http://www.icmc.sc.usp.br/ curso. html, preto).

Envia_Lista_Ancoras(Internet Explorer, http://www.icmc.sc.usp.br/ curso.html,1, $13 \sharp 14, \sharp 17 \sharp 23)$.

Para cada uma das âncoras (nesse caso, $\sharp 13 \sharp 14$ e $\sharp 17 \sharp 23$ ) enviadas na lista de âncoras da mensagem anterior, deve ser enviada uma mensagem:

Apresenta_Selecao(Internet Explorer,http://www.icmc.sc.usp.br/curso. html, $\sharp 13 \sharp 14$, azul);

Apresenta_Selecao(Internet Explorer,http://www.icmc.sc.usp.br/curso. htm I, $\sharp 17 \sharp 23$, verde).

Essa mensagem define como cada âncora de um determinado documento será destacada durante a apresentação desse.

Considerando que o estado Avaliação faça parte da configuração de contexto corrente do hyperchart estendido e, dessa forma, o documento $d_{2}$ associado a esse deve ser apresentado. Um HSP que suporte o modelo deve enviar as seguintes mensagens para 0 aplicativo responsável pela apresentação de $d_{2}$ :

Esta_Aberto(Microsoft Word, c:/textos/Avaliação_Statecharts.doc). 
Apresenta_Documento(Microsoft Word, c:/textos/Avaliação_Statecharts.doc, preto).

Envia_Lista_Ancoras(Microsoft Word, c:/textos/Avaliação_Statecharts.doc,2, $\sharp 05 \sharp 06$,

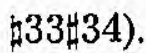

Para cada uma das âncoras (nesse caso, $\sharp 05 \sharp 06$ e $\sharp 33 \sharp 34$ ) enviadas na lista de âncoras da mensagem anterior, deve ser enviada uma mensagem:

Apresenta_Selecao(Microsoft Word, c:/textos/Avaliação_Statecharts.doc, $₫ 05 \sharp 06$, verde);

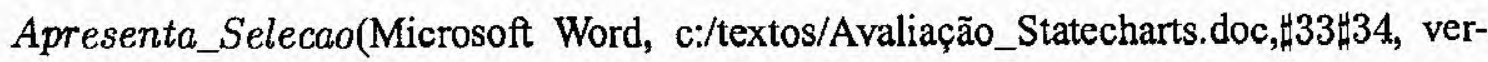
de).

Considerando que o estado Statecharts_texto faça parte da configuração de contexto corrente do hyperchart estendido e, dessa forma, o documento $d_{4}$ associado a esse deve ser apresentado. Um HSP que suporte o modelo deve enviar as seguintes mensagens para o aplicativo responsável pela apresentação de $d_{4}$ :

Esta_Aberto(Microsoft Word, c:/textos/Statecharts.doc).

Apresenta_Documento (Microsoft Word, c:/textos/Statecharts.doc, preto).

Envia_Lista_Ancoras (Microsoft Word, c:/textos/Statecharts.doc,3, $\sharp 10 \sharp 09, \sharp 23 \sharp 24$, $\sharp 02 \sharp 01)$.

Para cada uma das âncoras (nesse caso, $\sharp 10 \sharp 09, \sharp 23 \sharp 24$ e $\sharp 02 \sharp 01$ ) enviadas na lista de âncoras da mensagem anterior, deve ser enviada uma mensagem:

Apresenta_Selecao(Microsoft Word, c:/textos/Statecharts.doc, $\sharp 10 \sharp 09$, azul);

Apresenta_Selecao(Microsoft Word, c:/textos/Statecharts.doc, $\sharp 23 \sharp 24$,verde);

Apresenta_Selecao(Microsoft Word, c:/textos/Statecharts.doc, $\sharp 02 \$ 01, v e r d e)$.

Considerando que o estado Notas faça parte da configuração de contexto corrente do hyperchart estendido e, dessa forma, o documento $d_{6}$ associado a esse deve ser apresentado. Um HSP que suporte o modelo deve enviar as seguintes mensagens para o aplicativo responsável pela apresentação de $d_{6}$ :

Esta_Aberto(Microsoft Excel, c:/textos/Notas_Statecharts.xls).

Apresenta_Documento (Microsoft Excel, c:/textos/Notas_Statecharts.xls, preto).

Envia_Lista_Ancoras (Microsoft Excel, c:/textos/Notas_Statecharts.doc,3, $\sharp 27 \sharp 28$, $\sharp 56 \sharp 57, \sharp 66 \sharp 67$ ). 
Para cada uma das âncoras (nesse caso, $\sharp 27 \sharp 28, \sharp 56 \sharp 57$ e $\sharp 66 \sharp 67$ ) enviadas na lista de âncoras da mensagem anterior, deve ser enviada uma mensagem:

Apresenta_Selecao(Microsoft Excel, c:/textos/Notas_Statecharts.xls, $\sharp 27 \$ 28$, amarelo); Apresenta_Selecao(Microsoft Excel, c:/textos/Notas_Statecharts.xls, $\sharp 56 \sharp 57$,verde); Apresenta_Selecao(Microsoft Excel, c:/textos/Notas_Statecharts.xls, $\sharp 66 \sharp 67$, azul).

Considerando que o estado Statecharts_web faça parte da configuração de contexto corrente do hyperchart estendido e, dessa forma, o documento $d_{9}$ associada a esse deve ser apresentado. Um HSP que suporte o modelo deve enviar as seguintes mensagens para 0 aplicativo responsável pela apresentação de $d_{9}$ :

Esta_Aberto(Internet Explorer, http://www.icmc.sc.usp.br/curso/ curso.html).

Apresenta_Documento(Internet Explorer, http://www.icmc.sc.usp.br/ curso/curso.html, preto).

Envia_Lista_Ancoras(Internet Explorer, http://www.icmc.sc.usp.br/ curso/curso. html, $1, \sharp 93 \sharp 94, \sharp 79 \sharp 49)$.

Para cada uma das âncoras (nesse caso, $\sharp 93 \sharp 94$ e $\sharp 79 \sharp 49)$ enviadas na lista de âncoras da mensagem anterior, deve ser enviada uma mensagem:

Apresenta_Selecao(Internet Explorer, http://www.icmc.sc.usp.br/curso/ curso.html, $\sharp 93 \sharp 94$, azul);

Apresenta_Selecao(Internet Explorer, http://www.icmc.sc.usp.br/curso/ curso. htm $1, \sharp 79 \sharp 49$, verde).

Para exemplificar a navegação de uma âncora, por exemplo anc $c_{3}$, consideremos que o sistema encontra-se no estado Statecharts_texto, ou seja, apresentando o documento $d_{4}$ que contextualiza $a n c_{3}$.

Caso o leitor selecione a âncora fonte $a n c_{3}$, o aplicativo responsável pela apresentação de $d_{4}$ envia a mensagem: Seguir_ligacao (amiotto@icmc.sc.usp.br, Microsoft Word, c:/textos/Statecharts.doc, $\sharp 10 \sharp 09$ ) ao HSP que suporta o modelo e tem como resposta um conjunto de âncoras destino da âncora fonte selecionada (juntamente com uma descrição da localização física dos documentos que as contextualizam e dos aplicativos que são responsáveis pela apresentação dessas). Nesse exemplo, a resposta da mensagem Seguir_Ligacao seria: (Internet Explorer, http: //www. i cmc.sc.usp.br/ curso.html, $\sharp 13 \sharp 14)$. 
Dessa forma, o leitor seleciona a âncora destino que deseja navegar; nessc exemplo, essa só pode ser $a n c_{1}$, ou seja $\sharp 13 \sharp 14\left(\right.$ Anc__Localizacao $\left.\left(a n c_{1}\right)=\sharp 13 \sharp 14\right)$. Em seguida, através das funções $A n c_{-} F$ ont e $A n c_{-}$Dest $\left(A n c_{-}\right.$Font $\left(t_{2}\right)=a n c_{3}, A n c_{-} \operatorname{Dest}\left(t_{2}, a n c_{3}\right)=$ $a n c_{1}$ ) é identificada a transição $t_{2}$ que associa as âncoras, fonte e destino, selecionadas.

$\mathrm{O}$ evento $e_{2}$ definido no rótulo de $t_{2}$ é então gerado, a transição é disparada e o sistema passa a estar no estado $D T E$, ou seja, a nova configuração de estados tem como estado ativo $D T E$. Antes que o documento associado a $D T E$ seja apresentado (as mensagens envolvidas na apresentação do documento associado a $D T E$ já foram descritas anteriormente), os estados da configuração de estados atual, nesse caso Statecharts_texto, são desativados e os documentos associados a esses que estavam sendo apresentados são retirados da apresentação através da mensagem $F$ echa_Canal_Ativo, no contexto desse exemplo Fecha_Canal_Ativo(Microsoft Word).

\subsection{Análise de Especificações OXHMBS}

Nesta Seção são apresentados e discutidos alguns pontos importantes com relação a utilização do OXHMBS como técnica para especificação de aplicações em sistemas hipermídia abertos.

\subsubsection{OXHMBS e os requisitos das aplicações em sistemas hiper- midia abertos}

Com base nas discussões apresentadas ao longo do capítulo 4, na Tabela 5.16 é apresentada uma análise de como o OXHMBS se comporta frente aos requisitos das aplicações em sistemas hipermídia abertos.

Tabela 5.16: OXHMBS e os requisitos das aplicações em sistemas hipermídia abertos

\begin{tabular}{|l|l|l|}
\hline Requisito & $\begin{array}{l}\text { Satisfeito pelo } \\
\text { OXHMBS }\end{array}$ & Observação \\
\hline $\begin{array}{l}\text { Documentos relacionados } \\
\text { de diversas formas }\end{array}$ & Sim & $\begin{array}{l}\text { São suportadas no modelo OXHMBS ligações es- } \\
\text { pecificas, bidirecionais, globais e locais. Somente } \\
\text { ligações dinâmicas ou computadas não são suporta- } \\
\text { das diretamente na notação do modelo, uma vez que } \\
\text { estão relacionadas com a implementação de um me- } \\
\text { canismo de busca por um HSP que suporte o mode- } \\
\text { lo. }\end{array}$ \\
\hline
\end{tabular}


Tabela 5.16: OXHMBS e os requisitos das aplicações em sistemas hipermídia abertos (continuação)

\begin{tabular}{|c|c|c|}
\hline Requisito & $\begin{array}{l}\text { Satisfeito pelo } \\
\text { OXHMBS }\end{array}$ & Observação \\
\hline $\begin{array}{l}\text { Ligações em termos da } \\
\text { semảntica da informação }\end{array}$ & Não & $\begin{array}{l}\text { O OXHMBS não suporta esse requisito diretamente } \\
\text { em sua notação, porém através do uso do título dos } \\
\text { documentos e de palavras-chave associadas a esses, } \\
\text { é possível estabelecer um cenário no qual recupera- } \\
\text { ção baseada na semântica da informação possa ocor- } \\
\text { rer. Esse requisito também é dependente da imple- } \\
\text { mentação de um mecanismo de busca adequado por } \\
\text { um HSP que suporte o modelo. }\end{array}$ \\
\hline $\begin{array}{l}\text { Bases de ligações públi- } \\
\text { cas e privadas }\end{array}$ & $\operatorname{Sim}$ & $\begin{array}{l}\text { Através da definição do conjunto Raiz e das fun- } \\
\text { ções Base_Lig e Autorizacao o OXHMBS permi- } \\
\text { te a especificação de bases de ligações públicas e } \\
\text { privadas. }\end{array}$ \\
\hline $\begin{array}{l}\text { Separação entre estrutura } \\
\text { e conteúdo da informação }\end{array}$ & Sim & $\begin{array}{l}\text { A existência de conjuntos distintos para documentos } \\
\text { e para âncoras e também o uso de funções distintas } \\
\text { para relacionar documentos a estados, âncoras a do- } \\
\text { cumentos, transições a âncoras fonte, âncoras fonte } \\
\text { a âncoras destino e âncoras a suas localizações fisi- } \\
\text { cas, faz com que toda a estrutura de uma aplicação } \\
\text { hipermídia esteja em um nível diferente daquele em } \\
\text { que se encontram as porções de conteúdo da infor- } \\
\text { mação. }\end{array}$ \\
\hline $\begin{array}{l}\text { Ligações "de" e "para" in- } \\
\text { formações read-only }\end{array}$ & $\operatorname{Sim}$ & $\begin{array}{l}\text { Como no OXHMBS toda a estrutura de uma apli- } \\
\text { cação hipermídia encontra-se em um nivel diferente } \\
\text { daquele em que se encontram as porções de conteú- } \\
\text { do da informação, quando uma ligação é criada em } \\
\text { um documento (read-only) no qual não se tem per- } \\
\text { missão de escrita, nenhuma alteração é feita no con- } \\
\text { teúdo desse (nem poderia, uma vez que não é pos- } \\
\text { sível realizar operações de escrita em documentos } \\
\text { read-only). }\end{array}$ \\
\hline
\end{tabular}


Tabela 5.16: OXHMBS e os requisitos das aplicações em sistemas hipermidia abertos (continuação)

\begin{tabular}{|l|l|l|}
\hline Requisito & $\begin{array}{l}\text { Satisfeito pelo } \\
\text { OXHMBS }\end{array}$ & Observação \\
\hline $\begin{array}{l}\text { Documentos em diferen- } \\
\text { tes formatos }\end{array}$ & Sim & $\begin{array}{l}\text { Através da definição de um conjunto de } \\
\text { Aplicativos, da função Visualizacao, e co- } \\
\text { mo conseqüência do suporte à separação entre o } \\
\text { conteúdo e a estrutura da informação, é possível } \\
\text { especificar no OXHMBS documentos em diferentes } \\
\text { tipos de formatos. }\end{array}$ \\
\hline $\begin{array}{l}\text { Comunicação, distribui- } \\
\text { ção e cooperação }\end{array}$ & Sim & $\begin{array}{l}\text { Através da especificação de mensagens definidas no } \\
\text { protocolo OHP. }\end{array}$ \\
\hline
\end{tabular}

\subsubsection{Utilização de uma abordagem formal - OXHMBS}

Segundo Turine (1998), a utilização de um modelo de especificação formal durante a definição do projeto estrutural e navegacional de uma aplicação hipermídia e, conseqüentemente de uma aplicação em sistema hipermídia aberto, pode conduzir a um aumento da qualidade ${ }^{8}$ e confiabilidade dessas. Nesse contexto, é possivel realizar análises rigorosas na especificação dessas e, conseqüentemente em sua implementação em alguma linguagem de programação. Também é possivel verificar a completitude de uma especificação e, ainda, verificar se uma implementação satisfaz aos requisitos de análise estabelecidos.

Uma especificação formal pode ser analisada através do uso de operadores matemáticos, uma vez que argumentos de prova formal podem ser usados para testar e provar a consistência e a corretitude da sintaxe dessa.

De acordo com Turine (1998), os formalismos Statecharts, técnica subjacente ao OXHMBS, e Redes de Petri possuem um comportamento semelhante no que diz respeito à análise de propriedades dinâmicas para sistemas reativos. Dessa forma, Boaventura (1992) e Masiero et al. (1994) definiram para Statecharts algumas propriedades usadas para Redes de Petri, tais como alcançabilidade, reiniciabilidade, impasse, seqüência de disparos e uso de transições, que podem também ser aplicadas no domínio das aplicações em sistemas hipermídia abertos. A maioria dessas propriedades é verificada em Statecharts utilizando técnicas de análise do espaço de estados e, em especial, tais técnicas são derivadas a partir da árvore de alcançabilidade, uma estrutura que representa as possíveis configuraçöes de estado alcançáveis durante a sua execução.

\footnotetext{
${ }^{8}$ Qualidade, nesse caso, está sendo usada como sinônimo de adequação ao uso (Turine, 1998).
} 
A partir da geração da árvore de alcançabilidade de uma especificação OXHMBS (isso só é possivel, porque essa tem seu hyperchart estendido convertido em nível semântico em um statechart equivalente), análises, como a das propriedades destacadas acima, podem ser realizadas em tempo de autoria para validar essa, permitindo ao autor detectar anomalias. Tal abordagem é interessante, principalmente em documentos que crescem sem uma organização cuidadosa como os disponiveis nas páginas da $W W W$.

No contexto das aplicações hipermidia e, conseqüentemente das aplicações em sistemas hipermídia abertos, através da propriedade alcançabilidade, é possivel identificar a existência de documentos de uma aplicação que não são alcançáveis durante a navegação; através da propriedade reiniciabilidade, é possivel verificar se uma aplicação é reiniciável, ou seja, se para toda configuração de contexto " $C C$ ", alcançada a partir de " $C C_{0}$ ", existe uma seqüência de âncoras que permite retornar a configuração inicial " $C C_{0}$ ”; através da propriedade impasse, é possivel detectar situações de deadlock na aplicação hipermídia. A ausência de deadlock garante que o leitor, durante a navegação, nunca atingirá um documento, no qual possa permanecer por um tempo indefinido. Essa situação ocorre quando, por exemplo, o leitor visita um documento terminal, ou seja, um documento que não tem âncoras a serem ativadas; através da propriedade seqüência de disparos ou seqüência de âncoras, pode-se analisar as possiveis seqüências de ativação de âncoras a partir do documento inicial, ou seja, as relações de ordem temporal entre os documentos visitados; através da propriedade vivacidade das ligações ou uso das transições, é possivel identificar se existem transições especificadas no statechart que nunca disparam, ou seja, se existem ligações na aplicação hipermidia que não podem ser ativadas pelo leitor.

Deve-se destacar que na aplicação exempio especificada em OXHMBS (Seção 5.4) todas as propriedades descritas acima são satisfeitas.

Um estudo mais detalhado sobre a análise de propriedades de aplicações hipermídia, especificadas por meio de modelos baseados em Statecharts, a partir da geração de árvores de alcançabilidade pode ser observado em (Turine, 1998).

A possibilidade de uso das propriedades destacadas acima, para a análise de especificações OXHMBS, enriquece o modelo e permite a especificação de aplicações em sistemas hipermídia abertos mais confiáveis e consistentes.

Finalmente, neste trabalho não é desconsiderado o esforço requerido para lidar com a complexidade inerente a uma especificação formal. Contudo, com a utilização do modelo para construção do exemplo apresentado na Seção 5.4 pode-se reforçar a opinião de que a modelagem formal e o desenvolvimento convencional de aplicações hipermídia são processos que devem ser realizados de forma complementar e paralela.

Essa abordagem pode ser observada no trabalho de (Carvalho, 1998; Carvalho et al., 1999) onde foi definida a metodologia de projeto para hiperdocumentos HMBS/M que inclue o modelo formal HMBS para a especificação da estrutura navegacional de uma aplicação hipermidia. 


\subsection{Considerações Finais}

Neste capítulo foi apresentado o modelo OXHMBS, com suas novas características, as quais aumentam seu poder de especificação com relação ao XHMBS. As principais extensões realizadas estão relacionadas com o suporte à especificação de aplicações em sistemas hipermídia abertos, uma evolução no conjunto de aplicações suportadas pelo XHMBS.

Uma das principais diferenças entre os modelos OXHMBS e XHMBS, é a substituição de Hypercharts por Hypercharts Estendido como técnica subjacente. Além disso, foram realizadas extensões no próprio modelo como, a definição de novas funções, tais como Anc_Doc, Anc_Font, Anc_Dest, e a redefinição de alguns conjuntos, como é o caso de Doc e Anc. A semântica de navegação do XHMBS, baseada em canais de apresentação Pchannels e comunicação Cchannels, também foi modificada, através da substituição desses, pela especificação de um conjunto de mensagens do protocolo OHP. Essas características foram apresentadas nas Seções 5.2 e 5.3 deste capítulo.

$\mathrm{Na}$ Seção 5.4, foi apresentado, como exercício de validação, um exemplo de uma aplicação em sistema hipermidia aberto real especificada no sistema protótipo Webvise e no OXHMBS.

Finalmente, na Seção 5.5 o modelo proposto foi confrontado com os requisitos das aplicações em sistemas hipermídia abertos, e pode-se observar que sua satisfação em relação a esses é praticamente completa. Também foi apresentada uma discussão sobre o uso das características inerentes às técnicas formais como ferramenta para construção de aplicações em sistemas hipermídia abertos mais consistentes e confiáveis.

No próximo capítulo serão apresentadas as conclusões deste trabalho, em termos de contribuições destacadas e sugestões de trabalhos futuros. 


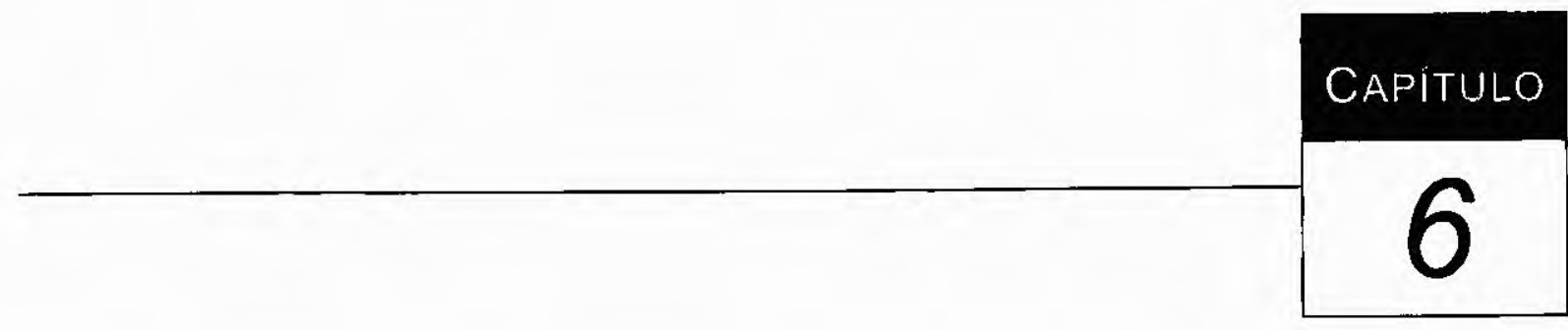

\section{Conclusões}

Este trabalho apresenta o modelo OXHMBS, uma extensão do modelo XHMBS, que tem como principal característica a capacidade de especificação de aplicações em sistemas hipermídia abertos. Dessa forma, este trabalho teve como objetivo realizar uma evolução no domínio das aplicações suportadas pelo modelo XHMBS (Paulo, 1997).

As extensões propostas a modelo XHMBS, pelo OXHMBS, podem ser classificadas em dois niveis: relativo à técnica Hypercharts que foi substituída por Hypercharts Estendido, e relativo ao próprio modelo.

No contexto das extensões realizadas em Hypercharts, o objetivo foi a definição de uma técnica de "aito nível", cuja semântica pudesse ser descrita por um statecharts, facilitando a especificação de alguns recursos muito encontrados nas aplicações em sistemas hipermídia abertos, tais como a definição de ligações bidirecionais, globais e locais e a definição de bases de ligações públicas e privadas.

No contexto das extensões realizadas ao modelo XHMBS, foram redefinidos alguns conjuntos originais desse ( $A n c$ e $D o c$ ), e também foram definidas funções adicionais necessárias à adequação do modelo às novas características definidas em Hypercharts Estendido, e aos requisitos das aplicações em sistema hipermídia abertos.

Uma modificação de grande impacto foi realizada na semântica de navegação do XHMBS, de forma que os canais de apresentação (Pchannels) e de comunicação (Cchannels) foram substituidos pela especificação de um subconjunto de mensagens do protocolo OHP. Essa modificação foi de extrema importância para o modelo OXHMBS, pois a utilização dessa nova abor- 
dagem possibilitou o suporte de funcionalidades hipermídia a partir dos aplicativos integrados ao modelo (habilitado-os, dessa forma, a criar, remover e navegar ligações de uma especificação OXHMBS), uma vez que foram especificadas tanto as mensagem que são enviadas pelo OXHMBS para os aplicativos hipermídia habilitados, quanto as mensagens enviadas pelos aplicativos hipermidia habilitados para esse. Essa característica é muito importante (chave) nos sistemas hipermídia abertos.

Foram conduzidas algumas análise das especificações OXHMBS, primeiramente, confrontando-as com os requisitos das aplicações em sistemas hipermidia abertos, e depois identificando como é possivel aplicar no domínio das aplicações em sistemas hipermídia abertos propriedades definidas para a técnica formal subjacente ao modelo.

Com o resultado da primeira análise, que foi extremamente positivo, pode-se observar que o modelo atende praticamente a todos os requisitos das aplicações em sistemas hipermídia abertos que haviam sido previamente propostos na Seção 2.2.

Deve-se destacar que para viabilizar a utilização do modelo e para a realização de uma análise detalhada das especificações OXHMBS é necessária a criação de um ambiente de apoio ao modelo que suporte a autoria e navegação de aplicações especificadas nesse. A definição desse ambiente é uma pesquisa sugerida como trabalho futuro.

Também é importante ressaltar que o OXHMBS não foi completamente validado, pois essa tarefa envolveria o planejamento e a realização de experimentos utilizando o modelo. Neste trabalho apenas foi realizado, como exercício de validação, a especificação em OXHMBS de um exemplo de uma aplicação em sistema hipermídia aberto real. A validação do modelo também é sugerida como trabalho futuro.

\subsection{Contribuições deste Trabalho}

Pode-se destacar algumas contribuições deste trabalho:

- Identificação de um conjunto de requisitos das aplicações em sistemas hipermidia abertos.

- Verificação da adequação do modelo XHMBS em relação a especificação de cada um dos requisitos das aplicações em sistemas hipermidia abertos previamente identificados.

- Proposição de extensões ao XHMBS, culminando no modelo OXHMBS, de forma a tomá-lo adequado à especificação de aplicações em sistemas hipermídia abertos.

- Definição da sintaxe e da semântica de navegação do modelo OXHMBS.

- Publicação dos resultados da pesquisa: (Miotto et al., 2001; Miotto e Fortes, 200 1a,b). 


\subsection{Sugestões de novas pesquisas}

A partir das propostas apresentadas nos capitulos anteriores pode-se vislumbrar uma variedade de possibilidades no que se refere a novas pesquisas nessa área. Dessa forma, pode-se destacar:

- Definição de um ambiente de apoio ao OXHMBS, que suporte a autoria e navegação de aplicações especificadas nesse.

Uma abordagem interessante seria a realização de extensões ao ambiente HySCharts $(\mathrm{Hy}$ permedia System based on stateCharts)(Turine, 1998), desenvolvido no ICMC-USP, que apóia a autoria e navegação de aplicações especificadas em HMBS.

O HySCharts foi implementado como uma extensão do ambiente Statsim (Masiero et al., 1991) e, portanto, baseia-se em uma máquina de simulação de Statecharts. Dessa forma, o trabalho de extensão do ambiente HySCharts para que esse venha a apoiar o OXHMBS, deveria ser conduzido em duas frentes: a extensão do Statsim para a obtenção de uma máquina Hypercharts Estendido, e a extensão das características de autoria e navegação do próprio HySCharts para que esse suporte os recursos do OXHMBS.

Este ambiente viabilizará o uso do modelo OXHMBS bem como a realização de análises em suas especificações.

- Planejamento e realização de experimentos para validação do modelo OXHMBS.

- Investigação e adaptação de abordagens tradicionais de teste e validação de especificações statecharts, para sua aplicação no contexto do modelo OXHMBS.

- Definição de operadores que permitam a realização de comparações e composições (tais como: junção e intersecção) de especificações OXHMBS. 


\section{Referências Bibliográficas}

Begoray, J. A. (1990). An introduction to hypermedia issues, systems and applications areas. International Journal of Man-Machine Studies, 33:121-147.

Bieber, M. e Kacmar, C. (1995). Designing hypertext support for computational applications. Communications of the ACM, 38(8):99-107.

Bieber, M. e Vitali, T. (1997). Toward support for hypermedia on the World Wide Web. IEEE Computer, $40(1): 62-70$.

Boaventura, I. A. G. (1992). Propriedades dinâmicas de Statecharts. Dissertação de mestrado, Instituto de Ciências Matemáticas e de Computação - Universidade de São Paulo. 116p.

Carvalho, M. R. (1998). HMBS/M- an object oriented method for the design and development of hypermedia applications. Dissertação de mestrado, Instituto de Ciências Matemáticas e de Computação - Universidade de São Paulo. 133p.

Carvalho, M. R., Oliveira, M. C. F., e Masiero, P. C. (1999). HMBS/M-an object oriented method for hypermedia design. In Anais do SBMIDIA'99: V Simpósio Brasileiro de Sistemas Multimidia e Hipermidia, páginas 43-62.

Cavallaro, U., Garzotto, F., Paolini, P., e Totaro, D. (1993). HIFI: Hypertext Interface for Information Systems. IEEE Software, 10(6):48-51.

Ceri, S., Fraternali, P., e Bongio, A. (2000). Web modeling language (WebML): a modeling language for designing web sites. WWW9, Computer Networks, 33(1-6):137-157.

Conklin, J. (1987). Hypertext: an introduction and survey. IEEE Computer, 20(9):17-41.

Cooper, K. (1995). TSPNUI: a Petri Net model for specifying user interactions in multimedia presentations. Dissertação de mestrado, University of British Columbia. 
Courtiat, J. P. e Oliveira, R C. D. (1996). Proving temporal consistency in a new multimedia synchronization model. In Proceedings of the ACM Multimedia'96, páginas 18-22.

Davis, H., Knight, S., e Hall, W. (1994). Light hypermedia link services: a study of third-party applications integration. In Proceedings of the ECHT'94: European Conference on Hypertext Technologies, páginas 41-50. ACM Press.

Davis, H., Lewis, A., e Rizk, A. (1996). OHP: a draft proposal for a standard Open Hypermedia Protocol. In Proceedings of the 2nd Workshop on Open Hypermedia Systems (Hypertext'96), páginas 27-53. ACM Press.

Diaz, M. e Senac, P. (1993). Time stream Petri Nets: a model for multimedia streams synchronization. In Proceedings of the First International Conference on Multimedia Modeling, páginas $257-273$, Singapore.

Garzotto, F., Mainetti, L., e Paolini, P. (1994). Adding multimedia collections to the Dexter model. In Proceedings of the ECHT'94: European Conference on Hypertext Technologies, páginas 70-80. ACM Press.

Garzotto, F., Mainetti, L., e Paolini, P. (1995). Hypermedia design, analysis and evaluation issues. Communications of the ACM, 38(8):74-86.

Garzotto, F., Paolini, P., Bolchini, D., e Valenti, S. (1999). Modelling by patterns of web applications. In Proceedings of the First International Workshop on Conceptual Modelling and the WWW, volume 1727, páginas 293-306, Paris, France. Lecture Notes in Computer Science.

Garzotto, F., Paolini, P., e Schwabe, D. (1993). HDM - a model-based approach to hypertext application design. ACM Transaction on Information Systems, 11(1):1-26.

Grønbæk, K., Hem, J. A., Madsen, O. L., e Sloth, L. (1994). Cooperative hypermedia systems: a Dexter-based architecture. Communications of the ACM, 37(2):64-74.

Grønbæk, K. e Trigg, R. H. (1994). Design issues for a Dexter-based hypermedia system. Communications of the $A C M, 37(2): 40-49$.

Grønbæk, K. e Trigg, R. H. (1996). Toward a Dexter-based model for open hypermedia: unifying embedded references and link objects. In Proceedings of the 2nd Workshop on Open Hypermedia Systems (Hypertext'96), páginas 149-160. ACM Press.

Grønbæk, K. e Trigg, R. H. (1999). From web to workplace: designing open hypermedia systems, volume 1 . MIT Press. $386 \mathrm{p}$. 
Halazs, F. e Schwartz, M. (1990). The Dextcr hypertext reference model. In Proceedings of the NIST Hypertext Standardization Workshop Gaithersburg, páginas 95-133. National Institute of Standards and Technology - Special Publications.

Hardman, L., Bulterman, D. C. A., e Rossum, G. V. (1994). The Amsterdan Hypermedia Model: adding time and context to the dexter model. Communications of the ACM, 37(2):50-62.

Harel, D. (1987). Statecharts: a visual formalism for complex systems. Science Computer Programming, 8(3):231-274.

Harel, D., Pnuelli, A., Schmidt, J. P., e Shermand, R. (1987). On the formal semantics of Statecharts. In Proceedings of the 2nd IEEE Symposium on Logic in Computer Science, páginas 4-64, Ithaca, New York.

Isakowitz, T., Kamis, A., e Koufaris, M. (1997). Extending the capabilities of RMM: Russian dolls and hypertext. In Proceedings of the 30th Annual Hawaii International Conference on System Sciences, volume 6. IEEE Press.

Isakowitz, T., Strohr, E. A., e Balasubramanian, P. (1995). RMM: A methodology for structured hypermedia design. Communications of the $A C M, 38(8): 34-43$.

Lamport, L. (1986). Latex: a document preparation system, volume I. Addison-Wesley Publishing Company. 242p.

Little, T. D. C. (1990). Synchronization and storage models for multimedia objects. IEEE Journal on Selected Areas in Communications, 8(3):413-427.

Malcon, K. C., Poltrock, S. E., e Schuler, D. (1991). Industrial strength hypermedia: requirements for a large engineering enterprise. In Proceedings of Hypertext'91: Third ACM Conference on Hypertext, páginas 13-24. ACM Press.

Masiero, P. C., Fortes, R. P. M., e Batista, N. (1991). Editando e simulando os aspectos comportamentais de sistemas de tempo real. In Anais do XVIII Semish: Seminário Integrado de Software e Hardware, páginas 45-61.

Masiero, P. C., Maldonado, J. C., e Boaventura, I. A. G. (1994). A reachability tree for Statecharts and analysis of some properties. Information and Software Technology, 36(10):615624.

Miotto, A. M. M., Bulcão, R. F., Pimentel, M. G. C., e Fortes, R. P. M. (2001). OXHMBS - a formal approach for supporting Open Hypermedia Applications. Cadernos de Computação do ICMC-USP. [Aceito para publicação]. 
Miotto, A. M. M. e Fortes, R. P. M. (2000). Uma visão geral das características de sistemas hipermídia abertos. Relatório Técnico 124, Instituto de Ciências Matemáticas e de Computação (ICMC-USP). 22 p.

Miotto, A. M. M. e Fortes, R. P. M. (2001a). Extending XHMBS for supporting open hypermedia applications. In Anais do IV Workshop de Métodos Formais (WMF'2001) do Simpósio Brasileiro de Engenharia de Software (SBES'2001), páginas 1-12, Rio de Janeiro, Rio de Janeiro.

Miotto, A. M. M. e Fortes, R. P. M. (2001b). Um modelo formal para aplicaçôes em sistemas hipermídia abertos: Características específicas. In Anais do XXVII Conferência Latino Americana de Informática (CLEI'2001), página 104, Mérida, Venezuela. (abstract impresso, anais disponíveis em CD-ROM).

Nicholls, J. (1995). Z Notation. University of Oxford, United Kingdom. 286 p.

OHSWG (2001). Open Hypermedia Systems Working Groups. on-line in World Wide Web. http://www. csdl . tamu. edu/ohs/.

Oliveira, M., Turine, M., e Masiero, P. (2001). A statechart-based model for hypermedia applications. ACM Transactions on Information Systems, 19(1):28-52.

Østerbye, K. e Wiil, U. K. (1996). The Flag taxonomy of open hypermedia systems. In Proceedings of the 2nd Workshop on Open Hypermedia Systems (Hypertext'96), páginas 129-139. ACM Press.

Paulo, F. B. (1997). Especificação de aplicações hipermídia baseadas em Statecharts. Dissertação de mestrado, Instituto de Ciências Matemáticas e de Computação - Universidade de São Paulo. 152p.

Paulo, F. B., Masiero, P. C., e Oliveira, M. C. F. (1997). Hypercharts: an extension of statecharts to support hypermedia specifications. In Proceedings of the Third IEEE International Conference on the Engineering of Complex Computer Systems (ICECCS'97), páginas 152-161, Como, Italy.

Paulo, F. B., Turine, M. A. S., Oliveira, M. C. F., e Masiero, P. C. (1998). XHMBS: A formal model to support hypermedia specification. In Proceedings of Hypertext'98: The Ninth ACM Conference on Hypertext and Hypermedia, páginas 161-170, Pittsburgh PA USA.

Peterson, J. L. (1977). Petri Nets. Computing Surveys, 9(3):223-255.

Pressman, R. S. (2000). Software engineering - a practitioner's approach. McGraw-Hill, 5 edition. 888p. 
Rizk, A. e Sauter, L. (1992). Multicard: an open hypermedia system. In Proceedings of the ECHT'92: European Conference on Hypertext Technologies, páginas 4-10. ACM Press.

Schwabe, D., Esmeraldo, L., Rossi, G., e Lyardet, F. (2001). Engineering web applications for reuse. IEEE Multimedia, 8(1):20-31.

Schwabe, D. e Rossi, G. (1995). The object-oriented hypermedia design model. Communications of the $A C M, 38(8): 45-46$.

Schwabe, D. e Rossi, G. (1998). An object oriented approach to web-based application design. Theory and Practice of Object Systems, 4(4):207-225.

Senac, P. (1996). Contribuition a la modélisation des systèmes multimédias et hypermédias. Tese de doutorado, University Paul Sabatier of Toulouse, Tolouse, France.

Senac, P., Diaz, M., e Saqui-Sannes, P. (1994). Towards a formal specification of multimedia synchronization scenarios. Les Annales des Télécommunications, 49(5-6):297-314.

Stotts, P. D. e Furuta, R. (1990). Temporal hyperprogramming. Journal of Visual Languages and Computing, 1(3):237-253.

Tai, L. C. (1996). Architecture support for content-based hypermedia. In Proceedings of the 2nd Workshop on Open Hypermedia Systems (Hypertext'96), páginas 1-5, Wahsington D.C., USA. ACM Press.

Turine, M. A. S. (1998). HMBS: Um Modelo Baseado em Statecharts para a Especificação Formal de Hiperdocumentos. Tese de doutorado, Instituto de Física de São Carlos - Universidade de São Paulo. 194p.

Wiil, U. K. e Whitehead, E. J. (1997). Interoperability and open hypermedia systems. In Proceedings of the 3nd Workshop on Open Hypermedia Systems (Hypertext'97), páginas 67, Southampton, UK. ACM Press. 